\title{
Leaving rehab: enhancing transitions into stable housing
}

From the AHURI Inquiry: Inquiry into enhancing the coordination of housing supports for individuals leaving institutional settings

Authored by

Cameron Duff, RMIT University

Nicholas Hill, RMIT University

Hazel Blunden, University of New South Wales

kylie valentine, University of New South Wales

Sean Randall, Curtin University

Rosanna Scutella, RMIT University

Guy Johnson, RMIT University
Publication Date July 2021

DOI 10.18408/ahuri53211 
Title

Leaving rehab: enhancing transitions into stable housing

\section{Authors}

Cameron Duff, RMIT University

Nicholas Hill, RMIT University

Hazel Blunden, University of New South Wales

kylie valentine, University of New South Wales

Sean Randall, Curtin University

Rosanna Scutella, RMIT University

Guy Johnson, RMIT University

\section{ISBN}

978-1-922498-26-7

\section{Key words}

Housing security, homelessness, care coordination, mental health, substance use treatment, infrastructures, service integration.

\section{Series}

AHURI Final Report

\section{Number}

359

\section{ISSN}

1834-7223

\section{Publisher}

Australian Housing and Urban Research Institute Limited Melbourne, Australia

DOI

10.18408/ahuri53211

\section{Format}

PDF, online only

\section{URL}

https://www.ahuri.edu.au/research/final-reports/359

\section{Recommended citation}

Duff, C., Hill, N., Blunden, H. valentine, k., Randall, S., Scutella, R. and Johnson, G. (2021) Leaving rehab: enhancing transitions into stable housing, AHURI Final Report No. 359, Australian Housing and Urban Research Institute Limited, Melbourne, https://www.ahuri.edu.au/research/final-reports/359, doi: 10.18408/ahuri53211.

\section{Related reports and documents}

Inquiry into enhancing the coordination of housing supports for individuals leaving institutional settings

https://www.ahuri.edu.au/housing/research-in-progress/ enhancing-the-coordination-of-housing-supports-forindividuals-leaving-institutional-settings

\section{AHURI}

AHURI is a national independent research network with an expert not-for-profit research management company, AHURI Limited, at its centre.

AHURI's mission is to deliver high quality research that influences policy development and practice change to improve the housing and urban environments of all Australians.

Using high quality, independent evidence and through active, managed engagement, AHURI works to inform the policies and practices of governments and the housing and urban development industries, and stimulate debate in the broader Australian community.

AHURI undertakes evidence-based policy development on a range of priority policy topics that are of interest to our audience groups, including housing and labour markets, urban growth and renewal, planning and infrastructure development, housing supply and affordability, homelessness, economic productivity, and social cohesion and wellbeing.

\section{Acknowledgements}

This material was produced with funding from the Australian Government and state and territory governments. AHURI Limited gratefully acknowledges the financial and other support it has received from these governments, without which this work would not have been possible.

AHURI Limited also gratefully acknowledges the contributions, both financial and in-kind, of its university research partners who have helped make the completion of this material possible.

\section{Disclaimer}

The opinions in this report reflect the views of the authors and do not necessarily reflect those of AHURI Limited, its Board, its funding organisations or Inquiry Panel members. No responsibility is accepted by AHURI Limited, its Board or funders for the accuracy or omission of any statement, opinion, advice or information in this publication.

\section{AHURI journal}

AHURI Final Report journal series is a refereed series presenting the results of original research to a diverse readership of policy makers, researchers and practitioners.

\section{Peer review statement}

An objective assessment of reports published in the AHURI journal series by carefully selected experts in the field ensures that material published is of the highest quality. The AHURI journal series employs a double-blind peer review of the full report, where anonymity is strictly observed between authors and referees.

\section{Copyright}

(C) Australian Housing and Urban Research Institute Limited 2021

This work is licensed under a Creative Commons Attribution-NonCommercial 4.0 International License, see http://creativecommons.org/licenses/by-nc/4.0/. 


\section{Contents}

List of tables

List of figures $\quad$ iv

Acronyms and abbreviations used in this report

Executive summary

1. Introduction: the coordination of 'exit planning'

1.1 Policy contexts: enhancing transition planning and coordination $\quad 7$

1.2 Insights from the housing, mental health and substance use literature: findings, gaps and conceptual problems

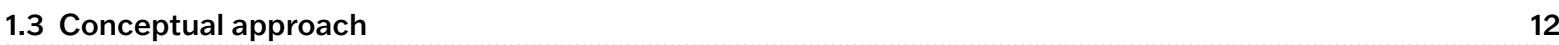

1.3.1 The role of infrastructure in support of 'liveable life'

1.3.2 Infrastructures of care and housing

1.4 Research aims, methods and procedures

1.4 .1 Key research questions

1.4.2 Study design

1.4.3 Ethical review $\quad 16$

1.4.4 Methods and procedures 16

2. Linked data analysis: youth leaving mental health residential treatment 19

2.1 Mental health in Victoria: background

2.1.1 Patterns of service use: what we know

2.1.2 What is linked administrative data (LAD)? 22

2.2 Research design

2.2.1 The population cohort and linked service use data

2.2.2 Characteristics of the mental health cohort

2.3 What services do the mental health cohort use? $\quad 26$

2.3.1 What services were used in the lead up to the reference event? 28

2.3.2 Service use by sex

2.3.3 Service use by Indigenous status

2.3.4 Does service use differ for those in public housing?

2.3.5 Housing and homelessness trajectories after the reference event

2.3.6 Housing trajectories 36

2.4 Patterns of service use $\quad 41$

$\begin{array}{ll}2.5 \text { Heavy service users } & 43\end{array}$

2.6 Implications $\quad 46$

3. Housing Struggles and social support needs $\quad 48$

$\begin{array}{ll}\text { 3.1 The role of housing in social care } & 48\end{array}$

3.1.1 Housing struggles

3.2 Mental health and housing support needs

3.2.1 The coordination of housing supports in psychiatric inpatient settings 53

3.3 Substance use and housing support needs $\quad 56$

3.3.1 Care planning in substance use treatment 37

$\begin{array}{ll}3.4 \text { Housing coordination futures } & 60\end{array}$ 
4. Coordinating complex service systems

4.1 Integrating housing, health and social care $\quad 62$

4.2 Coordinating care, managing silos: opportunities and problems 63

4.2.1 Managing bureaucracies, managing coordination 63

4.2.2 The challenge of coordinating care: policy gaps, problems and pitfalls 66

4.3 The effects of system failures: when coordination breaks down 69

4.3.1 Service and system failures and their effects on individuals $\quad 69$

4.3.2 Family and social supports

4.4 When it works: effective care, program successes $\quad 72$

4.4.1 'Golden Ticket' housing programs

4.4.2 Peer support

$\begin{array}{ll}4.5 \text { Coordinating complex care systems: key policy insights } & 78\end{array}$

5. Infrastructure of care: supporting liveable lives

5.1 Vulnerability, infrastructures and the support of liveable lives $\quad 79$

5.2 What are the goals of care? On the support of liveable lives 81

$\begin{array}{ll}5.3 \text { Housing as material infrastructure } & 83\end{array}$

$\begin{array}{ll}5.4 \text { Community as social infrastructure } & 86\end{array}$

5.5 Home as affective infrastructure $\quad 87$

5.6 Coordinating the infrastructures of liveable life $\quad 89$

6. Towards more effective models of care coordination $\quad 91$

6.1 Responding to our major research questions 992

6.1.1 What models of best practice may enhance transition planning and service integration for individuals leaving residential treatment?

6.1.2 How does residential treatment affect individual housing careers overtime? 94

6.1.3 How can post-exit support packages be tailored and delivered to individuals leaving residential treatment who are most at risk of homelessness?

6.1.4 Effectiveness of existing service integration and opportunities for improvements 96

$\begin{array}{ll}6.2 \text { Concluding remarks } & 97\end{array}$

References $\quad 99$

Appendix 1: Description of Victorian Government datasets available for mental health cohort 107

Appendix 2: Mental health diagnosis categories

Appendix 3: Interview and focus group schedules 112 


\section{List of tables}

Table 1: Characteristics of mental health cohort and duration of hospital stay at reference event

Table 2: Percentage of individuals in the mental health cohort who had particular service records after exit from reference event

Table 3: The proportion of individuals in the mental health cohort who had a particular service in the two years prior to their reference event

Table 4: The proportion of individuals in the mental health cohort with a service record in the four years after exit from reference event, by sex (\%)

Table 5: The proportion of individuals in the mental health cohort with a service record in the four years after exit from reference event, by recorded Indigenous status

Table 6: Proportion of individuals in the mental health cohort with a service record in the four years after exit, by housing status at index exit (\%)

Table 7: Proportion of individuals with potential predictors of homelessness, by homelessness status, mental health cohort (\%)

Table 8: Demographic characteristics and primary diagnosis of housing trajectory clusters (\%)

Table 9: Service use (hospital and emergency) of individuals in housing trajectory clusters (\%)

Table 10: Service use (other) of individuals in housing trajectory clusters (\%)

Table 11: Median number of services for those who had at least one service of a particular type in the four years after exit from reference event

Table 12: Characteristics of mental health cohort by cumulative length of hospital stay (\%)

Table 13: \% share of service used and \% of individuals who used a service, over varying time-horizons, by cumulative length of stay

Table A 1: Service information from the homelessness dataset for each cohort

\section{List of figures}




\section{Acronyms and abbreviations used in this report}

$\begin{array}{ll}\text { AHURI } & \text { Australian Housing and Urban Research Institute Limited } \\ \text { AIHW } & \text { Australian Institute of Health and Welfare } \\ \text { AOD } & \text { Alcohol and Other Drug Support Services } \\ \text { CHART } & \text { Common Homelessness Assessment \& Referral Tool } \\ \text { CRC } & \text { Care and Recovery Coordination } \\ \text { CSA } & \text { Crisis Supported Accommodation (also known as TCA) } \\ \text { CVDL } & \text { Centre for Victorian Data Linkage } \\ \text { DHHS } & \text { Department of Health and Human Services } \\ \text { DSP } & \text { Disability Support Pension } \\ \text { HASI } & \text { Housing and Accommodation Support Initiative (NSW) } \\ \text { HEF } & \text { Housing Establishment Fund } \\ \text { HSS } & \text { Homelessness Support Services/Providers } \\ \text { HREC } & \text { Human Research Ethics Committee } \\ \text { IAP } & \text { Initial Assessment and Planning } \\ \text { IQR } & \text { Interquartile range } \\ \text { LAD } & \text { Linked administrative data } \\ \text { LOS } & \text { Length of stay } \\ \text { MoU } & \text { Memoranda of Understanding } \\ \text { NDIS } & \text { National Disability Insurance Scheme } \\ \text { PRAP } & \text { Private Rental Assistance Program (Victoria) } \\ \text { PY } & \text { Person year } \\ \text { SAAP } & \text { Supported Accommodation Assistance Program } \\ \text { SHS } & \text { Specialist Homeless Services } \\ \text { SLK } & \text { Statistical linkage key } \\ \text { VDM } & \text { Victorian Data Map } \\ \text { HA Help Ourselves Fellowship } \\ \text { Hossness Action Plan }\end{array}$




\section{Executive summary}

- This report outlines policy and practice recommendations for enhancing the coordination of housing, health and social care supports for individuals leaving residential treatment for mental health or substance use problems.

- In contexts of growing service complexity and fragmentation, discharge and transition planning arrangements are becoming more complex and uncertain across the housing, mental health and substance use treatment sectors.

- Admission to psychiatric inpatient care and/or enrolment in residential treatment for substance use problems, typically involves significant risks of housing insecurity, particularly for individuals with unstable housing histories.

- There is considerable variation in the ways housing issues are managed within mental health and substance use treatment services in New South Wales and Victoria, and significant discrepancies in the quality of support offered to those in care.

- We identified important instances of 'best practice' along with opportunities for significant improvements to the management of housing insecurity among individuals undertaking mental health and/or substance use treatment.

- There is scope for enhanced discharge planning arrangements in psychiatric inpatient settings that focus on the provision of tailored housing supports for vulnerable individuals, particularly those with histories of multiple admissions.

- There is scope for enhanced focus on housing transitions in 'after-care' and 'exit' planning in residential substance use treatment settings. This planning ought to commence at admission for individuals identified at risk of housing insecurity. 
This project responds to the Inquiry question: 'What are the most effective ways of tailoring and delivering housing supports for individuals exiting institutional settings?'. The project focusses on individuals leaving residential treatment for mental health and/or substance use problems within a sample of institutional settings in either Victoria or New South Wales. Our goals are to identify models of best practice in discharge and transition planning, and to propose strategies for enhancing coordination between residential treatment providers and key social and housing support services to mitigate the risk of homelessness for individuals leaving these settings. On the basis of our investigations, this report features innovative recommendations for improving service coordination and enhancing transition planning across residential treatment settings.

\section{The study: aims, design and methods}

The project employed a mixed methods study design to investigate our key research questions. This involved secondary analysis of linked administrative data collected in Victoria, and original qualitative research conducted in New South Wales and Victoria among samples of service providers and individuals with lived experience of residential treatment for either mental health and/or substance use disorders. Our formal research questions were as follows:

- RQ1: What models of best practice may be derived from the available literature to enhance transition planning and service integration for individuals leaving residential treatment?

- RQ2: How does residential treatment affect individual housing careers over time?

- RQ3: How can post-exit support packages be tailored and delivered to individuals leaving residential treatment who are most at risk of homelessness?

- RQ4: How effective is existing service integration between housing and other sectors in transition planning and post-exit support for individuals leaving residential treatment? What opportunities exist for service improvement and enhanced coordination?

Extending the analysis of linked administrative data conducted by the Inquiry Program, this report details the findings of our analysis of a linked administrative dataset maintained by the then Victorian Department of Health and Human Service (DHHS). Access to this dataset enabled analysis at person-level of service use patterns of a cohort of individuals across health and mental health services, family and justice services, and housing services, the latter viewed through housing applications and tenancy information from the Speciality Homeless Information Platform.

The analysis of this data (presented in Chapter 2) explores the complexity of pathways into and out of treatment, and how service contacts mediate housing outcomes over time. By analysing service use patterns following treatment exits we have been able to clarify risk factors for housing instability for different cohorts, along with policy recommendations to reduce these risks.

Subsequent chapters detail the findings of reviews of the international research and policy literature designed to identify models of best practice in care coordination (Chapter 1), along with thematic analysis of interviews and focus groups with service providers and recent service users conducted in Victoria and New South Wales (Chapters 3-5). Our qualitative research offers significant new insights into effective models of post-exit support and discharge planning for individuals leaving residential settings for mental health and/or substance use disorders. This research has enabled us to identify and analyse: key barriers to successful reintegration into stable housing; relevant risk and protective factors mediating pathways into stable housing; and the role of formal service supports and informal social and family supports in retaining housing. 


\section{Key research findings}

Failure to adequately plan for and support safe transitions from residential treatment into secure and affordable housing can have catastrophic consequences for individuals leaving care, with strong impacts on their housing security, their health and wellbeing, and their economic and social participation in the community. By canvassing options for improving discharge and transition planning in mental health and substance use treatment settings across New South Wales and Victoria, this report identifies significant opportunities to reform transition planning to enhance housing security and support the health and wellbeing of individuals leaving these settings.

Our research provides strong endorsement of the 'housing first' model as a guide to enhance the coordination and integration of diverse housing, health and social care supports for individuals transitioning out of residential treatment settings for mental health and/or substance use problems. 'Housing readiness' approaches provide supported housing arrangements according to a so-called 'staircase' model based on assessments of an individual's capacity (or 'readiness') to maintain stable housing. In contrast, 'housing first' emphasises the centrality of stable housing for individuals living with complex and persistent mental health and/or substance use problems.

In the latter approach, there are no behavioural or treatment prerequisites that must be met before an individual is provided with suitable and appropriate accommodation. Despite these differences, each approach provides key insights into the most effective support practices and services models to support enhanced discharge and transition planning for individuals exiting complex care settings. Both approaches suggest that housing is an indispensable condition of effective 'post-exit' care across the provision of mental health and substance use treatment and support.

Our linked data analysis, along with qualitative data collected via interviews with service providers working in mental health care and/or substance use treatment settings, and individuals with recent experiences of these settings, highlights points of interception where care coordination can be significantly improved. Focussing attention and effort at these points can improve health and housing outcomes for individuals accessing services, while reducing costs. Linked data analysis indicates a strong correlation between the volume and frequency of service useage across mental health and substance use treatment settings and the risk of housing insecurity among diverse service user cohorts. This finding is consistent with national and international research, which has consistently found that frequency and volume of service useage, particularly for mental health, housing and/or substance use services, strongly predicts housing insecurity over the lifecourse.

Equally, our linked data analysis confirms that service transitions have a significant impact on housing trajectories, particularly for younger individuals with complex health, housing and social care needs. This relationship is bidirectional in that frequency of service contact is obviously an indication of service demand and the complexity of individual's health care needs. Yet it is also the case that service contacts, particularly service experiences that involve periods of residential treatment (for example in mental health and/or substance use treatment settings) can themselves disrupt individual's housing arrangements. For example, periods of residential care may disrupt what were formerly relatively stable housing arrangements, such as when individuals enter residential treatment from private rental accommodation. On the other hand, individuals may decide, perhaps as a result of their treatment, that they wish to alter their housing arrangements post treatment, for example in favor of other accommodation in a different location.

In further exploring the effects of service contact on housing trajectories, our qualitative research has revealed inconsistent and sometimes ineffective discharge planning arrangements between diverse mental health and/or substance use treatment providers across Victoria and New South Wales. Housing, mental health and substance use treatment sectors in both New South Wales and Victoria remain largely separate service systems with little formal integration and coordination. There is significant scope, therefore, to enhance the integration of housing, mental health and/or substance use treatment services, along with other health and social care supports as needed, through more formal and systemic organisational and governance arrangements. 
Poor integration and a lack of coordination result in significant unmet demand across each sector resulting in higher rates of inpatient care, increased need for substance use treatment services, and greater pressure on specialist housing support services following an individual's discharge from care. Indeed, individuals entering and exiting mental health and/or substance use treatment settings typically have complex ongoing health and social care needs, requiring significant 'post-care' coordination between diverse health and social care providers. However, we discovered a significant gap between how care and service coordination is supposed to work in practice and what is commonly experienced by individuals exiting institutional spaces. Certainly, we identified instances of best practice in service delivery, but also many instances of poor transition planning.

Our findings suggest grounds for enhancing the design of post-exit support packages in order to more effectively meet the health and social care needs of individuals exiting institutional settings. Transition packages ought to be designed and delivered on the basis of what they enable an individual to do in their everyday life following their exit from care. Transitional services and supports ought to be tailored to individual needs in relation to material infrastructures such as housing, employment, education and finances, social infrastructures including community integration and belonging, and affective infrastructures such as intimate and social relationships, identity, social inclusion and hopes for the future. Furnishing the infrastructures central to the experience of a 'liveable life' ought to be the key focus of transition planning for individuals exiting mental health or substance use treatment settings, taking in their formal and informal housing, health and social care needs. Such a focus shifts the design of transition planning beyond the immediate goals of a specific organisation to emphasise an individual's unique support needs.

\section{Policy development options and recommendations}

Our research makes a compelling case for the more formal integration of specialist housing services into both inpatient psychiatric and substance use treatment settings, given the significant risks of housing insecurity that many individuals experience in these settings, including all too common experiences of homelessness. There are several instances of good practice to guide these efforts, including examples derived from innovative housing and social justice programs like 'Journeys to Social Inclusion' and 'Green Light' in Victoria, and the Housing and Accommodation Support Initiative (HASI) in New South Wales.

These programs clearly indicate the benefits of more formal integration of housing, health and social supports, demonstrating that long-term stable housing can be sustained for individuals regardless of the complexity of their health, housing and social support needs. In this respect, we already have clear models of effective care coordination and successful service integration to guide the provision of stable housing for all Australians. The task now is to scale up these endeavours to ensure that all Australians who need such support receive it, regardless of their circumstances. Equally critical is the need to increase funding support for the provision of new social housing to guarantee access to safe and secure housing for all Australians who require it.

Our analysis also suggests a series of site-specific policy development and service design recommendations for the delivery of more effective transition planning supports for individuals leaving mental health and/or substance use treatment settings in New South Wales or Victoria.

In particular, we would recommend urgent attention to the more effective integration of housing supports within the delivery of mental health care, particularly in inpatient psychiatric settings, and within the delivery of community-based substance use treatment, particularly residential services.

We discovered significant discrepancies in the delivery of community-based mental health services, and considerable strain upon psychiatric services in hospital settings, particularly in Melbourne and Sydney's largest hospitals. We also identified significant gaps and problems in the integration of housing supports into mental health care, despite the obvious need for such coordination, particularly among more vulnerable cohorts. A similar picture emerges in our analysis of substance use treatment services, with similarly patchwork mixes of public and private care provision, and a great diversity of treatment models and pathways. Here too, the formal integration of housing supports into the delivery of substance use treatment services is mixed. 
On the basis of analysis presented in this report, we identify the following key policy issues:

- Housing affordability, social housing shortages and lack of supported housing remain key challenges for individuals experiencing mental health and/or substance use challenges.

- Housing/homelessness, mental health and substance use treatment remain separate service systems across New South Wales and Victoria with only partial integration and coordination.

- Within these systems, there is significant unmet demand for housing support, as well as resource gaps and constraints on coordination between health and social care systems.

- Housing transition supports ought to be integrated more effectively into discharge planning in psychiatric inpatient care for individuals at risk of (or already experiencing) housing insecurity.

- There is scope to enhance the role of allied health staff and external community service providers in care conferencing and coordination in psychiatric inpatient care to improve the integration of housing support for individuals at risk of (or experiencing) housing insecurity.

- Individuals exiting mental health and/or substance use treatment services express strong preferences for greater choice and control over their housing transitions 'post-care'.

Addressing these outstanding policy and service design challenges will require significant service reforms. In particular, widespread emphasis across the mental health and substance use treatment sectors on bureaucratic and administrative processes over and above an individual's care needs must be reversed. All discharge planning must begin from the point of view of the individual in care in more 'person-centred' approaches to care coordination and service delivery.

Of added importance is the need to ensure that mental health, substance use treatment and specialised housing supports are more formally integrated through service and system design innovations. At a practical level, this could include the introduction of novel housing assessment tools to guide admissions and care-planning protocols in both psychiatric inpatient settings and residential substance use treatment. Improved screening and assessment protocols are a critical means of ensuring that individuals in need of housing support are identified at admission in these settings. Such assessments may then inform the design of tailored discharge planning arrangements in psychiatric inpatient settings, and more effective 'after care' and transition supports for individuals leaving residential treatment to more effectively support their housing needs. Peer workers and lived experience advisory groups working within housing, mental health and/or substance use treatment spaces are a significant source of knowledge and expertise that could be drawn on in the development of enhanced screening and assessment instruments.

The formal integration of housing assessments into screening protocols in each sector will enable formal assessment of individual's existing housing status including their housing preferences upon discharge, along with their risk of housing insecurity. Representatives of specialised housing services ought to be formally integrated into discharge planning processes in each service sector to reduce experiences of housing insecurity and homelessness for individuals following discharge from mental health and/or substance use treatment settings.

Within psychiatric inpatient settings, housing representatives could work more closely with clinical and allied health teams (particularly social workers) to enhance discharge and transition planning. Within residential substance use treatment settings, housing supports ought to be more formally integrated into transition planning from the point of intake. Our findings suggest that assertive case management is an effective means of supporting vulnerable individuals with complex care needs to access and maintain stable housing, while also reducing costs in the longer term. 
Our research also has important implications for the organisation of social care services and supports-for example, in terms of work design issues, leadership and governance approaches, role descriptions and task allocations-across and between specialist housing services, mental health and substance use treatment services in Australia. Successive waves of policy reform involving changes to funding arrangements, policy priorities, performance indicators, work design matters and organisational structures within and across the broad community health and social care sector have had enormous impacts on the everyday work of delivering care in specialist housing services, mental health and substance use treatment services in Victoria and New South Wales. Unquestionably, the service system landscape is becoming more complex, more diffuse and fragmented, more competitive and more focussed on delivering short-term outcomes for vulnerable individuals. As a result, service pathways are becoming more complex with significant impacts on individual care 'trajectories' within and across specialist housing services, mental health and substance use treatment services in Victoria and New South Wales. Finding ways to assist vulnerable individuals to navigate these complex systems of care, perhaps via expanded support and 'way-finding' roles for peer workers in each sector, are strongly recommended. 


\section{Introduction: the coordination of 'exit planning'}

- This chapter introduces the broad study contexts, including brief reviews of the relevant research and policy literature, along with the primary research aims.

- We then develop and discuss an innovative conceptual framework for addressing the central research problems of vulnerability, care, treatment and recovery.

- We use this framework to recast treatment for mental health and/or substance use treatment in terms of the repair of key infrastructures central to the enjoyment of a more 'liveable life' for vulnerable individuals and groups.

- We close by briefly reviewing key problems canvassed in the chapters to follow.

Reviewing key innovations in the housing policy literature, this chapter identifies models of best practice in transition planning, and proposes strategies for enhancing coordination between residential treatment providers and other key social and housing supports to mitigate the risk of housing insecurity for individuals leaving these settings. This review will complement analysis presented in subsequent chapters of linked administrative data (Chapter 2) and qualitative inquiries with service providers and recent service users (Chapters 3-5). These findings will inform the service and policy recommendations offered in Chapter 6 for improving coordination and enhancing transition planning in institutional settings, as per our key research questions.

\subsection{Policy contexts: enhancing transition planning and coordination}

Residential treatment for mental health and/or substance use problems is typically reserved for individuals with complex needs who have not responded to non-residential treatment modalities (Manning, Garfield et al. 2017). This includes psychiatric in-patient admissions to specialist mental health wards, which tend to work on a triage model, whereby less intensive 'low barrier' treatment options are preferred for all but the most complex presentations (see Brackertz, Borrowman et al. 2020: Brunero, Fairbrother et al. 2007; Tran, Lambeth et al. 2020). Similarly, treatment for substance use disorders in most Australian jurisdictions is typically offered in 'out-patient' day programs via a mix of detoxification services, counselling and substitution therapies (see Nathan, Bethmont et al. 2016; Ritter, Berends et al. 2014). 
In a reflection of the complex needs of individuals entering residential programs, along with challenges associated with targeting and delivering care to address these needs, residential treatment outcomes are mixed, with more than three-quarters of Australians who exit residential treatment returning to treatment at least once in their lifetime (Kelly, Leung et al. 2016). Post-treatment contacts with housing assistance and other service agencies are also common, as are contacts with the criminal justice system, including police and protective services (Holmes, Carlisle et al. 2017).

This is often called the 'relapse-treatment-recovery cycle' (Scott, Foss et al. 2005:325-6). Relapse and return to treatment are common among individuals with co-occurring mental health and substance use problems (Manning, Garfield et al. 2017), while adolescents and young adults have similarly mixed outcomes (Ritter,Berends et al. 2014). Housing insecurity and weak social supports are key risk factors for relapse and subsequent service contacts for individuals with a history of substance use disorders (Lubman, Garfield et al. 2016), with similar reports for individuals with a history of mental health treatment (see Brackertz, Borrowman et al. 2020: Tran, Lambeth et al. 2020). These risks are compounded with each subsequent episode of residential treatment, with the associated disruption to housing creating challenges for individuals attempting to maintain stable housing after a period of residential treatment for either substance use disorders and/or mental health problems. These challenges are especially acute in the weeks and months following discharge, although there is evidence that the risk of homelessness persists over subsequent years for vulnerable individuals (Willis 2016).

International research evidence, including detailed program evaluations in diverse sites, indicates that detailed transition planning, and careful coordination between health and social services are central to successful reintegration into stable housing for individuals leaving residential treatment for either substance use disorders and/or mental health problems (Aubrey, Goering et al. 2016; Holmes, Carlisle et al. 2017; USDHUD 2007). Effective and coordinated transition planning has also been shown to reduce the subsequent incidence of service contact for individuals with a mental health diagnosis (see Xiao, Tourangeau et al. 2019). Reports also confirm the role of discharge planning in reducing relapse rates among individuals leaving residential treatment for substance use disorders (see Ritter, Berends et al. 2014). More broadly, there is strong evidence that effective transition support has a host of health and social benefits including reduced involvement with the criminal justice system (Holmes, Carlisle et al. 2017), improved primary health outcomes (see AlHW 2019b), and stronger self-reported experiences of subjective wellbeing and social inclusion (see Duff, Jacobs et al. 2013).

While individuals leaving residential treatment typically express a preference for independent housing (Richter and Hoffmann 2017), 'conditional' forms of housing support are more common in all Australian jurisdictions, with most housing supports (including access to social housing) contingent on some form of 'housing readiness' assessment (see Clarke, Parsell et al. 2020). Often involving so-called 'staircase' models of staggered support, most housing support services in Australia involve step-wise transitions from residential care into supported accommodation, and on to independent living (Henwood, Stefancic et al. 2015; Brunette, Mueser et al. 2004). This is despite strong evidence for 'housing first' models that emphasise immediate access to secure accommodation for individuals with complex health and social needs, rather than more staggered approaches that rely on some form of conditional assessment of an individual's 'housing readiness' (see Clarke, Parsell et al. 2020:955-960; Richter and Hoffmann 2017).

The present study should be understood within this context of research and policy debates regarding the most effective forms of housing support for individuals leaving residential settings for mental health and/or substance use disorders. Little is known about the most effective models of transitional accommodation, including what supports are needed, when and how they should be delivered. It is also unclear how services may be most effectively integrated into supported accommodation programs, and how allied social supports can be coordinated in the delivery of housing assistance. While the role of informal carers and networks is known to be critical to the maintenance of stable housing for vulnerable individuals (Duff, Jacobs et al. 2013), there is little guidance on how these informal supports may be integrated into formal support efforts. 
These debates highlight the need for fresh insights into the most effective ways of customising 'post-exit' care planning for individuals leaving residential treatment for either mental health and/or substance use disorders to address their particular housing needs. Effective tailoring of housing and social support is currently limited by the lack of good Australian data on: pathways into and out of residential care; the relative importance of risk and protective factors; and the most effective sequencing of supports over time. The program of research conducted for the current project has explored these problems with key findings outlined over the following four chapters. The report closes with a detailed set of recommendations for policy makers and service providers for enhancing transition planning and post-exit supports for individuals leaving residential settings.

\subsection{Insights from the housing, mental health and substance use literature: findings, gaps and conceptual problems}

Significant numbers of Australians access mental health care, alcohol and other drug (AOD) treatment services, and/or specialist housing support services across Australia each year. In 2018-2019, 137,000 Australians accessed AOD treatment services, involving around 220,000 closed treatment episodes, with an average of 1.6 episodes per client (AlHW 2019a). Of these treatment episodes, 65 per cent involved non-residential treatment; 15 per cent were delivered via outreach services (i.e. away from main service location); and 15 per cent were delivered through residential treatment programs. Roughly 260,250 individuals underwent a mental health-related hospital separation for one or more nights across Australia in 2017-2018, with 63.6 per cent of these admissions involving specialised psychiatric care (AlHW 2019b). Approximately 36.3 per cent of overnight stays involving specialised psychiatric care were involuntary admissions. Mental health-related hospitalisations are increasing year-onyear, with a 3.5 per cent increase per year observed in the five years to 2017-2018 (AlHW 2019b). National and international evidence consistently demonstrates that people exiting institutional spaces, including mental health inpatient services and AOD residential programs, experience a high risk of housing insecurity, particularly in the weeks and months following discharge (see also Johnson, Natalier et al. 2010; Mendes and Snow 2016).

Appropriate, safe and affordable housing is consistently shown to support an individual's mental health and wellbeing, facilitating community participation, and supporting recovery (Kavanagh, Aitken et al. 2016; Paquette and Pannella Winn 2016; Thornicroft, Deb et al. 2016). Despite strong evidence of the health and social benefits of housing, housing insecurity continues to be a problem for many individuals leaving mental health inpatient services and AOD residential treatment in Australia. Of the 241,113 Australians who accessed specialist homeless services (SHS) in 2017-2018, one-third $(81,000)$ reported a concurrent mental health issue, while the number of clients with a mental health issue has increased by around 8 per cent over the previous five years (AlHW 2019c). One in ten SHS clients were identified as having AOD problems in 2018-2019, with 55 per cent of this group known to be homeless at the point of presentation to services (AlHW 2019c). Largely as a result of these trends, the National Housing and Homelessness Agreement (2018-2023) identifies individuals exiting institutional spaces as a priority cohort and outlines the need for improved early intervention and prevention approaches, including more evidence-based service development.

How homelessness is defined and assessed has significant implications for discharge planning, allocation of financial supports, and the types of programs and services that an individual might receive upon discharge. The 'cultural definition' of homelessness includes sleeping rough, staying with friends or family temporarily, emergency accommodation, boarding houses and caravan parks (Chamberlain and MacKenzie 2008; Scutella, Johnson et al. 2012). While this definition is useful for identifying the risk of homelessness, it cannot explain why a particular individual experiencing mental ill health and/or substance use might become homeless and, further, what post-exit supports might be effective and when they should be provided. These latter failings have inspired efforts to develop novel understandings of housing insecurity, and more refined understandings of the risk and protective factors associated with experiences of housing crisis. 
As a result of these efforts, researchers have noted how a combination of psychosocial and structural factors is typically involved in the experience of housing crises including homelessness (Batterham 2019a, 2019b; Chamberlain and Johnson 2013). Relevant structural factors include local housing markets and the composition and delivery of health and social care services and supports. Psychosocial factors linked to family and community ties, along with histories of AOD use and misuse are also known to be important. However, the connection between substance use and homelessness is complex, with some people experiencing housing insecurity as a result of problematic substance use and others only beginning to use substances to cope with the experience of homelessness (see Johnson and Chamberlain 2008 for a review).

The link between housing insecurity and mental illness is similarly complex with some people experiencing mental ill health prior to becoming homeless, whereas others link their mental distress to their experience of homelessness (Johnson and Chamberlain 2011). Moreover, family support, particularly in the form of accommodation provision, financial assistance, and practical aid can be a strong protective factor against homelessness, just as the experience of family conflict and the withdrawal of financial and practical support can be associated with housing insecurity (Johnson and Chamberlain 2011). Indeed, the relationship between housing and mental health pathways are rarely linear (Brackertz, Borrowman et al. 2020), leading to calls for improved discharge planning and transition support between services (Dej, Gaetz et al. 2020; Xiao, Tourangeau et al. 2019). More broadly, efforts to identify pathways for people exiting institutional settings (such as mental health inpatient settings and AOD residential settings) have led to calls for tailored, wrap-around post-exit supports that better support housing and recovery (Aubry, Goering et al. 2016; Stein 2012).

Effective discharge planning, and the effective integration of housing, mental health, and/or AOD supports in this planning, have been shown to produce better individual outcomes while reducing 'post-care' economic and social costs (Dunt, Benoy et al. 2017; Nurjannah, Mills et al. 2013; Watson, Wagner et al. 2013). Furthermore, individualised interventions integrated across systems in ways that systematically address individual needs typically produce the best health and social outcomes (Greer, Shinn et al. 2016). For example, there is strong evidence for 'housing first' approaches in which permanent housing is viewed as a condition for the provision of other health and social services, the rebuilding of community ties, stronger recovery outcomes, and enhanced social and economic participation (Blunden and Drake 2015; Johnson, Parkinson et al. 2012).

Despite the benefits of early intervention and prevention, the mental health, AOD and housing sectors in Australia are still largely 'crisis-based' insofar as they largely respond to existing health and social problems with limited 'up-stream' prevention (Dej, Gaetz et al. 2020; Mackie, Thomas et al. 2017). Crisis responses in the mental health, AOD and housing sectors are often marked by poor individual outcomes and high economic and social costs (Kidd 2013). The complexity of risk factors that produce housing insecurity points to the need for the development of wraparound supports that integrate health and social support across what are consistently identified as fragmented systems.

Indeed there is still very limited integration between the mental health, AOD, and housing sectors in Australia despite long-standing calls for improvements (Brackertz, Borrowman et al. 2020; Power and Mee 2020). Key problems include the design of post-exit housing supports; the staging and delivery of these supports; the most effective ways of coordinating support across service domains; and the integration of formal programs into family and social networks (Duff, Jacobs et al.], 2013; Stein 2012).

Poor discharge planning, a lack of service integration, and poor transition and/or referral pathways between services can lead to negative outcomes for people exiting institutional settings such as mental health inpatient services and AOD residential treatment (Backer, Howard et al. 2007). Successful homelessness prevention and early intervention initiatives require the development of a responsive and integrated service system. The homelessness prevention typology developed by Dej, Gaetz et al. (2020) provides helpful insights into the refinement of discharge planning arrangements across mental health inpatient services and AOD residential treatment in Australia. 
Dej et al's typology consists of structural prevention, early intervention, eviction prevention, and housing stabilisation, leading to recommendations for intervention at three levels as follows. Primary prevention addresses the systemic and structural factors that produce the risk of housing insecurity and attempts to strengthen relevant protective factors. Secondary prevention targets those at imminent risk (or those who have recently experienced homelessness) with specialised housing and social care supports. Tertiary prevention involves interventions that ensure that individuals already in care are able to maintain their housing for the duration of their treatment.

Discharge planning is relevant to all three prevention strategies, though it is especially important in secondary and tertiary settings where it can be understood as a 'strategic intercept' (Backer, Howard et al. 2007:240) for managing living arrangements, financial and social supports, health and wellbeing issues for individuals receiving treatment. As a practical example, rent subsidies to support client's private rental arrangements for the duration of their stay in residential treatment have been shown to be highly effective 'tertiary prevention' strategies for mitigating the risk of housing insecurity for vulnerable care recipients (see Dej, Gaetz et al 2020). Effective discharge planning requires the development of comprehensive needs assessment procedures, patient-centred care, adequate resourcing, effective communication, and strong service coordination (Xiao, Tourangeau et al. 2019).

The recent turn to the analysis of 'capabilities' within the housing literature provides further insights to guide the refinement of discharge planning processes within mental health and AOD treatment services in Australia. This approach expands the definition of homelessness by going beyond housing to include ideas of belonging, connection, safety and wellbeing (see Batterham 2019b; Evangelista 2010; Nichols McNaughton 2010; Haffner and Elsinga 2019). The discussion of capabilities within housing debates has been informed by the work of Martha Nussbaum (2011) and Amartya Sen (1999, 2005), whose work draws attention to the social and political conditions necessary for individuals to secure and enact certain rights (including, importantly, the right to safe and secure housing). Attention to capabilities grounds human rights by focussing on the opportunities available within everyday contexts for individuals to routinely do those things they 'actually value doing' (Sen 2005:153). Rather than focussing on access to resources as a proxy for wellbeing, the capabilities approach draws attention to an individual's actual capacity to turn these resources into routine 'functionings'. The link between capabilities and functionings is central to a socially just society, and the dignity and flourishing of all citizens (Nussbaum 2011).

Applied to housing policy questions, the capabilities approach recognises that housing is a critically important resource (or 'infrastructure') for the realisation and expression of diverse social, health and personal capabilities. It also recognises that individuals require different types of housing supports depending on their particular 'housing capabilities' and associated resource advantages or deprivations (Haffner and Elsinga 2019:18). According to this approach, housing may be reconceptualised as the key site where every-day 'practices of freedom are defined and constructed' (Envangelista 2010:197); that is, where a life filled with meaning and purpose is enacted. This positions housing as a critical recovery infrastructure.

The capabilities model also suggests innovative approaches to discharge planning by emphasising the role of housing in the realisation of unique capabilities. Effective discharge planning ought to prioritise the ways that housing supports diverse social, material and affective goals and capabilities. In this sense, housing is not an end in itself, but provides the social, affective and material means that sustain life. It is by way of these social, affective and material infrastructures that individuals carve out a life of value as they see and understand it.

These insights suggest a more holistic approach to discharge planning that emphasises an individual's particular 'housing capabilities', inasmuch as different forms of housing support the expression of different kinds of capabilities. It also emphasises the unique diversity of individuals' housing needs, and the importance of thinking about housing as a means of supporting health and social capabilities. This approach also responds to consumer calls for an expanded definition of recovery that includes a greater emphasis on autonomy, choice over services, access to safe, secure and appropriate housing, employment opportunities and avenues for social and economic participation (see Deegan 1997; Fomiatti 2020; Frank 2018; O'Hagan 2004; Rose 2019). 
Notions of 'housing capability' (Batterham 2019b) therefore encompass holistic, multidimensional aspects of the experience of home and homelessness, including the physical adequacy of the dwelling, stability and control, interpersonal safety, connection and belonging, financial deprivation/affordability and the affective notions of home and identity. By bringing together the concepts of home, adequate housing, and homelessness, and considering them alongside the multidimensional experience of actual living situations (Batterham 2019b) and support needs (Dej, Gaetz et al. 2020), a capabilities approach offers a strong framework for assessing individual needs and providing tailored supports. It is for this reason that this framework has been employed across this study to guide our research, particularly our understanding of 'infrastructures'.

\subsection{Conceptual approach}

\subsubsection{The role of infrastructure in support of 'liveable life'}

In this section, we rethink housing and social care policy and service provision by focussing on notions of a 'liveable life' and 'infrastructure' rather than individual risks or deficits. Discussions of infrastructure complement the capabilities approach outlined above by locating people within their affective, material, political and social relations (Amin 2014). In select circumstances, these relations enable individuals and communities to flourish in the experience of a 'liveable life' (Butler, 2016). 'Liveable life' is a life of meaning and value, taken to encompass the varied means by which all individuals in a community, regardless of ability, cultural identification, ill health, and background, are supported in their pursuit of a 'good life', as they create a place for themselves, contribute to their community, and work to have their humanity and dignity recognised and valued (see Amin 2014; Nussbaum 2011; Wilson 2016). This analysis brings into view the often 'invisible work' (Star 1999:380) of the social infrastructures that sustain life. This approach will guide the analysis of our qualitative data in later chapters, in which we consider the complex needs of people accessing mental health, AOD, and/or housing services. It will also inform our recommendations for more holistic, coordinated responses between these services. In each case we approach care and support in terms of the specific social, affective and material infrastructures that individuals need to achieve a life filled with meaning and purpose in practice.

Within social care debates, ideas of 'liveability' and 'liveable lives' have been taken up by disability advocates, organisations and scholarship to challenge normative ideas of personhood underpinning policy and service provision, and to draw attention to the role of care and support in facilitating, producing and/or sustaining the lives of all citizens regardless of ability (Taylor 2013).

Crucially, approaches informed by the notion of liveable life insist that autonomy, independence, and selfdetermination are not characteristics of individuals but a product of policy and social relations (see Berlant 2016; Butler 2016; Fineman 2008). This insight has led scholars, practitioners and policy makers to reconsider the aims of social care in the broadest possible terms, rejecting the fragmentation of siloed social service systems. Rather than viewing individual recipients of housing, mental healthcare, and treatment support as having departed from an ideal state of autonomous personhood, such that the provision of social care is required to ensure individuals may return to this state, the notion of liveable life anchors individual experience within relations of care and support that vary in degree and quality over the life-course (Berlant 2016; Taylor 2013). The point here is that all lives require support, inasmuch as all individuals, groups and communities require access to social, affective and material infrastructures to flourish, regardless of their economic, social and political circumstances. In the next section, we define infrastructure and draw attention to its use as a framework for rethinking the objectives of social care and housing support, and reassessing individual and collective outcomes of these supports. 


\subsubsection{Infrastructures of care and housing}

Recent discussions of infrastructure offer a host of conceptually nuanced and methodologically flexible understandings of the relations, supports, services and benefits that facilitate and sustain a liveable life. This material should also help us to clarify the ideal outcomes, and/or anticipated goals of coordinated service provision for individuals exiting mental health and/or substance use treatment settings. Central to this analysis is the idea that health and social care are ultimately concerned with the work of repairing social, material and affective infrastructures. Infrastructures in this expanded sense are not just objects or public goods, but dynamic relational patterns that undergird forms of social organisation crucial to liveable life (Power and Mee 2020). This understanding goes well beyond the scale and scope of what infrastructure is commonly taken to refer to, for example, to road and rail networks, water mains, gas pipelines and utilities.

Moving beyond these material networks, scholars have sought to include the varied processes, norms, practices and relations by which the civic, social and cultural life of a city is organised. This is to regard infrastructure in terms of all the varied processes, services and events 'implicated in the making of urban functionality, sociality and identity' (Amin 2014:137). It is to draw together all the technical, material, social and symbolic characteristics of community life in order to begin to indicate how they shape and reshape the dynamics of 'urban wellbeing' (Amin 2014:138).

Taken from this broader perspective, a community's infrastructures may be said to include roads, water mains, telecommunications networks and electricity grids, along with its libraries, schools, hospitals and emergency services. Yet these infrastructures also include the more subtle relations and bonds by which networks of social capital emerge in a community, shaping the ways identities are formed, and how distinctive experiences of place, belonging and culture unfold. This extended understanding of infrastructure draws together the formal and informal, public and private, visible and invisible, material and immaterial structures and relations by which liveable life is sustained.

Given the principal research questions guiding this project, the notion of infrastructure is compelling for the insights it provides into the circumstances and support needs of individuals entering treatment for mental health and/or substance use problems. The very fact of people entering such settings is evidence of the earlier failure of particular infrastructures to provide the supports necessary for individuals to experience liveable life (see also Butler 2016). It may indicate a failure, for example, of the infrastructures of family life, education and training, the criminal justice system, health and social services to provide the supports necessary for the 'good life'. This approach shifts analysis from individual deficits, problems or risk factors to a broader sweep of infrastructural relations. Rather than focus on individual deficits, we are interested in the infrastructural failures that might be implicated in mental distress or substance use.

In this respect, the notion of infrastructure is useful precisely because it directs analytical attention to the social, affective and material supports needed to live life well, however one might define a 'liveable life' (see Berlant 2011; Wilson 2016; Amin 2014). The notion of infrastructure also sheds light on the goals of treatment for mental health and/or substance use problems, inasmuch as treatment might be understood in terms of the work of restoring, repairing, rebuilding or 'patching up' the infrastructures supporting (or hitherto failing to support) individuals as they leave treatment. If life is made liveable according to the social, affective and material infrastructures that sustain it, then we might regard treatment as an effort to repair or replace these infrastructures in order to render life more liveable by promoting the social and material means of recovery.

This approach suggests an alternative conceptual basis for thinking about the most effective ways of tailoring housing and social supports for individuals leaving institutional settings. Individuals and groups may be characterised in terms of their specific infrastructural supports and vulnerabilities. This shift brings into focus a broader sweep of factors and conditions than is typically included within risk and protective factor models (see for example Alam and Houston 2020; Power and Mee 2020; Williams 2017). Individuals exiting treatment require resilient and adaptive social, affective and material infrastructures to sustain their health and wellbeing (Duff, Jacobs et al., 2013). These adaptive infrastructures vary from case to case, to the extent that an individual's social 
and family networks, for example, afford either infrastructural supports or vulnerabilities, or to the extent that individuals are already supported within employment and training networks, or whether these infrastructures need to be augmented and extended (see also Power and Mee 2020). In considering these support needs, the notion of infrastructure provides a conceptual means of moving back and forth between different scales of analysis, from the social and intimate textures of personal life (Wilson 2016), to the broader structural forces that shape vulnerabilities and life opportunities across economies, cities and communities (Butler 2016).

In follows that failures in infrastructure may be significant factors in the experience of mental distress, substance use and/or housing insecurity, just as the formal and informal provision of housing and social care support may be understood in terms of the work of restoring or repairing infrastructures in support of a more liveable life for vulnerable individuals (see Alam and Houston 2020; Williams 2017). This suggests that treatment, social care and housing support may be treated as distinctive infrastructures of care that serve to augment, replace or repair liveable life.

To define what we mean by care we turn to Joan Tronto's (1993:103) seminal account: 'On the most general level, we suggest that caring be viewed as a species activity that includes everything that we do to maintain, continue, and repair our 'world' so that we can live in it as well as possible. That world includes our bodies, our selves, and our environment, all of which we seek to interweave in a complex, life-sustaining web'. This definition has the advantage of explicitly endorsing the infrastructural forms essential to the experience of a liveable life. Infrastructure is the 'complex life-sustaining web' that enables individuals and groups to live 'as well as possible'. Care, in this respect, is an 'activity' by which the social, affective and material infrastructures necessary to live well are sustained. It follows that the work of care also encompasses activities to 'repair' or augment these infrastructures (see Alam and Houston 2020; Power and Mee 2020).

Infrastructural analysis of mental health, AOD, and housing support demands consideration of the unique and evolving support and care needs of individuals such that they may come to enjoy more liveable lives, expressed in feelings of safety, security, belonging and home (see Alam and Houston 2020; Batterham 2019b; Duff, Jacobs et al. 2013; Williams 2017). Understanding care in terms of infrastructure also helps draw attention to what the work of delivering treatment for mental health and/or substance use problems actually entails, insofar as we can approach these supports in terms of the work staff do to restore or repair the infrastructures central to liveable life (Power and Mee 2020). Brackertz, Borrowman et al. (2020), for example, highlight the complex care-work involved in addressing the housing support needs of individuals experiencing significant mental health problems. This complex care-work includes: psychosocial supports beyond a person's immediate mental health needs; complex care coordination to encompass allied health services; work to restore trust in services and in some cases individual workers; a focus on issues of financial security and financial literacy; identification of new education and training pathways; and holistic support for a return to paid employment. In each instance, the delivery of mental health care can be regarded as a complex process of repairing the infrastructures central to a liveable life.

Other researchers have recently turned to an infrastructural analysis of housing to examine how housing mediates the possibility of giving and receiving care (Alam and Houston 2020; Easterlow and Smith 2004; Mee and Power 2020; Power 2019). These studies demonstrate how the quality of housing-including location, neighbourhood amenity and affordability-influence caring practices, including the giving and receiving of care, along with opportunities for self-care. Building on this work, the analysis to follow in later chapters will consider the ways mental health and substance use treatment services help to sustain (or fail to sustain) the infrastructures necessary to support a more liveable life. We are particularly interested in exploring how the delivery of stable housing grounds the ongoing development of the infrastructures necessary to sustain liveable life. We will also canvas recommendations for enhancing these infrastructures through more effective care coordination. Infrastructural analysis renders visible what is in need of 'repair' and the types of supports required by people to achieve and maintain liveable life over time. 
Moreover, thinking about housing and social care services in terms of 'caring infrastructures' helps us to move beyond referral pathways and interventions built on the assumption of linear progress towards health and recovery. In order to rethink how care and support is provided, we argue that it is necessary to move beyond systems-based thinking where needs are narrowly defined in terms of satisfying immediate support and service delivery priorities. Shifting the discussion away from the contested and overly-medicalised and service-oriented language of treatment and recovery towards a liveable life brings into focus the everyday relations that generate meaning and foster a sense of place, connection and belonging for vulnerable individuals in receipt of care.

\subsection{Research aims, methods and procedures}

\subsubsection{Key research questions}

- RQ1: What models of best practice may be derived from the available literature to enhance transition planning and service integration for individuals leaving residential treatment?

- RQ2: How does residential treatment affect individual housing careers over time?

- RQ3: How can post-exit support packages be tailored and delivered to individuals leaving residential treatment who are most at risk of homelessness?

- RQ4: How effective is existing service integration between housing and other sectors in transition planning and post-exit support for individuals leaving residential treatment? What opportunities exist for service improvement and enhanced coordination?

\subsubsection{Study design}

The project employs a mixed methods study design to investigate our key research questions. This has involved secondary analysis of linked administrative data and original qualitative research conducted among samples of service providers and individuals with lived experience of residential treatment for either mental health and/or substance use disorders. Extending the analysis of linked administrative data conducted by the Inquiry Program, this report details the findings of systematic analysis of linked administrative data maintained by the Victorian Department of Health and Human Service (DHHS). Linked data enabled analysis at person-level of service use patterns of a cohort of individuals across health and mental health services, family and justice services, and housing and homelessness services, the latter viewed through housing applications and tenancy information from the Speciality Homeless Information Platform.

Analysis presented in Chapter 2 explores the complexity of pathways into and out of treatment, and how service contacts mediate housing outcomes over time for a cohort of mental health service users. By analysing service use patterns following treatment exits we have been able to clarify risk factors for housing instability in this cohort, along with ideas for service enhancements.

In addition to the analysis of linked administrative data, the project team undertook brief reviews of the national and international research and policy literature, along with policy reviews and stakeholder interviews and focus groups with service providers and recent service users in Victoria and New South Wales. Interviews and focus groups offered significant new insights into effective models of post-exit support and discharge planning for individuals leaving residential settings for mental health and/or substance use disorders. This qualitative research enabled us to explore in more depth: key barriers to successful reintegration into stable housing; relevant risk and protective factors; the character of social, affective and material infrastructures necessary for the experience of liveable life; and key factors promoting and sustaining the return to stable housing, including formal service supports and informal social and family supports (see also Duff, Jacobs et al. 2013). 


\subsubsection{Ethical review}

Empirical research undertaken for this report was subject to two unique ethics approval processes; one to enable analysis of linked data held at the Centre for Victorian Data Linkage (CVDL) within DHHS; and a second application to enable the completion of qualitative research with treatment service providers (managers and administrators) and treatment service users. In each case the Human Research Ethics Committee (HREC) at RMIT University has been the appropriate source of institutional ethical approval, with secondary approvals then obtained from institutional review bodies at collaborating universities (UNSW and Curtin).

The research team, working in close coordination with the Inquiry Program team, elected to obtain ethics approval for the linked data analysis first. This approval was obtained in March 2019 (RMIT HREC Approval Certificate Number-21896). The ethics review process pursuant to the qualitative arm of the study required extensive planning, including the development of novel research instruments to guide the proposed focus groups and individual interviews, with separate schedules required for service providers and service users. As per the advice of the RMIT HREC, ethical approval to enable the commencement of the qualitative phases of research was divided into individual application processes (one for each planned cohort). Phase 1 approval to complete interviews and focus groups with treatment service providers was obtained in October 2019, with data collection proceeding over subsequent months in both Victoria and New South Wales. Phase 1 research was completed in early March 2020. Separate HREC approval to conduct Phase 2 research with treatment service users was submitted in early February 2020, with approval granted on March 30 (RMIT HREC Approval Certificate Number-22500). Research was subsequently conducted over May and June subject to covid-safe protocols described below.

\subsubsection{Methods and procedures}

Consistent with our key research questions (1.4.1), original research proceeded in three stages:

Stage 1

Complementing the literature review conducted by the Inquiry Program team, the project team conducted a targeted review of relevant international literature to establish a framework to guide subsequent stages of research (see sections 1.2 and 1.3). Our goal was to identify the most effective forms of housing and social supports for individuals exiting residential treatment, tailored to specific needs and risk profiles. International evidence suggests that enhanced discharge planning may significantly reduce the incidence of insecure and/ or inappropriate housing for individuals exiting residential treatment for either mental health and/or substance use disorders by establishing the optimal packaging of supports for specific cohorts, along with the optimal sequencing for the delivery of these supports (see Aubry, Goering et al. 2016). The review proposed for Stage 1 identified models of best practice for the integration, coordination and staging of housing and social supports for individuals leaving residential treatment, which then guided subsequent stages of research, including interviews with service users, and focus groups with treatment service providers. This review has also informed the identification of key recommendations for the enhancement of housing and social supports described in Chapter 6.

\section{Stage 2}

Stage 2 involved the analysis of linked administrative data to identify and elaborate relevant care pathways to guide recommendations for reforming housing assistance for individuals leaving institutional settings. Note also that linked data analysis informed the design and conduct of all aspects of the two qualitative phases of research (viz. interviews and focus groups with treatment service providers and/or managers; and a second phase of interviews and focus groups with service users). Approval protocols were negotiated with the CVDL within DHHS, following HREC approval (noted in section 1.4.3). The CVDL application involved lengthy administrative procedures with data released in two tranches; in October 2019, and the second in March 2020. 
For the present study, administrative data has enabled analysis of a cohort of individuals discharged from acute mental health services. Limitations inherent in the linked data did not permit matching analyses of a 'substance use' cohort and so admission to acute mental health care was selected as the key 'reference event' for all subsequent linked data analyses. This has included two years of 'look-back' data and up to four years of follow-up data for the cohort of interest. Released data include the following collections:

- Hospital admissions data (Victorian Admitted Episode Dataset)

- Emergency department presentations (Victorian Emergency Management Database)

- Clinical mental health service information (CMI-ODS)

- Mental health community support services (MHCSS)

- Victorian death registrations (Victorian death index)

- Child protection data (Crisis Information Referral System [CRIS])

- Public housing data, including applications and tenancies (Housing Integrated Information Platform [HIIP])

- Homelessness services

- Youth justice orders

- Family services data (Integrated Reports and Information System [IRIS])

- Family violence data (Integrated Reports and Information System [IRIS])

- Sexual assault services (Integrated Reports and Information System [IRIS])

- Alcohol and drug services (Alcohol and Drug Information System).

The CVDL also provided data dictionaries (where available) and custodian contact information to enable the research team to contact departmental knowledge experts as/when required to advise on technical aspects to do with data screening, security and custody.

The analysis of Victorian linked data focussed on three key questions:

1. What government services do individuals use in the immediate years after leaving mental health treatment? How does this pattern of use vary with gender/age/other factors?

2. What factors account for variations in service use by individuals in the immediate years after leaving the system?

3. What pathways/service-related factors lead to homelessness and/or housing insecurity? And what servicerelated factors predict housing needs after treatment?

\section{Stage 3}

Stage 3 proceeded in two phases: the first involved interviews and focus groups with a sample of service providers in Victoria and New South Wales, and the second involved interviews with a sample of individuals with lived experience of residential treatment in either Victoria or New South Wales. To ensure that we were able to capture a breadth of views and diversity of experiences within each phase of data collection, the research team sketched different pathways into Mental Health Inpatient Units and AOD residential rehabilitation spaces within Victoria and New South Wales. We then undertook a mapping exercise of AOD, mental health and housing services, including advocacy services, within each state. Through a combination of conversations with key stakeholders and the project team's knowledge and relationships within relevant service sectors, we were able to target specific services in recruiting service providers and service users. 
Consistent with the research approaches adopted in the other Inquiry projects (Projects B and C), interview and focus group questions for service providers examined pathways into and out of agencies, with emphasis on housing outcomes, service availability and gaps, and responses to individuals with complex and multiple needs (see Appendix 3 for copies of all relevant interview schedules). In phase 1 of Stage 3, we conducted 17 interviews (10 in Victoria and 7 in New South Wales) and four focus groups (1 in Victoria and 3 in New South Wales) with service providers for a total of $\mathbf{3 5}$ participants across the two study sites. The Victorian sample included three $A O D$, three mental health and four housing service providers and advocacy organisations and the New South Wales sample was comprised of three AOD, one mental health, and three housing service providers and advocacy organisations. Interviews were conducted in person or over the phone, and all focus groups were conducted in person across the two study sites. Interviews and focus group discussions highlighted pathways into and out of residential settings, the types of supports available, and the significant structural barriers encountered by service providers to provide adequate and effective support. These sessions also provided an opportunity to establish relationships to help facilitate recruitment for the second phase interviews with service users.

The second phase of Stage 3 was disrupted by COVID19-related restrictions on movement, particularly in Melbourne. In consultation with the research team and key stakeholders who assisted with recruitment for phase 1, it was decided to proceed with the interviews with service users online or over the phone. Recruitment information was circulated via the communication channels of supporting organisations and through personal networks via social media. We also worked with services and advocacy organisations to recruit members via lived experience advisory groups. These channels of recruitment were felt to be appropriate because of the potential complexities around the interviews, such as access to technology and the potentially distressing content of the interview schedule. Due to sensitivities, technological requirements and restrictions around movement we were unable to interview people living in unstable housing, such as boarding houses and supported residential services (SRSs).

Interviews with service users explored options for optimising post-exit support, guided by the models of best practice derived from the evidence review conducted in Stage 1. Service user interviews probed the availability and utility of informal social supports such as carer and extended social networks, along with options for more effectively integrating formal and informal supports into transition planning and post-exit support. We conducted 25 interviews (15 in Victoria and 10 in New South Wales) with individuals who had experience of residential treatment in order to generate first-person accounts of transition pathways and post-exist supports. There was significant diversity within the lived experience data set across Victoria and New South Wales with many people recounting significant and extensive contacts with mental health, substance use, and housing services. Some people spoke of experiences of homelessness, whereas others described housing difficulties, including the need for respite care in order to maintain housing.

Data from Phases 1 and 2 of Stage 3 were integrated and analysed using a thematic approach, and coding was conducted iteratively and inductively (Nowell, Norris et al. 2017). In close consultation with the research team, Cameron Duff led the development of the coding framework and analysis of transcripts. Through regular discussions, the coding framework was refined and developed, informing the subsequent organisation of the qualitative data chapters (see Chapters 3, 4 and 5). 


\section{Linked data analysis: youth leaving mental health residential treatment}

- This chapter introduces findings derived from analysis of linked administrative data (LAD) collected in Victoria. Given the data sources available for analysis we focus on a cohort of young people accessing acute mental health services.

- A significant majority of the cohort, between two-thirds and four-fifths, are 'light' users of services. Yet, around 20-30 per cent of the cohort uses a range of services and has used them quite regularly from a young age $(>18$ years of age).

- We detail the key characteristics of 'heavy' service users, and then offer recommendations for more effective care coordination and service integration strategies to reduce the risk of housing insecurity within this cohort.

\subsection{Mental health in Victoria: background}

\footnotetext{
The system is achieving exactly the results it was set up to achieve. Every time a decision was made to take funding out, without keeping track of its impact on patients and their families, it is achieving the results it was set up for. Every time decisions were made to fragment the system further by introducing elements that linked poorly with one another and that were not integrated with the broader health system of preventative primary health [...] every time we turned a blind eye to deteriorating hospitals, the sub-standard accommodation, the homelessness, the poverty and the violence that is all too common an experience for people with severe mental illness [...] We all have a hand in where we are today. (Associate Professor Simon Stafrace, Program Director of Alfred Mental and Addiction Health, Alfred Health (State of Victoria 2019:98))
}

\footnotetext{
Each year, one in five Victorians experience a mental health issue and almost 1 in 2 will experience some sort of mental health issue in their lifetime. The severity and duration of poor mental health varies, but it is estimated that of those that experience poor mental health about half (54\%) will experience mild mental health problems, approximately one-quarter will experience fluctuating mental health with episodes of poor mental health mixed with periods of good health, and about 1 in 5 will experience severe and enduring mental health issues (State of Victoria 2019:28-29).
} 
Poor mental health affects people throughout the community but the risk of poor mental health is higher for some groups. Studies show that rates of anxiety and depression are higher among Indigenous rather than nonIndigenous people (State of Victoria 2019:466). Spatial and socio-economic factors play a role as well. Although the overall prevalence of mental illness in metropolitan, rural, and regional areas is similar (Enticott, Meadows et al. 2016), rates of anxiety and depression among adults in regional areas (32.7\%) are nearly 7 percentage points higher than in metropolitan areas (25.8\%) and the rate of suicide among men aged between 35-54 is 60 per cent higher in regional Victoria than in Melbourne (State of Victoria 2019:290). Likewise, numerous studies both here and overseas indicate that low socio-economic status is a risk factor for mental illness (Issacs, Enticott et al. 2018.; Pickett and Wilkinson 2010; Patel, Lund et al. 2010). Of particular significance is the fact that the onset of mental health problems generally occurs at an early age. In the National Comorbidity Study Replication, a large US study of DSM-IV disorders, Kessler, Berglund et al. (2005) found that half of all lifetime cases start by 14 and three-quarters by 24. Early onset has led researchers to describe mental disorders as 'chronic diseases of the young' (Insel and Fenton 2005), suggesting any attempt to improve mental health in the community must pay close attention to young people's needs and their associated patterns of service use.

A further reason underpinning the importance of a strong policy focus on young people's wellbeing is the negative consequences of untreated mental health concerns, both in the short-term and the long-term. For children, adolescents and young adults, mental health problems occur at crucial developmental stages. Poor mental health can lead to emotional, behavioural and relationship difficulties, increasing the risk of further harms such as drug and alcohol misuse (Reavley, Cyetkovski et al. 2010), self-harm (De Leo and Heller 2004) and suicide (Caldwell, Jorm et al. 2004). It is also known that some young people are at greater risk than others. Youth leaving care and youth justice facilities, those from lower socio-economic backgrounds, young people that identify as LGBTIQ+ are all disproportionately represented among young people with poor mental health.

Poor mental health can also lead to difficulties engaging with the education system, which can in turn adversely impact on young peoples' life opportunities. Indeed, low education attainment and poor mental health cam amplify the labour market disadvantages young people often experience. When young people are excluded from the labour market this can result in a reliance on government income support, which is low. This in turn creates additional difficulties such as finding and sustaining housing. Affordable private rental housing for young people on government income support is extremely limited, and where affordable housing is available it is often far removed from education and employment opportunities. Public housing is an even scarcer resource and young people are under-represented in public housing. ${ }^{1}$ Evidence of the precarious nature of the housing circumstances of young people with a mental illness is found in numerous studies that report high rates of mental illness among the homeless, with rates among young homeless people ranging from 30-80 per cent depending on how homelessness is defined (Craig and Hodson 1998; Kamieniecki 2001; Martijn and Sharpe 2006). Homelessness and chronic housing instability exacerbate poor mental health but can also trigger the onset of poor mental health by exposing young people to stressors such as sexual predation and social stigma, in addition to the stress of having nowhere permanent to live. Indeed, safe, stable, affordable and well located housing are all considered to be prerequisites for effective clinical treatment and counselling (Rose 2019).

For some people in the community, particularly those with enduring and serious mental illnesses, protracted homelessness, sustained social and economic exclusion, and chronic physical and mental health problems can often be traced back to untreated childhood/adolescent mental health concerns. Policy makers and practitioners have long recognised the importance of an effective mental health system built around early intervention and adequate, appropriate, accessible services, but Victoria has failed to design, deliver or fund such a system, something that has come to stark attention with the report of the recent Royal Commission into Victoria's Mental Health System (State of Victoria 2019). The Royal Commission has drawn attention to a range of systemic problems that undermine effective mental health treatment for young people including long waiting times for services, and a 'postcode lottery' with respect to adequate treatment that favours people living in some areas

1 https://www.aihw.gov.au/reports/housing-assistance/housing-assistance-in-australia-2017/data. (Social housing tenants. Table 4haa2017-social-housing-tenants.xIs), accessed 28 September 2020. 
at the expense of others. The Royal Commission also noted there are insufficient services for those with moderate to severe mental illness, as well as poor discharge practices (2019:338). The Royal Commission paints a damning picture of a fragmented and inefficient system. Not only do system level inefficiencies have harmful individual consequences, they have significant social and economic costs, with poor mental health estimated to cost the Victorian economy \$14b per annum. Yet, despite this cost, per capita recurrent expenditure on mental health services in Victoria is the lowest in the country, as is the proportion of Victorians receiving clinical mental health care (State of Victoria 2019). Enduring discrepancies in funding and case load management between the states are the subject of explicit recommendations in the recent final report of the Royal Commission into Victoria's mental health system, with an expectation in the sector that significant new investments will be forthcoming.

\subsubsection{Patterns of service use: what we know}

The delivery of timely and appropriate services to young people with poor mental health has been the subject of political concern and research interest for many years. A more recent focus on service integration within the mental health system and the broader health, social and community services sector has drawn further attention to patterns of service use, with the (in)appropriateness of use and accessibility challenges two key foci of research interest. In line with these two concerns, previous studies have identified important variations in the use of mental health services. One particularly important strand focusses on 'heavy service users'. While definitions of heavy use vary, the key characteristic of the concept is that the frequency of use and/or the duration of service is significantly higher than the majority of people receiving similar treatment (Hadley, Culhane et al. 1992). Interest in heavy service users is largely motivated by the fact that despite accounting for approximately 10-20 per cent of service users, heavy service users account for anywhere between 50-75 per cent of inpatient costs. The identification of heavy service users and who is likely to become a heavy service user therefore offers the promise of large cost savings. A better understanding of what contributes to heavy service use might also assist policy makers to devise better, less expensive ways to meet health and social care needs.

Researchers with an interest in public health, as well as housing instability and homelessness (Kuhn and Culhane 1998; Benjaminsen and Andrade 2015: Taylor and Johnson 2019), have examined the characteristics of heavy service users. With respect to mental health systems, most studies suggest that the demographic and diagnostic characteristics of heavy service users differ from non-heavy users (Jessop, Hassall et al. 2000). Heavy users typically experience more severe distress, are often disadvantaged with low incomes, have little family or social support, and may also experience co-morbidities such as substance misuse (Lucas, Harrison-Read et al. 2001). No studies to our knowledge have explicitly examined service use patterns of young people with a mental disorder.

While heavy users of mental health systems share some common characteristics, heavy service use is influenced by the design of health and social care systems. Hadley, McGurrin et al.(1990:280) argue 'disproportionate use of costly acute services is, in part, a product of the public mental health system's inability to create an effective continuum of comprehensive, community-based programming for the SPMI [seriously and persistently mentally ill]'. Given the high and potentially preventable costs associated with heavy service use, resolving the problems of heavy users is 'critical to the success of health system reform' (Malone 1995:474).

Australian researchers have shown an interest in service use patterns, yet studies examining patterns of service use within the Victorian mental health system, and between the mental health and other government systems are limited. Existing studies demonstrate significant variation in patterns of service use. For instance, one study estimated that between 35-50 per cent of people with a mental illness receive no treatment (Slade, Johnston et al. 2009), although it is unclear if this is because they do not need treatment or because they cannot get it. At the other end of the service use continuum, studies highlight how people accessing mental health services are also often users of multiple systems. A recent analysis indicates that people accessing public specialist clinical mental health services in 2017-18 were more than twice as likely as the general Victorian population to be admitted to hospital (40.6\% vs $20.5 \%), 8$ times more likely to use a homelessness service (17.3\% vs $2.0 \%$ ) and over 10 times more likely to use a Drug and Alcohol service (8.9\% vs 0.6\%) (State of Victoria 2019:368/9). These are important 
studies, but we need more information about how young people experiencing mental health-related concerns use health and social care services over time. There is a particular need for a greater focus on patterns of heavy service use according to diagnosis and the type of service user. We need to know more about those individuals who access multiple health and social care services and how their support needs might differ from those who do not. Of utmost importance is understanding who is most likely to experience housing instability and homelessness and making adequate and appropriate services available at the earliest possible point. One way to address these questions is through the analysis of linked administrative data.

\subsubsection{What is linked administrative data (LAD)?}

Administrative data are the records collected by agencies and organisations in the course of doing their business. Governments and NGOs hold a great deal of information on individual clients of government services in their administrative systems that is both longitudinal and systematically collected. While administrative data offers many opportunities to enhance policy decision making and program design, the potential value of these data can be vastly increased by linking administrative dataset across multiple systems. Data linkage, or the process of merging records from different systems for the same individuals, allows for clearer insights into patterns of service use within and across systems over time. Of particular importance is that statistical analysis of linked administrative data offers opportunities to better 'monitor and evaluate the effectiveness of discharge and aftercare practices' (Culhane 2016:115) of key institutions and service systems.

While LAD offers opportunities to understand how complex systems of care such as the mental health system operate, who uses those systems, transitions between systems and the number and characteristics of people who use multiple systems, it has its limitations. People who do not use services are not included, which is an important issue given access to services is a commonly reported problem. Administrative data is not collected for research purposes, and despite substantial technological gains in data security and protection, security and privacy issues can still be challenging and time consuming to overcome. Despite these limitations, LAD is a useful and viable low-cost real-time approach. In the next section we describe our research design. 


\subsection{Research design}

\subsubsection{The population cohort and linked service use data}

Figure 1: Datasets available for analysis of the mental health cohort

\begin{tabular}{|c|}
\hline Victorian Admitted Episodes Dataset \\
\hline Victorian Emergency Management Dataset \\
\hline $1 / 1 / 2011$-31/12/2018 \\
\hline
\end{tabular}

Cause of Death Unit Record File

\begin{tabular}{|c|}
\hline $\begin{array}{c}1 / 01 / 2011-31 / 12 / 2018 \\
\text { Alcohol and Drug Information System }\end{array}$ \\
\hline $\begin{array}{r}1 / 01 / 2011 \text { - 31/12/2018 } \\
\text { Child Protection Dataset }\end{array}$ \\
\hline $\begin{array}{c}1 / 01 / 2011-31 / 12 / 2018 \\
\text { Mental Health Community Support Services }\end{array}$ \\
\hline $\begin{array}{c}\text { 1/01/2011 - 31/12/2018 } \\
\text { Clinical Mental Health (CMI/ODS) }\end{array}$ \\
\hline $\begin{array}{c}01 / 07 / 2013-31 / 12 / 2018 \\
\text { Family Services (IRIS) }\end{array}$ \\
\hline $\begin{array}{l}01 / 07 / 2013-31 / 12 / 2018 \\
\text { Family Violence (IRIS) }\end{array}$ \\
\hline $\begin{array}{c}\text { 01/07/2013 - 31/12/2018 } \\
\text { Sexual Assault Support Services (IRIS) }\end{array}$ \\
\hline $\begin{array}{c}\text { 1/01/2011 - 31/12/2018 } \\
\text { Housing Integrated Information Program (HIIP) }\end{array}$ \\
\hline
\end{tabular}

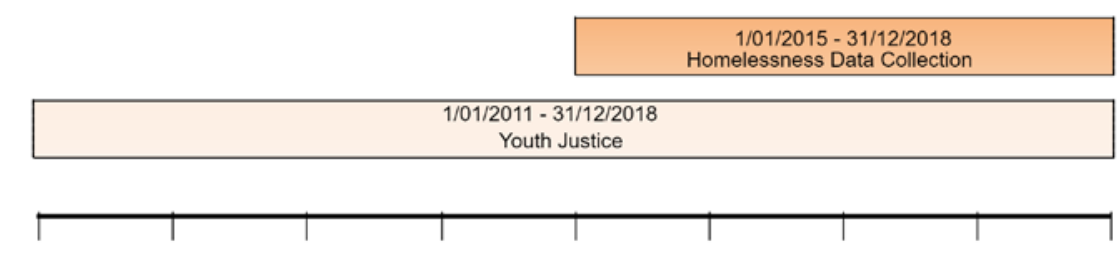

$1 / 01 / 2011$

$31 / 12 / 2018$

Source: Authors.

The following sections examine service use patterns of a cohort of young people leaving acute mental health residential treatment in Victoria (i.e. discharged from hospital after admission for mental health reasons). The population that forms the basis of the analysis comprises the 5,127 individuals aged 15-24 who were admitted to a hospital in Victoria for mental health issues and who were discharged from hospital sometime in 2013-2014. ${ }^{2}$ We call this population 'the mental health cohort'. The decision to focus on a population aged 15-24 years at the time of their service contact was made because, as noted earlier, in nearly three-quarters of cases the onset of mental health problems occurs before the age of 24 suggesting that improving treatment responses and services accessibility in this cohort should yield the most significant individual, social and economic benefits.

2 The population comprises individuals aged 15-25 from the Victorian Admitted Episodes Dataset with a separation date (1/1/201331/12/2014), and with a care type of 5A Acute adult mental health service, 5E Mental health secure extended care unit (SECU), 5G Acute aged persons mental health service (APMH), 5K Child and adolescent mental health service (CAMHS), 5 S Acute specialist mental health service, or 5 T Mental health nursing home care. 
Our analysis of this cohort draws on administrative data from 13 separate Victorian Government databases using a unique identifier created by the Centre of Victorian Data Linkages (CVDL) within the DHHS. The CVDL has software that uses a series of deterministic passes to confirm if records belong to the same person based on the name, date of birth, sex and where applicable address of the individual. However, there are some datasets where only a statistical linkage key (SLK) has been provided to the CVDL. In these cases, the unit uses the SLK in matching (see Centre for Data Linkage 2018 for an assessment of the quality of this method). We had access to records from eight datasets from the year 2011 through to 2018 (Figure 1), but only had information available from a later date in five of the databases (further detail on what is available in each dataset is provided in Appendix A). Nonetheless, the LAD provide data about service use patterns prior to, as well as after our populations exit from hospital in 2013-2014, what we term their 'reference event'. Drawing on the LAD this chapter investigates four questions.

1. What proportion of individuals in the mental health cohort use other government services, both prior to and after their reference event?

2. Does the proportion of individuals using other government services vary depending on the sex, indigeneity and housing status of individuals?

3. What are the housing trajectories of individuals in the mental health cohort?

4. To what extent do some people use government services more frequently than others?

Before we consider these research questions, we first describe the characteristics of the cohort.

\subsubsection{Characteristics of the mental health cohort}

Table 1 outlines the characteristics of our mental health cohort based on the service information recorded for their reference event. There were 5,174 individuals in this cohort with a median length of stay (LOS) of 8 days with 1 in 10 spending longer than a month in hospital. Slightly more than half of the cohort were females (56\%). Although the age distribution is fairly even, the two older age groups had slightly longer hospital stays with median stays of 9 days (vs the 8 days of the 15-18 year age group) and longer stays over the interquartile range (IQR). Indigenous Australians are overrepresented with 7 per cent in the cohort recorded as an Indigenous Australian compared to 1.6 per cent in the Victorian population overall (ABS, 2017). Interestingly however, they spend slightly less time in hospital for their reference event with a median stay of 8 days compared to the 9 -day median for non-Indigenous persons. Over three- quarters (79\%) of the cohort were in major cities where longer hospital stays were recorded.

The most common mental health conditions in the cohort based on primary diagnosis were depression (22\%), childhood onset disorder (19\%), and schizophrenia/psychosis (18\%), with 'other mental health condition' (15\%) and stress adjustment disorder (13\%) also quite common. Longer hospital stays were more common for individuals admitted with a schizophrenia/psychosis diagnosis and for those with a 'other mental health condition' diagnosis. Indeed, the median hospital stay for those diagnosed with schizophrenia/psychosis was 14 days and for the 'other' diagnosis group 17 days, whereas the median hospital stay for those diagnosed with self-harm and stress adjustment disorder was 3 and 4 days respectively. Almost three-quarters (72\%) of individuals were admitted to hospital voluntarily, but those admitted involuntarily tended to have longer stays with a longer median duration and longer durations over the interquartile range. The vast majority (94\%) were discharged home with around three-quarters referred to community mental health services. 
2. Linked data analysis:

youth leaving mental health

residential treatment

Table 1: Characteristics of mental health cohort and duration of hospital stay at reference event

\begin{tabular}{|c|c|c|c|c|}
\hline & $\mathrm{N}$ & $\%$ & $\begin{array}{r}\text { Median } \\
\text { LOS (days) }\end{array}$ & $\begin{array}{r}\mathrm{IQR} \\
\text { (days) }\end{array}$ \\
\hline Number of individuals & 5,174 & $100 \%$ & 8 & $3-18$ \\
\hline \multicolumn{5}{|l|}{ Gender } \\
\hline Male & 2,254 & $44 \%$ & 8 & $3-18$ \\
\hline Female & 2,920 & $56 \%$ & 8 & $3-19$ \\
\hline \multicolumn{5}{|l|}{ Age } \\
\hline $15-18$ & 1,734 & $34 \%$ & 8 & $3-15$ \\
\hline $19-21$ & 1,470 & $28 \%$ & 9 & $3-19$ \\
\hline $22-25$ & 1,970 & $38 \%$ & 9 & $4-21$ \\
\hline \multicolumn{5}{|l|}{ Indigenous status } \\
\hline Indigenous & 339 & $7 \%$ & 8 & $3-16$ \\
\hline Non-indigenous & 4,835 & $93 \%$ & 9 & $3-19$ \\
\hline \multicolumn{5}{|l|}{ Region } \\
\hline Major cities & 4,080 & $79 \%$ & 9 & $4-19$ \\
\hline Regional/remote areas & 1,026 & $20 \%$ & 7 & $3-16$ \\
\hline \multicolumn{5}{|l|}{ Primary diagnosis } \\
\hline Depression & 1,129 & $22 \%$ & 8 & $4-17$ \\
\hline Anxiety & 235 & $5 \%$ & 9 & $4-22$ \\
\hline Schizophrenia/psychosis & 909 & $18 \%$ & 14 & $8-25$ \\
\hline Stress/adjustment disorder & 676 & $13 \%$ & 4 & $2-7$ \\
\hline Personality disorder & 415 & $8 \%$ & 5 & $2-10$ \\
\hline Childhood onset disorder & 981 & $19 \%$ & 7 & $3-14$ \\
\hline Self-harm & 49 & $1 \%$ & 3 & $1-7$ \\
\hline Other mental health condition & 780 & $15 \%$ & 17 & $8-31$ \\
\hline \multicolumn{5}{|l|}{ Legal status } \\
\hline Voluntary & 3,735 & $72 \%$ & 8 & $3-17$ \\
\hline Involuntary & 1,439 & $28 \%$ & 10 & $5-21$ \\
\hline \multicolumn{5}{|l|}{ Mode of separation } \\
\hline Discharge to private residence & 4,843 & $94 \%$ & 8 & $3-18$ \\
\hline Transfer to mental health residential facility & 185 & $4 \%$ & 11 & $5-23$ \\
\hline Left against medical advice & 99 & $2 \%$ & 6 & $2-14$ \\
\hline Other & 47 & $1 \%$ & 4 & $2-14$ \\
\hline \multicolumn{5}{|l|}{ Referral on separation } \\
\hline Mental health community services & 2,868 & $72 \%$ & 8 & $4-16$ \\
\hline General practitioner & 479 & $12 \%$ & 5 & $2-9$ \\
\hline Private psychiatrist & 254 & $6 \%$ & 10 & $5-17$ \\
\hline Other & 221 & $4 \%$ & 5 & $1-14$ \\
\hline Missing & 1,163 & $22 \%$ & 16 & $7-28$ \\
\hline No referral provided & 189 & $5 \%$ & 3 & $1-10$ \\
\hline
\end{tabular}

Source: Author's analysis of linked administrative data. 


\subsection{What services do the mental health cohort use?}

In this section we examine service use patterns of the mental health cohort following their reference event. While we do not have unit record data to compare service use patterns of those in the mental health cohort with that of the general youth population in Victoria, we can refer to other data sources to compare overall rates of hospital admissions, emergency presentations, alcohol and drug treatment, and use of specialist homelessness services. The mental health cohort use services at a much higher rate than does a comparable Victorian youth population. More specifically, we find that those in the mental health cohort have more than 7 times the rate of hospital admissions as compared to all Victorians aged 15-24 over the same time period (140.5 admissions per 100 person year (PY) as compared to 18.6 admissions per $100 \mathrm{PYs}){ }^{3}$ They also have more than six times the rate of emergency department presentations (163.0 presentations per 100 PYs as compared to 26.4 per 100 PYs). ${ }^{4}$ They are also much more likely to use alcohol and drug treatment (26.9 per 100 PYs as compared to 1.8 per 100 PYs). ${ }^{5}$ Similarly, while on average 1.8 per cent of young Victorians access homelessness services in a given year, for those in the mental health cohort 13.3 per cent accessed homelessness services in the same time period. ${ }^{6}$

Utilising the linked data, we can drill down further into service usage patterns of the mental health cohort following their reference event. Table 2 shows the services used by the mental health cohort after exit from their reference event over three different time horizons: 30 days after exit, 12 months after exit, and 4 years after exit. In the 30 days after exit, 18 per cent of individuals were re-admitted into hospital with mental health the most common reason (9\%). After 12 months, over half (55\%) the cohort had been re-admitted to hospital with over a quarter of the cohort (29\%) admitted for a mental health reason. After 4 years from their reference event, over three-quarters (78\%) had been re-admitted to hospital. Again mental health reasons were the most common reason for readmission (42\% of the overall cohort), but now we find a substantial minority of people were also readmitted for self-harm and alcohol/drugs issues (28\%).

The statistics on emergency department presentations show very similar patterns, presumably reflecting the fact that the vast majority of hospital admissions for this cohort typically occur via presentation to a hospital emergency department. When we look at drug and alcohol service use, we find that less than 5 per cent of the mental health cohort had treatment for alcohol/substance use issues within 30 days of exiting their reference event, but four years after the reference event 1 in 5 individuals had presented to a drug and alcohol service for treatment.

Not unexpectedly, presentations at clinical mental health services were more common. Inpatient services largely overlap with hospital admissions data, although there are also inpatient mental health facilities that are not part of the hospital data collection. An additional 38 per cent used outpatient services within 30 days, growing to 62 per cent over 4 years. Mental health community support services, which are supports for those with severe psychiatric disability to help them look after themselves, were not commonly used-only 10 per cent of the mental health cohort used these services within a year of exit from their reference event and 15 per cent within 4 years after exit.

3 AlHW principal diagnosis data cubes. Data is not broken down by state. Data was extracted from 2015 to 2018 for all Australians aged 15-25. While principal ICD codes were available, the classifications used utilised principal diagnosis codes, external cause codes and additional diagnosis codes and as such no direct comparison could take place.

4 Source: Emergency department care: Australian hospital statistics series of reports by AlHW. These reports contain counts of admissions for each financial year, by state and age category. Data was extracted from 2015 to 2018 for Victorians aged 15-25.

5 Source: Alcohol and other drug treatment services in Australia series of reports from AlHW. These reports contain counts of episodes for each financial year, by state and age category. Data was extracted from 2015 to 2018 for Victorians aged 10-29.

6 Source: Specialist Homelessness Services annual report series from AlHW. These reports contain the number of clients for each financial year by state for young people (aged 15-24). The number of clients for years 2015 to 2018 in Victoria aged 15-24 was extracted. 
2. Linked data analysis:

youth leaving mental health

residential treatment

Table 2: Percentage of individuals in the mental health cohort who had particular service records after exit from reference event

\begin{tabular}{|c|c|c|c|c|}
\hline & & 30 days & 1 year & 4 years \\
\hline \multirow[t]{7}{*}{ Hospital admission } & Alcohol/drugs & 4 & 15 & 28 \\
\hline & Self-harm & 5 & 19 & 28 \\
\hline & Assault & - & 1 & 3 \\
\hline & Injury & 0 & 3 & 11 \\
\hline & Mental health & 9 & 29 & 43 \\
\hline & Other & 2 & 16 & 42 \\
\hline & Any & 18 & 55 & 78 \\
\hline \multirow[t]{7}{*}{ Emergency presentation } & Alcohol/drugs & 2 & 10 & 21 \\
\hline & Self-harm & 6 & 21 & 32 \\
\hline & Assault & - & - & 1 \\
\hline & Injury & 2 & 15 & 34 \\
\hline & Mental health & 8 & 27 & 44 \\
\hline & Other & 5 & 25 & 51 \\
\hline & Any & 18 & 54 & 76 \\
\hline Alcohol/Drug treatment & & 4 & 12 & 20 \\
\hline \multirow[t]{2}{*}{ Clinical mental health } & Inpatient & 13 & 32 & 44 \\
\hline & Outpatient & 38 & 53 & 62 \\
\hline \multirow{2}{*}{\multicolumn{5}{|c|}{$\begin{array}{l}\text { Mental Health Community } \\
\text { Support Services }\end{array}$}} \\
\hline & & NA & 10 & 15 \\
\hline Child protection & & NA & 4 & 5 \\
\hline Family services & & 0 & 1 & 3 \\
\hline Family violence & & 0 & 3 & 8 \\
\hline Sexual support services & & 0 & 3 & 6 \\
\hline \multirow[t]{2}{*}{ Public housing applications } & Primary applicant & 0 & 2 & 9 \\
\hline & Non-primary appl. & - & 0 & 2 \\
\hline \multirow[t]{2}{*}{ Public housing tenancy } & Had tenancy & 6 & 7 & 9 \\
\hline & New independent tenancy & - & 1 & 3 \\
\hline \multirow[t]{3}{*}{ Homelessness } & At risk of homeless & NA & NA & 15 \\
\hline & Currently homeless & NA & NA & 14 \\
\hline & Any & NA & NA & 22 \\
\hline \multirow[t]{2}{*}{ Youth justice } & Custodial & - & 1 & 1 \\
\hline & Community & 0 & 1 & 2 \\
\hline Mortality & & - & 1 & 2 \\
\hline
\end{tabular}

Source: Author's analysis of linked administrative data. 
Child and family violence services were not commonly used, which is not surprising given the age profile of this cohort (i.e. they are too old to now be in child protection but too young typically to have started their own families). Public housing tenancies are also not very common among this cohort due to their age profile. Only 6 per cent were a public housing tenant in the 30 days after exit from their reference event, and only 9 per cent four years after exit. Most of these will be living with a parent or guardian, with an additional 3 per cent entering a new independent tenancy within four years.

Although SHS data is only available from July 2015 onwards (and so we do not observe usage patterns over the shorter time horizons), almost a quarter (22\%) use specialist homelessness services in the four years after their reference event. Interactions with the youth justice system are limited as most of the cohort would now be too old for juvenile justice and have migrated to the adult justice system where relevant. We do not have data dealing with adult justice interactions. Sadly, 2 per cent of the mental health cohort died within four years of their reference event.

\subsubsection{What services were used in the lead up to the reference event?}

While the cohort selection was guided by an intention to capture an age group where many mental health issues emerge, it was, to a certain degree, arbitrary. It is therefore of interest to examine whether there are earlier interactions with services for this cohort. Table 3 shows a relatively high proportion of individuals using services in the two years prior to exit. ${ }^{7}$ Half (51\%) had been hospitalised in the two years prior to their reference event, with one in five (21\%) previously hospitalised for mental health causes, and 17 per cent had previous hospitalisations for self-harm and 12 per cent for alcohol/drug-related issues. One in five had been an inpatient in a clinical mental health care setting, and 44 per cent had received outpatient clinical mental health services. Almost one in ten (9\%) had been in child protection. This data indicates that for most of this cohort, their reference event was not the start of their pathway through services, but that this occurred at a younger age.

7 These proportions do not include the reference event itself, i.e. the service that defined them as part of our cohort, or any services that form part of this stay in care (For instance, in the mental health cohort, their pathway to admission typically occurred through the emergency department (ED). ED presentation was not counted as a prior service use.). 
Table 3: The proportion of individuals in the mental health cohort who had a particular service in the two years prior to their reference event

\begin{tabular}{|c|c|c|}
\hline & & $\%$ \\
\hline \multirow[t]{7}{*}{ Hospital admission } & Alcohol/drugs & 12 \\
\hline & Self-harm & 17 \\
\hline & Assault & 1 \\
\hline & Injury & 6 \\
\hline & Mental health & 21 \\
\hline & Other & 25 \\
\hline & Any & 51 \\
\hline \multirow[t]{7}{*}{ Emergency presentation } & Alcohol/drugs & 12 \\
\hline & Self-harm & 21 \\
\hline & Assault & - \\
\hline & Injury & 24 \\
\hline & Mental health & 32 \\
\hline & Other & 35 \\
\hline & Any & 64 \\
\hline Alcohol/Drug treatment & & 13 \\
\hline \multirow[t]{2}{*}{ Clinical mental health } & Inpatient & 21 \\
\hline & Outpatient & 44 \\
\hline $\begin{array}{l}\text { Mental health community } \\
\text { support services }\end{array}$ & & 5 \\
\hline Child protection & & 9 \\
\hline \multirow[t]{2}{*}{ Public housing applications } & Primary applicant & 2 \\
\hline & Non-primary appl. & 1 \\
\hline \multirow[t]{2}{*}{ Public housing tenancies } & Had tenancy & 7 \\
\hline & New independent tenancy & 1 \\
\hline \multirow[t]{2}{*}{ Youth justice } & Custodial & 1 \\
\hline & Community & 2 \\
\hline Total number of individuals & & 5,174 \\
\hline
\end{tabular}

Source: Author's analysis of linked administrative data.

\subsubsection{Service use by sex}

Previous studies show gendered patterns in mental health concerns and, as Table 4 indicates, we found similar patterns in our cohort. Females are more likely to be hospitalised than males (83\% versus $72 \%$ ), and for all categories other than alcohol/drugs (24\% vs $34 \%$ ), assault (2\% versus $4 \%$ ), and injury (11\% versus $15 \%$ ). Interestingly however, there appears to be less of a difference in rates of emergency presentations by sex. While females remain slightly more likely to present to emergency departments (77\% versus $74 \%$ ), they are no more likely to present for mental health reasons. They are also no less likely to present for alcohol/drug-related issues or for assault. Males remain more likely to present for injury. A similarly gendered pattern is seen for alcohol/ drug treatment services with males being more likely to use these services than are females in this cohort. Interestingly, males are also more likely to be treated as inpatients in clinical mental health services, whereas females are more likely to use outpatient services. 
Table 4: The proportion of individuals in the mental health cohort with a service record in the four years after exit from reference event, by sex (\%)

\begin{tabular}{|c|c|c|c|c|c|}
\hline & & $\begin{array}{r}\text { Male } \\
(n=2,254)\end{array}$ & $\begin{array}{r}\text { Female } \\
(n=2,920)\end{array}$ & Chi Sq. & $\begin{array}{r}\text { Total } \\
(\mathrm{N}=5,174)\end{array}$ \\
\hline \multirow[t]{7}{*}{ Hospital admission } & Alcohol/drugs & 34 & 24 & $<0.001$ & 28 \\
\hline & Self-harm & 19 & 35 & $<0.001$ & 28 \\
\hline & Assault & 4 & 2 & $<0.001$ & 3 \\
\hline & Injury & 15 & 11 & 0.02 & 11 \\
\hline & Mental health & 36 & 49 & $<0.001$ & 43 \\
\hline & Other & 27 & 54 & $<0.001$ & 42 \\
\hline & Any & 72 & 83 & $<0.001$ & 78 \\
\hline \multirow[t]{7}{*}{ Emergency presentation } & Alcohol/drugs & 22 & 21 & n.s. & 21 \\
\hline & Self-harm & 25 & 38 & $<0.001$ & 32 \\
\hline & Assault & 1 & 1 & n.s. & 1 \\
\hline & Injury & 36 & 32 & 0.002 & 34 \\
\hline & Mental health & 44 & 43 & n.s. & 44 \\
\hline & Other & 45 & 56 & $<0.001$ & 51 \\
\hline & Any & 74 & 77 & 0.007 & 76 \\
\hline \multicolumn{2}{|l|}{ Alcohol/Drug treatment } & 26 & 16 & $<0.001$ & 20 \\
\hline \multirow[t]{2}{*}{ Clinical mental health } & Inpatient & 61 & 55 & $<0.001$ & 58 \\
\hline & Outpatient & 16 & 19 & 0.002 & 18 \\
\hline \multirow{2}{*}{\multicolumn{2}{|c|}{$\begin{array}{l}\text { Mental Health Community } \\
\text { Support Services }\end{array}$}} & & & & \\
\hline & & 16 & 15 & n.s. & 15 \\
\hline \multicolumn{2}{|l|}{ Child protection } & 3 & 6 & $<0.001$ & 5 \\
\hline \multicolumn{2}{|l|}{ Family services } & 0 & 5 & $<0.001$ & 3 \\
\hline \multicolumn{2}{|l|}{ Family violence } & 16 & 2 & $<0.001$ & 8 \\
\hline \multicolumn{2}{|l|}{ Sexual assault support services } & 1 & 10 & $<0.001$ & 6 \\
\hline \multirow[t]{2}{*}{ Public housing applications } & Primary applicant & 8 & 9 & n.s. & 9 \\
\hline & Non-primary appl. & 2 & 1 & 0.04 & 2 \\
\hline \multirow[t]{2}{*}{ Public housing tenancy } & Had tenancy & 9 & 9 & n.s. & 9 \\
\hline & New independent tenancy & 3 & 4 & n.s. & 3 \\
\hline \multirow[t]{3}{*}{ Homelessness } & At risk of homelessness & 15 & 15 & n.s. & 15 \\
\hline & Currently homeless & 15 & 14 & n.s. & 14 \\
\hline & Any & 21 & 22 & n.s. & 22 \\
\hline \multirow[t]{2}{*}{ Youth justice } & Custodial & 1 & 0 & $<0.001$ & 1 \\
\hline & Community & 3 & 1 & $<0.001$ & 2 \\
\hline \multicolumn{2}{|l|}{ Mortality } & 2 & 1 & $<0.001$ & 2 \\
\hline
\end{tabular}

Source: Author's analysis of linked administrative data. 
Females are more likely to be in child protection than males although overall rates in child protection over this period remain low (6\% for females compared to $3 \%$ for males). Family services and sexual assault services are also more likely to be used by females, whereas males (16\%) are much more likely to use family violence services than females (2\%). This is most likely reflecting men who are presenting as the perpetrator. In recent years there has been increased policy attention on working with perpetrators of violence, although whether this would account for the large difference is unclear. There are negligible differences in public housing tenancies and homelessness services by gender. Males are more likely to come into contact with youth justice than females in this cohort, although rates are very low overall. Mortality rates are also higher for males: 2 per cent of males in this cohort died over this period compared to 1 per cent of females.

\subsubsection{Service use by Indigenous status}

Table 5: The proportion of individuals in the mental health cohort with a service record in the four years after exit from reference event, by recorded Indigenous status

\begin{tabular}{|c|c|c|c|c|c|}
\hline & & $\begin{array}{l}\text { Indigenous } \\
\qquad(n=339)\end{array}$ & $\begin{array}{r}\text { Non- } \\
\text { Indigenous } \\
(n=48,35)\end{array}$ & Chi Sq. & $\begin{array}{r}\text { Total } \\
(\mathrm{N}=5,174)\end{array}$ \\
\hline \multirow[t]{7}{*}{ Hospital admission } & Alcohol/drugs & 50 & 27 & $<0.001$ & 28 \\
\hline & Self-harm & 34 & 28 & 0.02 & 28 \\
\hline & Assault & 7 & 3 & $<0.001$ & 3 \\
\hline & Injury & 15 & 11 & 0.02 & 11 \\
\hline & Mental health & 48 & 43 & n.s. & 43 \\
\hline & Other & 48 & 42 & 0.04 & 42 \\
\hline & Any & 8 & 77 & $<0.001$ & 78 \\
\hline \multirow[t]{7}{*}{ Emergency presentation } & Alcohol/drugs & 36 & 20 & $<0.001$ & 21 \\
\hline & Self-harm & 50 & 31 & $<0.001$ & 32 \\
\hline & Assault & 2 & 1 & 0.02 & 1 \\
\hline & Injury & 52 & 32 & $<0.001$ & 34 \\
\hline & Mental health & 63 & 43 & $<0.001$ & 43 \\
\hline & Other & 68 & 50 & $<0.001$ & 51 \\
\hline & Any & 92 & 75 & 0.007 & 76 \\
\hline Alcohol/Drug treatment & & 45 & 18 & $<0.001$ & 20 \\
\hline \multirow[t]{2}{*}{ Clinical mental health } & Inpatient & 76 & 56 & $<0.001$ & 58 \\
\hline & Outpatient & 18 & 18 & n.s. & 18 \\
\hline \multicolumn{6}{|l|}{ Mental Health Community } \\
\hline Support Services & & 24 & 15 & $<0.001$ & 15 \\
\hline Child protection & & 7 & 4 & 0.02 & 5 \\
\hline Family services & & 8 & 2 & $<0.001$ & 3 \\
\hline Family violence & & 20 & 7 & $<0.001$ & 8 \\
\hline Sexual assault support services & & 13 & 6 & $<0.001$ & 6 \\
\hline \multirow[t]{2}{*}{ Public housing applications } & Primary applicant & 23 & 8 & $<0.001$ & 9 \\
\hline & Non-primary appl. & 4 & 1 & $<0.001$ & 2 \\
\hline
\end{tabular}




\begin{tabular}{|c|c|c|c|c|c|}
\hline & & $\begin{array}{r}\text { Indigenous } \\
(\mathrm{n}=339)\end{array}$ & $\begin{array}{r}\text { Non- } \\
\text { Indigenous } \\
(\mathrm{n}=48,35)\end{array}$ & Chi Sq. & $\begin{array}{r}\text { Total } \\
(\mathrm{N}=5,174)\end{array}$ \\
\hline \multirow[t]{2}{*}{ Public housing tenancy } & Had tenancy & 28 & 8 & $<0.001$ & 9 \\
\hline & New independent tenancy & 14 & 3 & $<0.001$ & 3 \\
\hline \multirow[t]{3}{*}{ Homelessness } & At risk of homelessness & 34 & 14 & $<0.001$ & 15 \\
\hline & Currently homeless & 43 & 12 & $<0.001$ & 14 \\
\hline & Any & 53 & 20 & $<0.001$ & 22 \\
\hline \multirow[t]{2}{*}{ Youth justice } & Custodial & 1 & 1 & n.s. & 1 \\
\hline & Community & 4 & 2 & 0.01 & 2 \\
\hline Mortality & & 1 & 2 & n.s. & 2 \\
\hline
\end{tabular}

Source: Author's analysis of linked administrative data.

In Table 5 we see the breakdown of service use for the mental health cohort by Indigenous status. Indigenous Australians had higher proportions of service access in almost all service use types. The only categories where rates of service use were not significantly different for Indigenous Australians compared to non-Indigenous individuals in the mental health cohort were for mental health-related hospitalisations, outpatient clinical mental health services, and youth justice custodial services. Mortality rates were also not significantly different between the two groups. Indigenous Australians were significantly more likely to use all other service types and sometimes by quite a large margin. Of particular note were the 53 per cent of Indigenous Australians that had used a homelessness service whereas only 20 per cent of non-Indigenous Australians used homelessness services over the same time period.

\subsubsection{Does service use differ for those in public housing?}

The dataset held little information on the socio-economic characteristics of our cohort. This would have been helpful given the link between socio-economic status and health, education attainment and housing stability. One indicator of socio-economic status is residence in public housing, which is almost exclusively allocated to low-income and often high-need households. Table 6 contains an additional analysis of service use for the mental health cohort only, split by housing status at the time of their reference event. Given the age profile of this cohort, the sample numbers in public housing are quite low. There were 48 individuals (1\%) with their own independent public housing tenancy; another 250 individuals (5\%) reported living in public housing as a resident or dependent (likely as part of their family unit); 156 individuals (3\%) were not in public housing but had applied for public housing in the four years prior, with the vast majority of individuals not having a tenancy or having applied for public housing $(n=4,720,91 \%)$.

What is interesting about Table 6 is how similar the service usage patterns are of the three public housing groups and how different they are to the comparison group. This group is largely comprised of individuals living in private accommodation arrangements with or independent of their parents but also includes those in share house arrangements or community housing and, some who were experiencing homelessness. The public housing groups have higher service utilisation among almost all service types. This includes those on the waiting list. This highlights just how disadvantaged young people need to be to even consider applying for public housing. 
2. Linked data analysis:

youth leaving mental health

residential treatment

Table 6: Proportion of individuals in the mental health cohort with a service record in the four years after exit, by housing status at index exit (\%)

\begin{tabular}{|c|c|c|c|c|c|}
\hline & & $\begin{array}{r}\text { In independent } \\
\text { public housing } \\
(\mathrm{n}=48)\end{array}$ & $\begin{array}{l}\text { In public } \\
\text { housing as } \\
\text { resident or } \\
\text { dependent } \\
(n=250)\end{array}$ & $\begin{array}{l}\text { On waiting list } \\
\qquad(\mathrm{n}=156)\end{array}$ & $\begin{array}{r}\text { No tenancy or } \\
\text { application } \\
(n=4,720)\end{array}$ \\
\hline \multirow[t]{7}{*}{ Hospital admission } & Alcohol/drugs & 60 & 38 & 38 & 27 \\
\hline & Self-harm & 40 & 30 & 28 & 28 \\
\hline & Assault & 10 & 8 & 5 & 2 \\
\hline & Injury & 10 & 13 & 13 & 11 \\
\hline & Mental health & 63 & 48 & 53 & 43 \\
\hline & Other & 48 & 44 & 46 & 42 \\
\hline & Any & 90 & 85 & 85 & 77 \\
\hline \multirow[t]{7}{*}{ Emergency presentation } & Alcohol/drugs & 35 & 32 & 29 & 20 \\
\hline & Self-harm & 50 & 42 & 39 & 32 \\
\hline & Assault & 4 & 2 & 1 & 1 \\
\hline & Injury & 42 & 45 & 34 & 33 \\
\hline & Mental health & 73 & 59 & 60 & 42 \\
\hline & Other & 70 & 62 & 64 & 50 \\
\hline & Any & 94 & 90 & 88 & 75 \\
\hline Alcohol/Drug treatment & & 35 & 30 & 34 & 19 \\
\hline \multirow[t]{2}{*}{ Clinical mental health } & Inpatient & 77 & 61 & 63 & 43 \\
\hline & Outpatient & 90 & 79 & 75 & 60 \\
\hline Community mental health services & & 29 & 22 & 33 & 14 \\
\hline Child protection & & 0 & 11 & 4 & 4 \\
\hline Family services & & 13 & 8 & 9 & 2 \\
\hline Family violence & & 15 & 17 & 10 & 7 \\
\hline Sexual assault support services & & 8 & 11 & 8 & 6 \\
\hline \multirow[t]{3}{*}{ Homelessness } & $\begin{array}{l}\text { At risk of } \\
\text { homelessness }\end{array}$ & 23 & 29 & 29 & 14 \\
\hline & Currently homeless & 44 & 32 & 32 & 13 \\
\hline & Any & 48 & 44 & 43 & 20 \\
\hline \multirow[t]{2}{*}{ Youth justice } & Custodial & 0 & 3 & 1 & 1 \\
\hline & Community & 0 & 7 & 1 & 2 \\
\hline Mortality & & 4 & 1 & 4 & 1 \\
\hline
\end{tabular}

Source: Author's analysis of linked administrative data. 


\subsubsection{Housing and homelessness trajectories after the reference event}

There were 1,372 individuals with a record from a homelessness specialist service (27\%) between July 2015 and December 2018, which is when SHS data became available. ${ }^{8}$ Of these, 578 (11\% of all individuals) had a homelessness service record that identified at least one spell of homelessness. In Table 7 we examine the characteristics of those using homelessness services compared to those with no record of service use. The characteristics of individuals are taken at the date that their first record began (their 'index date'). For those without a homelessness record, an 'index date' was chosen by randomly selecting a date from all dates of first homelessness records for this cohort. The characteristics examined can be thought of as a subset of those that are commonly thought of as potential risk factors for homelessness. We note two substantial caveats to this analysis. The first is that the set of risk factors that we observe is limited by what information is available in the dataset. The second is that we only observe people as homeless if they use homelessness services, and of course many people that experience homelessness do not. Thus, a subset of those in the category 'no period of homelessness' may include a group of people who have experienced homelessness but have not sought out services.

From Table 7 we see evidence that many of the risk factors linked to homelessness are present among those that use specialist homelessness services. Indigenous Australians made up 4 per cent of those who did not have a homelessness record, but 15 per cent of those who did (and 19\% of those who were recorded as homeless at this presentation). Those with a history of alcohol and/or substance use (particularly opioid or amphetamine use) made up a larger share of those using homelessness services than those with no record of homelessness service use. For instance, amphetamine misuse occurred in 31 per cent of those with a homelessness services record, while 10 per cent of those with no homelessness record had evidence of amphetamine misuse. Likewise, 12 per cent of those with a homelessness services record had a history of opioid misuse whereas only 4 per cent of those with no record had a history of opioid misuse.

While those diagnosed with particular mental health disorders make up a slightly higher share of those using homelessness services than those without a homelessness service record-particularly those diagnosed with schizophrenia, stress/adjustment disorder or a personality disorder-it appears that it is those with multiple hospitalisations that are the most at risk of homelessness. Sixty per cent of those with a homelessness services record had been admitted as a mental health inpatient four or more times, nearly twice the number of those who had not used homelessness services (34\%). Our results also provide further confirmation of the link between out-of-home care and homelessness. Persons with histories in child protection also represent a larger share of those using homelessness services, particularly for those placed in out-of-home care. Also, although the numbers of those who have come into contact with the youth justice system are low overall, they make up a relatively larger share of those using homelessness services than those with no record of homelessness service use. Perpetrators of family violence using family violence services also make up a larger share of those with homelessness services records than those without a record of homelessness service use. As it is likely that perpetrators of family violence have had some contact with the justice system, this could be indicative of a broader relationship between the homelessness service system and the adult justice system, although we do not have data to analyse such a possibility here.

The tight targeting of public housing to those with priority needs is evident when examining the overlap between public housing tenancies and homelessness services use. Those in/waiting for public housing are particularly likely to have had an interaction with homelessness services and to have been homeless when presenting to services. Interestingly, even those who are children of tenants are more likely to interact with homelessness services. However, Table 7 also shows that 70 per cent of those who had a homelessness record and 62 per cent who had been homeless 'had no interaction with public housing. These findings, combined with information in Table 6 that shows only 156 people in our cohort were on a wait-list for public housing, raise some difficult questions.

8 This differs from the earlier figure of $24 \%$ as here we are looking at service use records from July 2015 onwards, whereas the earlier figure includes only those records observed within four years of exit from each individual's reference event. 
Given the patterns of service use we observe, their poor mental health, and that over 1,000 individuals clearly have had serious housing problems at some stage, there would seem to be a prima-facie case that the number of people on the wait list should be considerably higher. It may well be that young people consider public housing an inappropriate option, but equally it appears that agencies assisting young people are not paying sufficient attention to their clients' longer term housing needs by not putting in priority housing applications on their behalf.

Table 7: Proportion of individuals with potential predictors of homelessness, by homelessness status, mental health cohort (\%)

\begin{tabular}{|c|c|c|c|c|}
\hline & & $\begin{array}{r}\text { Had } \\
\text { homelessness } \\
\text { record } \\
(n=1,372)\end{array}$ & $\begin{array}{r}\text { Was } \\
\text { Homeless } \\
(n=578)\end{array}$ & $\begin{array}{r}\text { No period of } \\
\text { homelessness } \\
(n=3,802)\end{array}$ \\
\hline \multirow[t]{2}{*}{ Gender } & Male & 42 & 49 & 44 \\
\hline & Female & 58 & 51 & 56 \\
\hline \multirow[t]{4}{*}{ Age } & $<20$ & 19 & 19 & 19 \\
\hline & $20-22$ & 26 & 26 & 26 \\
\hline & $23-25$ & 31 & 31 & 29 \\
\hline & $26+$ & 25 & 24 & 26 \\
\hline Indigenous & Is Indigenous & 15 & 19 & 4 \\
\hline \multirow[t]{2}{*}{ Region } & Major cities & 74 & 75 & 82 \\
\hline & Regional/Remote & 26 & 25 & 18 \\
\hline History of alcohol abuse (ADIS) & & 14 & 14 & 5 \\
\hline History of alcohol abuse (secondary care) & & 24 & 25 & 13 \\
\hline History of opioid abuse & & 12 & 12 & 4 \\
\hline History of amphetamine abuse & & 31 & 31 & 10 \\
\hline History of other drug abuse & & 52 & 52 & 25 \\
\hline History of depression/anxiety & & 63 & 48 & 55 \\
\hline History of schizophrenia & & 44 & 39 & 27 \\
\hline History of stress/adjustment disorder & & 50 & 39 & 28 \\
\hline History of personality disorder & & 54 & 40 & 28 \\
\hline History of childhood onset disorders & & 13 & 7 & 6 \\
\hline History of other mental health condition & & 38 & 25 & 33 \\
\hline \multirow[t]{3}{*}{ No. mental health inpatient admissions } & 1 & 18 & 16 & 32 \\
\hline & $2-3$ & 21 & 20 & 26 \\
\hline & $4+$ & 60 & 63 & 34 \\
\hline History of self-harm & & 67 & 67 & 48 \\
\hline Has cognitive/developmental disability & & 10 & 12 & 5 \\
\hline Victim of child abuse (no care placement) & & 6 & 4 & 2 \\
\hline Victim of child abuse (placed in care) & & 13 & 13 & 2 \\
\hline Sexual assault victim & & 11 & 10 & 5 \\
\hline
\end{tabular}




\begin{tabular}{lrrr}
\hline & $\begin{array}{r}\text { Had } \\
\text { homelessness } \\
\text { record } \\
(n=1,372)\end{array}$ & $\begin{array}{r}\text { Homeless } \\
(n=578)\end{array}$ & $\begin{array}{r}\text { No period of } \\
\text { homelessness } \\
(n=3,802)\end{array}$ \\
\hline Physical assault victim & 16 & 19 & 5 \\
\hline Perpetrator of family violence & 11 & 14 & 3 \\
\hline History of custodial sentence (youth justice) & 3 & 3 & 1 \\
\hline History of community sentence (youth justice) & 7 & 62 & 93 \\
\hline No interaction with public housing & 10 & 14 & 4 \\
\hline In public housing as dependent/resident & 6 & 9 & 1 \\
\hline In public housing as independent tenant & 12 & 15 & 3 \\
\hline On waiting list, no housing received & 12 & 7 \\
\hline
\end{tabular}

Source: Author's analysis of linked administrative data.

\subsubsection{Housing trajectories}

Previous studies show that young people's housing trajectories are becoming more fluid and complex than in the past (Beer, Faulkner et al. 2006). Indeed, the idea of a housing career made up of a series of steps up a housing ladder culminating in home ownership bears little resemblance to the housing trajectories of young people in contemporary society (which is another reason why we have preferred the language of 'trajectories' over 'pathways' in this report). For young people with mental health concerns, their housing trajectories can be even more chaotic, especially for those with a disadvantaged background.

The datasets used in this study do not contain full housing information for each individual over time. Instead, we can derive housing information for each individual based on their service use over time. Particular service collections, such as public housing and the homelessness services dataset, contain housing information about our cohorts. However, many service collections also contain information on the individual's accommodation status at the date of service. Combining this information, we can develop a longitudinal understanding of each individual's housing. This understanding will be incomplete. We have only intermittent snapshots of information about an individual's housing status over time. Some individuals will have many service records, providing us with more insights into their current accommodation, while others may have no administrative records other than their original 'exit' record, meaning we can say very little about their housing status. While we have information about public housing use and homelessness services use, there is no 'private housing stock' database, which we must infer from recordings in other administrative collections, such as information recorded in emergency department records.

While our LAD does not provide the sort of granular data necessary to describe a complete range of housing transitions and trajectories, it does provide sufficient information to identify patterns in the housing trajectories of the mental health cohort over the four years after their reference event. We did this by creating longitudinal housing records for each individual, listing each individual's housing status over time (where available). These were examined and seven clusters of individuals with similar patterns of housing were identified.

Table 8 presents a summary of the characteristics of those in the seven clusters. For the first three clusters, which account for nearly two-thirds of the individuals in the mental health cohort, their housing appeared secure. The first cluster contained individuals who were in private residential accommodation four years after the reference event and who had no record of placement in public housing, or any other form of accommodation over this time. These individuals did not use homelessness services, or have any other evidence of periods of housing insecurity in the follow-up period. This is the largest group accounting for 42 per cent of the mental health cohort. 
There were 1,075 individuals in the next group, accounting for 21 per cent of the cohort. Although we had no available housing information for this group, there are a few things we can still say about this cohort. These individuals are not in public housing, nor did they access homelessness services, at least after 2015. Indeed, the majority of these individuals did not have any service records in the four years after exit, including no emergency department records outlining self-harm or mental health issues, no drug and alcohol treatment, and no contact with the youth justice system. This suggests that this group of individuals may have lower individual risk factors for housing insecurity. Given their lack of interaction with public housing and homelessness services, it is more likely than not that the majority of them resided in private residence in the time after exit. The lack of available housing status also reflects a lack of service use, as the mechanism by which we have housing information available is through service use records. These individuals may represent a fairly successful group, who have not faced some of the issues common in those experiencing more numerous and extended service interactions.

There were only 133 individuals (or $2 \%$ of the cohort) in the third cluster. They were people where we had information that they had resided for some time in public housing, and where we found no evidence of housing insecurity. For most, their entry into public housing occurred prior to their reference event, typically as a young child (i.e. they grew up in public housing). Individuals in this category could also have records indicating that they resided in housing in the private market for some of the follow-up period. These individuals did not use homelessness services, or have any other evidence of periods of housing insecurity in the follow-up period.

The fourth cluster included people in more marginal forms of accommodation outside of public housing and the private market. Individuals in this category did not have any evidence of homelessness or housing insecurity, but did spend time in other forms of accommodation, outside of public housing and the private market. This includes individuals who were incarcerated, individuals who spent significant time in a mental health facility (episodes longer than 30 days), individuals who spent time in a drug or alcohol treatment residence, individuals who were in statutory care, and individuals in supported accommodation. While these housing types differ, they are all housing types that are less stable, often short-term, suggesting the individual is at greater risk of housing insecurity and homelessness. Individuals in this category could also have spent time in public housing or in the private market. About 8 per cent of our cohort fell into this group.

For the remaining members of the mental health cohort there was clear evidence of housing insecurity. There were 367 individuals (or $7 \%$ of the cohort) for whom there is evidence of risk of homelessness. Individuals in this category sought homelessness services, but there was also evidence they experienced homelessness within the study period. The homelessness service records of these individuals indicate a risk of homelessness, even though they resided in their own housing (e.g. an individual unable to pay rent, seeking advice to avoid homelessness).

We had evidence that nearly one in five of the mental health cohort experienced homelessness during the study period, but there were two distinct patterns. The first cluster included individuals with a single episode of homelessness. This included those rough sleeping, couch surfing and those in short term/crisis accommodation. Records containing evidence of homelessness were considered to relate to the same 'episode' if they occurred within 90 days; otherwise this was considered to be two separate instances of homelessness. There were 376 individuals in this latter group, accounting for 7 per cent of the cohort. The second cluster included Individuals with multiple episodes of homelessness with two or more periods of homelessness listed. Individuals rough sleeping, couch surfing or in short term/crisis accommodation were considered to be homeless. There were 620 individuals in this group, accounting for 12 per cent of the cohort.

The different housing trajectories were associated with different patterns of service use. For instance, Table 8, which compares demographic information between housing trajectory groups, shows that females were more highly represented in those who resided in private residence only (61\%) and those at risk of homelessness (65\%) than other categories. Males were however more likely to be in public housing (53\%) or other accommodation (54\%). They were are also more likely to be in the 'multiple homeless episodes' homeless category relative to their overall representation in the mental health cohort (50\% vs $44 \%$ respectively). While Indigenous Australians made up only 3 per cent of those residing in private residence only, they made up 11 per cent of those in public housing, 13 per cent of those with one episode of homelessness and 20 per cent of the chronic homeless. It also 
looks like those living outside major cities at the time of their reference event are slightly more prone to housing insecurity than those initially living in a major Victorian city. For instance, while only 18 per cent of the private residence only category were residing in a regional/remote area at their reference event, 27 per cent of the at-riskof homelessness category, 24 per cent of the category with one homeless episode and 26 per cent of those with multiple homelessness episodes were.

Table 8 also shows that those with more severe forms of mental illness face more insecure housing. Those with a primary diagnosis of schizophrenia, or with one of the childhood onset disorders, represent a larger share of all the more insecure housing trajectory groups. People with these diagnoses are more likely to be in public housing, in marginal forms of accommodation, or experiencing multiple episodes of homelessness and more likely to experience homelessness overall. For homelessness services and social housing providers, working with individuals with more complex mental health needs is time consuming and the risk of tenancy loss is high.

Tables 9 and 10 outline service use by housing trajectory in the mental health cohort. Hospital and emergency department use is presented in Table 10 and use of other services is presented in Table 11. Hospitalisations for almost all categories are associated with some increase in housing instability. Housing instability appears most prominent however for those hospitalised for AOD related issues. Only 21 per cent of the private residence only group had been hospitalised for AOD issues, whereas 44 per cent of those at risk of homelessness had, and 60 per cent of those with multiple homelessness episodes had. Those in the other accommodation subgroup included those with long-term mental health stays. As such, this group had the highest proportion of hospitalisations for mental health conditions.

There also appears to be a prominent relationship between emergency presentations for mental health issues and housing insecurity. While 44 per cent of those in the private residence category presented to emergency departments for mental health reasons, this occurred in 60 per cent of those at risk of homelessness, 72 per cent of those with one homeless episode and 76 per cent of the chronic homeless group. This pattern is consistent with evidence from Australia and the US that shows the chronically homeless, although a small group, present at Emergency Departments with much greater frequency relative to the broader homeless population. This finding has focussed policy attention on reducing the inappropriate use of costly emergency services through the provision of Housing First and Permanent Supportive Housing (Culhane, Metraux et al. 2002; Gulcur, Stefancic et al. 2003; Larimer, Malone et al. 2009; Parsell, Peterson et al. 2016).

Table 10 describes the proportion of individuals accessing services by housing trajectory group in the mental health cohort. Almost all service types appeared to be at least somewhat correlated with housing instability, with the most prominent being alcohol and drug treatment services (increasing from $11 \%$ of those in private residence only, to $56 \%$ in the chronic homeless), family violence services (increasing from $5 \%$ of those in private residence only, to $24 \%$ in the chronic homeless) and community mental health (increasing from $10 \%$ of those in private residence only, to $36 \%$ in the chronic homeless). Although the overall number of individuals in question remain quite small, the use of child protection, sexual assault support and youth justice services also appear to be higher for those with higher levels of housing instability. For example, while only 3 per cent of those in private residence had been in child protection at some stage, 6 per cent of those at risk of homelessness and 10 per cent of the chronic homeless group had. 
2. Linked data analysis:

youth leaving mental health

residential treatment

Table 8: Demographic characteristics and primary diagnosis of housing trajectory clusters (\%)

\begin{tabular}{|c|c|c|c|c|c|c|c|c|}
\hline & $\begin{array}{r}\text { No known } \\
\text { housing } \\
\text { status }\end{array}$ & $\begin{array}{r}\text { Private } \\
\text { residence } \\
\text { only }\end{array}$ & $\begin{array}{l}\text { Resided } \\
\text { in public } \\
\text { housing }\end{array}$ & $\begin{array}{r}\text { Other } \\
\text { accommodation }\end{array}$ & $\begin{array}{r}\text { At risk of } \\
\text { homelessness }\end{array}$ & $\begin{array}{r}\text { One } \\
\text { episode of } \\
\text { homelessness }\end{array}$ & $\begin{array}{r}\text { Multiple } \\
\text { episodes of } \\
\text { homelessness }\end{array}$ & All \\
\hline Male & 46 & 39 & 53 & 54 & 35 & 47 & 50 & 44 \\
\hline Female & 54 & 61 & 47 & 46 & 65 & 53 & 50 & 56 \\
\hline Indigenous & 1 & 3 & 11 & 8 & 8 & 13 & 20 & 7 \\
\hline Non-indigenous & 99 & 97 & 89 & 92 & 92 & 88 & 80 & 93 \\
\hline $15-17$ & 19 & 29 & 32 & 26 & 27 & 22 & 23 & 25 \\
\hline $18-20$ & 27 & 27 & 32 & 28 & 26 & 30 & 27 & 28 \\
\hline $21-23$ & 34 & 26 & 24 & 31 & 30 & 26 & 32 & 29 \\
\hline $24-25$ & 20 & 17 & 12 & 16 & 17 & 23 & 18 & 18 \\
\hline Major cities & 83 & 81 & 74 & 82 & 73 & 76 & 74 & 80 \\
\hline $\begin{array}{l}\text { Regional/ } \\
\text { Remote }\end{array}$ & 15 & 19 & 26 & 18 & 27 & 24 & 26 & 20 \\
\hline \multicolumn{9}{|c|}{ Primary mental health diagnosis } \\
\hline Depression & 25 & 26 & 15 & 13 & 19 & 15 & 13 & 22 \\
\hline Anxiety & 6 & 6 & 4 & 1 & 4 & 2 & 2 & 5 \\
\hline Schizophrenia & 17 & 13 & 24 & 32 & 16 & 18 & 25 & 18 \\
\hline $\begin{array}{l}\text { Stress/ } \\
\text { adjustment } \\
\text { disorder }\end{array}$ & 10 & 14 & 16 & 7 & 14 & 16 & 15 & 13 \\
\hline $\begin{array}{l}\text { Personality } \\
\text { disorder }\end{array}$ & 5 & 8 & 5 & 8 & 11 & 10 & 9 & 8 \\
\hline $\begin{array}{l}\text { Childhood } \\
\text { onset disorder }\end{array}$ & 16 & 16 & 24 & 21 & 21 & 27 & 25 & 19 \\
\hline Self-harm & 0 & 1 & 1 & 1 & 2 & 1 & 1 & 1 \\
\hline Other diagnosis & 21 & 15 & 12 & 18 & 13 & 10 & 8 & 15 \\
\hline $\begin{array}{l}\text { Number of } \\
\text { individuals }\end{array}$ & 1,075 & 2,184 & 133 & 419 & 367 & 376 & 620 & 5,174 \\
\hline
\end{tabular}

Source: Author's analysis of linked administrative data. 
2. Linked data analysis:

youth leaving mental health

residential treatment

Table 9: Service use (hospital and emergency) of individuals in housing trajectory clusters (\%)

\begin{tabular}{|c|c|c|c|c|c|c|c|c|}
\hline & $\begin{array}{r}\text { No known } \\
\text { housing } \\
\text { status }\end{array}$ & $\begin{array}{r}\text { Private } \\
\text { residence } \\
\text { only }\end{array}$ & $\begin{array}{l}\text { Resided } \\
\text { in public } \\
\text { housing }\end{array}$ & $\begin{array}{r}\text { Other } \\
\text { accommodation }\end{array}$ & $\begin{array}{r}\text { At risk of } \\
\text { homelessness }\end{array}$ & $\begin{array}{r}\text { One } \\
\text { episode of } \\
\text { homelessness }\end{array}$ & $\begin{array}{r}\text { Multiple } \\
\text { episodes of } \\
\text { homelessness }\end{array}$ & All \\
\hline \multicolumn{9}{|c|}{ Hospital admission } \\
\hline Alcohol/drugs & 9 & 21 & 30 & 38 & 44 & 51 & 60 & 28 \\
\hline Self-harm & 6 & 31 & 23 & 35 & 32 & 40 & 44 & 28 \\
\hline Assault & - & 1 & 5 & 4 & 5 & 5 & 9 & 3 \\
\hline Injury & 2 & 12 & 17 & 9 & 16 & 14 & 19 & 11 \\
\hline Mental health & 26 & 42 & 37 & 69 & 49 & 50 & 57 & 43 \\
\hline Other & 19 & 49 & 42 & 36 & 61 & 46 & 50 & 42 \\
\hline Any & 49 & 82 & 80 & 94 & 90 & 89 & 91 & 78 \\
\hline \multicolumn{9}{|c|}{ Emergency presentation } \\
\hline Alcohol/drugs & - & 19 & 17 & 27 & 33 & 35 & 48 & 21 \\
\hline Self-harm & - & 34 & 33 & 39 & 44 & 51 & 58 & 32 \\
\hline Assault & - & 0 & - & 2 & 2 & & 3 & 1 \\
\hline Injury & - & 38 & 43 & 33 & 47 & 48 & 55 & 34 \\
\hline Mental health & 1 & 44 & 47 & 68 & 60 & 72 & 76 & 44 \\
\hline Other & 1 & 61 & 56 & 57 & 70 & 67 & 78 & 51 \\
\hline Any & 2 & 97 & 86 & 91 & 93 & 94 & 96 & 76 \\
\hline $\begin{array}{l}\text { Number of } \\
\text { individuals }\end{array}$ & 1,075 & 2,184 & 133 & 419 & 367 & 376 & 620 & 5,174 \\
\hline
\end{tabular}

Source: Author's analysis of linked administrative data.

Table 10: Service use (other) of individuals in housing trajectory clusters (\%)

\begin{tabular}{|c|c|c|c|c|c|c|c|c|}
\hline & $\begin{array}{r}\text { No known } \\
\text { housing } \\
\text { status }\end{array}$ & $\begin{array}{r}\text { Private } \\
\text { residence } \\
\text { only }\end{array}$ & $\begin{array}{l}\text { Resided } \\
\text { in public } \\
\text { housing }\end{array}$ & $\begin{array}{r}\text { Other } \\
\text { accommodation }\end{array}$ & $\begin{array}{r}\text { At risk of } \\
\text { homelessness }\end{array}$ & $\begin{array}{r}\text { One } \\
\text { episode of } \\
\text { homelessness }\end{array}$ & $\begin{array}{r}\text { Multiple } \\
\text { episodes of } \\
\text { homelessness }\end{array}$ & All \\
\hline $\begin{array}{l}\text { Alcohol/drug } \\
\text { treatment }\end{array}$ & 1 & 11 & 29 & 30 & 33 & 39 & 56 & 20 \\
\hline \multicolumn{9}{|c|}{ Clinical mental health treatment } \\
\hline Inpatient & 8 & 40 & 50 & 85 & 57 & 69 & 72 & 44 \\
\hline Outpatient & 29 & 62 & 68 & 92 & 75 & 75 & 82 & 62 \\
\hline $\begin{array}{l}\text { Community } \\
\text { mental health } \\
\text { support services }\end{array}$ & 3 & 10 & 11 & 30 & 24 & 29 & 36 & 15 \\
\hline Child protection & 1 & 3 & 10 & 8 & 8 & 6 & 10 & 5 \\
\hline Family services & - & 1 & - & 1 & 7 & 5 & 9 & 3 \\
\hline Family violence & 1 & 5 & 11 & 6 & 15 & 14 & 24 & 8 \\
\hline $\begin{array}{l}\text { Sexual assault } \\
\text { support services }\end{array}$ & 1 & 6 & 9 & 6 & 9 & 10 & 14 & 6 \\
\hline \multicolumn{9}{|l|}{ Youth justice } \\
\hline Custodial & - & - & - & 1 & - & 1 & 3 & 1 \\
\hline Community & - & 1 & 5 & 2 & 3 & 5 & 6 & 2 \\
\hline Total & 1,075 & 2,184 & 133 & 419 & 367 & 376 & 620 & 5,174 \\
\hline
\end{tabular}

Source: Author's analysis of linked administrative data. 


\subsection{Patterns of service use}

So far we have seen that a substantial proportion of our cohort had used the identified services, with three-quarters of the mental health cohort admitted to hospital or an emergency department over the four-year period after the reference event, while 1 in 5 had accessed an alcohol/drug service or sought assistance from a homelessness service. The number of people in our cohort accessing different government services was much higher than what is reported among Victorians of the same age. Now we turn our attention to how frequently each service type was used.

Some services were used very frequently. There were, for instance, 62,312 admissions to hospital and over 73,000 presentations to emergency departments in this cohort. Similarly, there were over 56,000 episodes of care in the clinical mental health system delivered to members of our cohort over the four-year period. To make sense of these numbers we now examine how they are distributed among members of the mental health cohort. Table 11 shows the median number of hospital admissions was 3, with an interquartile range of between 2 and 7 admissions.

For those that presented to an emergency department at least once, the median number of presentations was four times with an interquartile range of between 2 and 9 presentations. For those using alcohol and drug treatment services they tended to do so multiple times, with a median of three times. While not being used by many people, those who did use child and family services tended to use them infrequently, typically only once or twice. Homelessness services also tended to be used less frequently, although there is a caveat here that data for homelessness services were only available from July 2015 onwards.

A striking result from Table 11 is in relation to those in the youth justice system. Although we found that there were only a small number of people who had some contact with the youth justice system (see Table 2), Table 11 shows us that those that did tended to have multiple contacts. This is most apparent for those people who had received a custodial sentence. For those who had been in custody at least once, the median number of custodial episodes within the youth justice system was four. This is partly due to the nature of the data, where multiple orders commonly refer to the same offence which we cannot isolate due to the lack of any underlying offence identification. However, it also suggests potentially high rates of recidivism.

What is apparent from Table 11 is that usage of most services is quite skewed for this cohort. While a large number of individuals in the cohort use each particular service once or twice over the four-year period, the top quartile of users are much more frequent users. For example, looking at those who have used homelessness services at least once, the bottom quartile of users have only used these services once, with the middle person in the distribution using homelessness services twice. But the top quartile of users have used these services five or more times. 
Table 11: Median number of services for those who had at least one service of a particular type in the four years after exit from reference event

\begin{tabular}{|c|c|c|c|}
\hline & & Median & IQR \\
\hline \multirow[t]{7}{*}{ Hospital admission } & Alcohol/drugs & 2 & $1-4$ \\
\hline & Self-harm & 2 & $1-3$ \\
\hline & Assault & 1 & $1-1$ \\
\hline & Injury & 1 & $1-1$ \\
\hline & Mental health & 2 & $1-4$ \\
\hline & Other & 2 & $1-3$ \\
\hline & Any & 3 & $2-7$ \\
\hline \multirow[t]{7}{*}{ Emergency presentation } & Alcohol/drugs & 1 & $1-2$ \\
\hline & Self-harm & 2 & $1-3$ \\
\hline & Assault & 1 & $1-1$ \\
\hline & Injury & 1 & $1-1$ \\
\hline & Mental health & 2 & $1-4$ \\
\hline & Other & 2 & $1-3$ \\
\hline & Any & 4 & 2-9 \\
\hline \multicolumn{2}{|l|}{ Alcohol/drug treatment } & 3 & $1-6$ \\
\hline Clinical mental health & Inpatient & 3 & $1-5$ \\
\hline \multicolumn{2}{|l|}{ Child protection } & 2 & $1-3$ \\
\hline \multicolumn{2}{|l|}{ Family services } & 1 & $1-2$ \\
\hline \multicolumn{2}{|l|}{ Family violence } & 2 & $1-3$ \\
\hline \multicolumn{2}{|c|}{ Sexual assault support services } & 1 & $1-2$ \\
\hline \multicolumn{2}{|l|}{ Homelessness } & 2 & $1-5$ \\
\hline \multirow[t]{2}{*}{ Youth justice } & Custodial & 4 & $3-10$ \\
\hline & Community & 3 & $2-6$ \\
\hline
\end{tabular}

In the next section we try and get a better sense of the more intensive service users, or what we term 'heavy service' users. We do this by examining each individual's cumulative duration of hospital stay, which we take as a proxy for the severity of their mental health condition. By examining heavy service users we focus attention on the most costly group and the group that is likely to benefit the most from better integration of systems and agencies. Heavy service users are an acutely vulnerable population and their vulnerabilities are most exposed when they move out of systems of care. 


\subsection{Heavy service users}

Our hypothesis is that those with more severe mental illnesses requiring more intensive treatment use a larger share of other DHHS-provided services than do those with less severe issues. That is, we expect individuals' cumulative duration of hospital stay to be correlated with intensity of use of other services. To examine this hypothesis we first sort individuals based on the cumulative duration of their hospital stay/s in the four years after exiting their initial reference event. Those in the bottom quartile had no hospitalisations in the four years after their index mental health event, and so spent no time in hospital. Those in the bottom $50^{\text {th }}$ percentile had 0-9 days in hospital. Those in the top quartile had 39 or more days in hospital over the four years, while those in the top decile spent more than three months (>106 days) in hospital over the four years and accounted for 59 per cent of hospital stays, which highlights just how skewed the distribution is.

Table 12 presents the characteristics of the mental health cohort based on cumulative duration of hospital stay, presenting a comparison of the characteristics of the bottom and top quartile of cumulative stays. Females, Indigenous Australians, individuals diagnosed with schizophrenia/ psychosis or 'other' mental health conditions and those living in major cities make up a larger proportion of the top quartile.

Table 12: Characteristics of mental health cohort by cumulative length of hospital stay (\%)

\begin{tabular}{|c|c|c|}
\hline & Bottom quartile & Top quartile \\
\hline \multicolumn{3}{|l|}{ Gender } \\
\hline Male & 56 & 38 \\
\hline Female & 44 & 62 \\
\hline \multicolumn{3}{|l|}{ Age at index admission } \\
\hline $15-18$ & 35 & 30 \\
\hline $19-21$ & 33 & 29 \\
\hline $22-25$ & 32 & 41 \\
\hline \multicolumn{3}{|l|}{ Indigenous status } \\
\hline Indigenous & 4 & 7 \\
\hline Non-Indigenous & 96 & 93 \\
\hline \multicolumn{3}{|l|}{ Region } \\
\hline Major cities & 78 & 84 \\
\hline Regional/remote areas & 22 & 16 \\
\hline \multicolumn{3}{|l|}{ Primary diagnosis } \\
\hline Depression & 23 & 15 \\
\hline Anxiety & 3 & 5 \\
\hline Schizophrenia/psychosis & 17 & 24 \\
\hline Stress/adjustment disorder & 18 & 6 \\
\hline Personality disorder & 5 & 8 \\
\hline Childhood onset disorder & 20 & 19 \\
\hline Self-harm & 1 & 1 \\
\hline Other mental health condition & 13 & 23 \\
\hline \multicolumn{3}{|l|}{ Legal status } \\
\hline Voluntary & 68 & 71 \\
\hline Involuntary & 32 & 29 \\
\hline
\end{tabular}

Source: Author's analysis of linked administrative data. 
We now test our hypothesis that cumulative duration of hospital stay is correlated with intensity of use of other services. Table 13 presents the percentage share of total service use for each service for individuals in the bottom and top quartiles of cumulative duration of hospital stay. The shares are calculated over all service records for each respective service over three time horizons: i.e. two years prior to reference event, 30 days after exit, and four years after exit from reference event. ${ }^{9}$ For example, when looking at the percentage share of hospital stays over the four-year time horizon, we are comparing what proportion of the total number of hospital stay records observed over the four-year period were used by those with the lowest cumulative length of hospital stay, compared to those with the highest cumulative length of hospital stay. Likewise when looking at the percentage share in the 30 days after exit, we are comparing what proportion of the total number of hospital stay records observed over the 30-day period were used by those with the lowest cumulative length of hospital stay, compared to those with the highest cumulative length of hospital stay. For those services where we do not have episodic records for each presentation to a service (e.g. community mental health and child protection) we present the percentage of individuals who used these services. Likewise, we present the percentage of individuals who used public housing, as public housing applications and tenancies tend to be fairly limited, especially over these time frames.

As stated earlier, those in the bottom quartile had no hospitalisations in the four years after their reference mental health event, whereas those in the top quartile accounted for 69 per cent of all hospitalisations. Emergency Department (ED) presentations were similarly skewed with the bottom quartile accounting for only 3 per cent of presentations whereas the top quartile accounted for 57 per cent. Likewise the top quartile made up a significant share of all clinical mental health episodes, making up over three-quarters (77\%) of all clinical mental health inpatient episodes, over half (53\%) of all outpatient episodes, and over three-quarters (77\%) of involuntary episodes. This is not unexpected given that the top quartile are likely to be those with more severe mental illness requiring intensive care and support.

What is perhaps more surprising is how weak the relationship appears to be between length of hospital stay and use of non-health-related services. Those in the top quartile do use a larger share of each service than the bottom quartile. What is not shown in the table is that the top half of the distribution uses a larger share of services than the bottom half. Those individuals who have contact with the youth justice system are an exception. For the most part, use of non-health-related services does seem to be more equally distributed across the mental health cohort than general health service use. For instance, looking at the picture four years after the exit event, we find that the top quartile account for about a third of all alcohol/drug treatment records (34\%), whereas the bottom quartile account for 10 per cent. Likewise, the top quartile account for just under a third (29\%) of all youth justice custodial sentences, compared to 12 per cent of the bottom quartile. They account for a slightly larger share of specialist homelessness service records at 44 per cent, as compared to the 7 per cent share than the bottom quintile account for. But again, utilisation is more equally distributed for homeless services than it is for health services.

These findings suggest that individuals with more severe health issues require more assistance with their health relative to non-health needs. Given the high cost of hospital care, policy makers could look at alternative treatment models for those experiencing severe mental illness, particularly those that reduce reliance on hospital emergency departments for access to appropriate treatment services. The focus, however, must be on improving quality and continuity of care, not reducing access.

The top quartile accounted for a slightly lower share of services used in the 30 days after exit from their initial reference event, but the overall pattern of a relatively high share of service usage for this group was evident even in the early days of their exit. Note that in interpreting our findings, consideration should be made to the number of individuals using each type of service over each time frame as presented in Table 2. There are obviously fewer service records over the 30-day time frame as fewer individuals use each service in this window.

9 We also calculated the percentage share of services across the distribution of the number of times admitted to hospital (i.e. frequency rather than cumulative duration) and found qualitatively similar results. 
Table 13 reveals a pattern in the use of services in the two-year lead up to the mental health cohorts reference event. For those services we have data for a strikingly similar pattern of multiple service usage evident after the reference event. This is further evidence that for the heavy service use cohort contact with services began prior to the reference event and at a much younger age.

Table 13: \% share of service used and \% of individuals who used a service, over varying time-horizons, by cumulative length of stay

\begin{tabular}{|c|c|c|c|c|c|c|}
\hline \multirow[b]{2}{*}{$\%$ share of service used ${ }^{b}$} & \multicolumn{2}{|c|}{$\begin{array}{l}\text { Two years prior to } \\
\text { reference event }\end{array}$} & \multicolumn{2}{|c|}{30 days after exit } & \multicolumn{2}{|c|}{ Four years after exit } \\
\hline & $\begin{array}{l}\text { Bottom } \\
\text { quartile }\end{array}$ & $\begin{array}{r}\text { Top } \\
\text { quartile }\end{array}$ & $\begin{array}{l}\text { Bottom } \\
\text { quartile }\end{array}$ & $\begin{array}{r}\text { Top } \\
\text { quartile }\end{array}$ & $\begin{array}{l}\text { Bottom } \\
\text { quartile }\end{array}$ & $\begin{array}{r}\text { Top } \\
\text { quartile }^{a}\end{array}$ \\
\hline Hospital stays & 6 & 46 & 0 & 47 & 0 & 69 \\
\hline ED presentations & 10 & 37 & 4 & 44 & 3 & 57 \\
\hline Alcohol/drug treatment & 15 & 32 & 14 & 22 & 10 & 34 \\
\hline In treatment & 19 & 31 & 16 & 22 & 11 & 35 \\
\hline \multicolumn{7}{|l|}{ Clinical mental health episodes } \\
\hline Inpatient & 5 & 53 & 0 & 53 & 0 & 74 \\
\hline Outpatient & 11 & 46 & 17 & 33 & 8 & 53 \\
\hline Involuntary admissions & 7 & 56 & 0 & 49 & 0 & 77 \\
\hline \multicolumn{7}{|l|}{ Youth justice } \\
\hline Custodial & 12 & 33 & 0 & 25 & 12 & 29 \\
\hline Community & 23 & 20 & 40 & 10 & 14 & 20 \\
\hline Family services & NA & NA & 0 & 22 & 5 & 17 \\
\hline Family violence & NA & NA & 17 & 38 & 12 & 32 \\
\hline Sexual assault support services & NA & NA & 6 & 25 & 5 & 38 \\
\hline \multicolumn{7}{|l|}{ Homelessness services } \\
\hline At risk & NA & NA & NA & NA & 7 & 44 \\
\hline Homeless & NA & NA & NA & NA & 7 & 44 \\
\hline Any & NA & NA & NA & NA & 7 & 44 \\
\hline \multicolumn{7}{|l|}{$\%$ of individuals who used a service } \\
\hline $\begin{array}{l}\text { Mental health community Support } \\
\text { services }\end{array}$ & 2 & 9 & NA & NA & 7 & 29 \\
\hline Child protection & 4 & 8 & NA & NA & 5 & 3 \\
\hline $\begin{array}{l}\text { Public housing application (primary } \\
\text { applicant) }\end{array}$ & 1 & 1 & 0 & 0 & 4 & 13 \\
\hline $\begin{array}{l}\text { Public housing tenancy (independent } \\
\text { tenancy) }\end{array}$ & 0 & 1 & 0 & 0 & 1 & 5 \\
\hline
\end{tabular}

Notes: a) Quartiles are calculated in regard to individuals' cumulative length of hospital stay in the four years after exit from their reference event. b) Shares are calculated as a proportion of all relevant service records observed for the mental health cohort within each respective time horizon.

Source: Author's analysis of linked administrative data. 


\subsection{Implications}

The analysis of our linked data reveals a number of important findings. First, we can see that a significant majority of the mental health cohort, between two-thirds and four-fifths, remain relatively light users of government services. Yet, for around 20-30 per cent of this cohort, the situation appears to be quite different. This group tends to use a wide range of services and uses them quite regularly. They are particularly heavy users of health and allied services, but they also use other DHHS provided services intensively. They also appear to first access these services at a young age. Policy makers are well versed in the challenges of effectively responding to individuals with complex health, housing and social care needs, including serious mental illness and/or substance misuse problems. There is also a better recognition now that for many chronic service users, and chronically homeless individuals in particular, their pathways into services commence at an early age. Studies suggest that about half of the chronically homeless had their first experience of housing insecurity before the age of 18 (Chamberlain and Johnson 2013; Brackertz, Davidson et al. 2019). Our findings confirm this. All the same, we need to be cautious in how we interpret these findings. Our dataset, while valuable, is limited and we may be missing material that influences service use patterns. It is worth restating that our analysis identified service use patterns not needs per se.

Looking broadly at the key policy and service implications of our analysis, it is clear that access to affordable housing is central to addressing challenges of housing insecurity. Difficulties accessing affordable housing create bottle-necks in the broader social care system as well as contributing to poor discharge practices. Our analysis would suggest that while improvements to care coordination and service integration can make systems more responsive to the needs of vulnerable individuals, these reforms will not be enough on their own to deliver significant improvements to the health, wellbeing and housing security of vulnerable youth accessing care.

Access to affordable housing is critical. We must stress that access to public housing is difficult for this youth cohort. Moreover, they appear to be insufficiently profitable for Community Housing Providers to support given issues of income insecurity (lower Centrelink payment rates etc). At the same time, public housing may be unattractive for this cohort given how it tends to lock young people into a particular public housing tenancy in a particular location, when they may prefer to be more geographically mobile. For this reason, it may be worth considering a more portable type of housing assistance for young people along the lines of a targeted Housing First style model for youth. Of course, income support is also an issue, with many young people unlikely to be eligible for a disability support pension (DSP) unless they are assessed as having severe needs, so many young people are left with very low levels of income support if they can't work.

In terms of more site-specific housing support recommendations for individuals accessing care in psychiatric inpatient settings and other residential mental health care settings, our linked data analysis indicates a strong need for enhanced supports for individuals with experience of multiple hospitalisations. Frequency of hospitalisations is strongly linked to later contact with specialist homelessness services. This typically follows from the disruptions to individual housing arrangements that are often associated with periods of either voluntary or involuntary inpatient admissions to psychiatric care. This can happen for example when an individual enters hospital from private rental accommodation, which is then placed at risk if an individual is required to stay in hospital for longer than anticipated.

Under these circumstances, there is a strong need for housing assistance to sustain individual rental arrangements, for example, by subsidising rent payments for the duration of an individual's hospitalisation. There is scope to draw on Commonwealth housing and rental assistance support in these instances, or to access discretionary funding available at the psychiatric ward level (for example through brokerage funding available either through the Inpatient Unit Planning for Priority Discharge fund and/or the Psychiatric IIIness and Intellectual Disabilities Donations Trust Fund) to support private rental payments to ensure individuals may be discharged to their existing rental accommodation without risk of eviction. There are various international models of best practice to draw from in designing such schemes (see Stergiopoulos, Mejia-Lancheros et al. 2019 for a review), but all emphasise the importance of short-term financial support to retain the security of individual private rental arrangements for the duration of an individual's admission. 
This example further suggests the value of early intervention strategies in hospital settings for individuals experiencing multiple hospitalisations with a focus on housing security and support. It also suggests, in turn, the value of developing a novel screening instrument to assess levels of housing insecurity-or what Deb Batterham (2019b) calls 'housing capabilities'. Such a tool would assist the identification of those individuals being admitted to inpatient settings who may be at risk of housing insecurity upon discharge. Individuals identified at risk of housing insecurity could then be referred to specialist housing services. As we will see in later chapters, individuals admitted to inpatient settings are not at present routinely assessed for housing risks in either New South Wales or Victoria, indicating a significant gap in the provision of housing supports in these settings.

There is also a need for housing support that helps individuals admitted to psychiatric inpatient settings to maintain their housing. The vast majority of young people admitted to such settings do not own their accommodation at the time of admission, with many reporting either private rental accommodation or residing with family. Some of these youth might have relatively stable housing. Yet, there is evidence that the traumas associated with a severe mental health episode requiring hospitalisation presents a significant risk of eviction. This risk again suggests the value of enhanced housing supports for youth entering residential mental health care.

Finally, we would recommend select use of linked data in clinical practice, subject to all necessary confidentiality and privacy protections. Both clinical and allied health care providers, for example, might be in a better position to plan more effective discharge and transition care support arrangements if they were privy to the full extent of an individual's service history. While there are significant privacy and confidentiality issues to manage in such a scenario, more comprehensive access to service records, available in linked data, would enable care and support staff to plan for and deliver more appropriate treatment, discharge and follow up care and support.

Our analysis also suggests grounds for ongoing research innovation. For example, renewed efforts to link existing Victorian records with other government services data would be helpful. At a state level this would include education and adult justice service data and, at a federal level, Medicare, Centrelink and potentially even tax records. Linking data points in this way would furnish additional information on socio-economic status without intrusive questionnaires on hospital admission. This would also permit analysis of what happens to people who don't use DHHS services, thus facilitating more fine-grained differentiation of positive and negative impacts of housing and social care support across a wider cohort of demographic groups or populations. It would also be helpful to consider efforts to fill in gaps in existing homelessness services records. It is not clear, for example, why SHS data is only available to DHHS from 2015 onwards, even though it is available via AlHW earlier. There is much value in DHHS linking this earlier SHS data. 


\section{Housing Struggles and social support needs}

- This chapter introduces findings derived from interviews in New South Wales and Victoria with service providers working in mental health or substance use services, along with individuals with lived experience accessing these services.

- We focus on the diverse housing problems described by service users, and highlight some of the complex challenges identified by service providers as they discussed the work of assisting individuals to manage this housing insecurity.

- We also touch on some of the broad similarities and unique differences between the mental health and substance use service sectors, in terms of the specific ways that housing challenges are managed in each service domain, as a way of introducing the more detailed analysis to follow in later chapters.

\subsection{The role of housing in social care}

The relationships between housing insecurity and complex health and social problems (such as mental illness, substance misuse, unemployment, insecure and poorly paid work, family and domestic violence) are the subject of a comprehensive research literature (Chamberlain, Johnson et al. 2014; Dufty-Jones and Rogers 2016; Caton 2017 and/or Grohmann 2020 for reviews). Much of this work focusses on the key policy implications of complex interactions between health and social problems, and the forms of social and economic disadvantage that typically underpin them, with a strong focus on how complex care systems should be integrated in the delivery of tailored services for individuals experiencing compounding social and economic disadvantage. It has long been understood that secure housing is a critical foundation for improvements in, for example, physical and mental health (see Evans, Wells et al. 2003; Singh, Daniel et al. 2019); employment and training (see Poremski, Whitley et al. 2014); recovery from alcohol and/or other drug problems (see Tsemberis, Gulcur et al. 2004; Hall, Walters et al. 2020); and social inclusion and community participation (see Duff, Jacobs et al. 2013). 
and community participation, among other indicators, also increase the likelihood that individuals may secure and maintain stable housing (Duff, Jacobs et al. 2013). Such complex bi-directional relationships between housing and social disadvantage have been observed in diverse local and international settings, further indicating the need for holistic understandings of the role of housing in the delivery of social care support.

The relationship between housing insecurity and social and economic disadvantage is complex with each mediating the other. There is strong evidence that individuals who have repeated contact with health and social services, including mental health and/or substance use treatment, are also likely to be at the greatest risk of housing insecurity (see Chamberlain,Johnson et al. 2014). Indeed, our own LAD analysis presented in Chapter 2 further confirms this relationship. Moreover, individuals with the poorest outcomes in housing services, including those with histories of insecure housing, typically experience compounding health and social problems such as severe and persistent mental health problems, substance misuse, and poor physical health. These compounding issues present significant challenges for front line service providers and policy makers alike (see Hall, Walters et al. 2020; Singh, Daniel et al. 2019). For individuals with complex housing needs, service responses typically encompass diverse health, housing and social care supports, including mental health services, substance use treatment, vocational training, and social care. Historically these services have been poorly integrated, inhibiting service integration and delivery and compounding disadvantage for vulnerable clients.

Setting the tone for much of the analysis to follow, this chapter begins our reporting of key findings derived from the analysis of our qualitative data, commencing with a brief discussion of the place of housing in our participants' narrative accounts of their interactions with mental health and/or substance use treatment systems. Guided by our research aims, interviews with service providers revealed complex interactions between housing insecurity, social and economic disadvantage, and poor mental and physical health for individuals accessing housing services and support. The need for complex care coordination, something that has been emphasised repeatedly in the policy literatures noted in Chapter 1, is equally explicit in our qualitative data. We start by describing the housing struggles experienced by most if not all of our participants before briefly noting the specific compounding effects of mental health and/or substance use disorders, and the ways that these challenges shape participant's housing trajectories.

Consistent with the analysis of 'heavy service users' presented in the final sections of Chapter 2, the analysis presented below will seek to clarify the specific service needs of individuals with complex housing problems. In presenting our qualitative data, we should stress that we have elected to focus in this chapter on key sites of coordination (or potentially improved coordination) between housing, health and social supports across the mental health and substance use treatment sectors. This focus obviously aligns with our research questions (see 1.4.1), but it also means that we will not dwell on the aspects of these service systems that are working well, or the specific ways that housing supports provision might be improved. Discussion of service system successes and improvements will be the subject of analysis in Chapter 4. Our main goal here in this chapter is to identify those circumstances and arrangements that have the greatest scope for improving the coordination of housing, mental health and substance use treatment services.

\subsubsection{Housing struggles}

People shouldn't have to get to a point where they've got to spend a night or two sleeping on the street before they can get some help. (SU15VIC)

Before we consider the specific housing needs of people leaving mental health or substance use treatment services respectively, it is important that we describe more generally the variety of housing struggles experienced by our service user participants, and subsequently reiterated by service providers. Most service users described complex histories of insecure housing, with regular changes of accommodation, and multiple points of contact with housing support and service providers in diverse geographical settings. On this basis, we must stress how housing insecurity is experienced first and foremost as an existential condition of doubt, fear, insecurity and vulnerability that tends to pervade all aspects of daily life. To be uncertain about the stability of one's accommodation, or worse to be reduced to rough-sleeping out of doors, or the shuffle of couch surfing between family and friends, 
has compounding effects on one's physical and mental health, one's capacity to maintain stable employment, to cultivate lasting friendships, and to plan for the future. To live without secure housing is literally to live without secure foundations, to be subject to the support of housing services, wherever and whenever this support may be provided.

It means being forced to pack up one's life at a moment's notice and take up whatever transitional or emergency accommodation might be offered. It is important that we convey something of this existential condition right at the outset of the presentation of our qualitative findings to help set the tone for the discussion to follow regarding the most effective ways of tailoring and coordinating housing supports for individuals leaving mental health or substance use treatment services.

In making sense of the housing struggles reported by our participants, it is important to emphasise the pervasive impact of a decades long shift in Australia's housing markets, particularly in our two largest cities, but increasingly affecting regional and rural markets too. This recurrent 'housing crisis'-in which whole segments of the community have been effectively 'locked out' of metropolitan housing markets (see Johnson, Scutella et al. 2019), coupled with tight private rental markets and increasingly long waiting lists for social housing - serves as the key backdrop for the qualitative reports that follow. Respondents emphasised how rising housing costs, and increasingly tight private rental markets, affect vulnerable individuals on fixed incomes.

While these challenges have been much discussed in the literature (see Chamberlain, Johnson et al. 2014), it is noteworthy that our respondents reported that this housing crisis is getting worse:

There's no affordable housing, people are paying $\$ 300$ or $\$ 400$ for a bedsit. How can you afford that if you're on the dole? To be on the dole and to support yourself in a flat, you're going to need over $\$ 1,000$ a week. By the time you've paid for your electricity, your water, your gas, your phone, internet, that's all your pension gone. You haven't even got enough for food. So that's why people are on the street 'cause that's the only way they can get by, waiting for affordable housing. (SU05VIC)

Experiences of profound vulnerability were also reported in service provider discussions, with staff highlighting a chronic shortage of housing, especially transitional housing and affordable private rental accommodation, and the challenges that result from this shortage when referring people exiting mental health and/or substance use treatment for housing support. Equally prevalent was a sense of inconsistent and sometimes ineffective coordination between different community-based mental health and/or substance use treatment providers and social housing providers including specialist housing services (see Hall, Walters et al. 2020; Singh, Daniel et al. 2019).

In findings that have been widely reported in the literature (see Chamberlain, Johnson et al. 2014; Brackertz, Davidson et al. 2019), service providers also pointed to ongoing challenges in local private rental markets, particularly increases in the average cost of private rental accommodation, as well as long waiting lists for limited social housing. As a result, services may struggle to support the most vulnerable clients with the most complex needs, as the following excerpt indicates:

There's always a waiting list [for social housing], and there can be a tendency for services to pick and choose the easy ones. It's not [always a case of] 'you were first on the list, so you're next in line'. There's lots of different services who won't touch the difficult ones. So, it can be difficult from that point of view. Then, if they're not ready [for independent living], I mean the amount of cases who go into transitional housing, and we have to evict them, because they have to have an activity plan, which usually means getting out of bed and doing something. A lot of them just can't instantly do that, so there's a real revolving door around that. So services do try and pick the easy ones. (SP11NSW) 
The rising costs of private rentals, coupled with inadequate income support, were also noted by service users and service providers, though again there is a strong sense of growing problems:

The big issue is there's no [social] housing stock, and a lot of people, especially on Newstart, but even the DSP, because there's been no rise in the DSP for years, the private rental market keeps increasing so that's more and more out of people's range. Whereas ten years ago they could've found something within the private rental system that they could afford, now it's so much harder. (SP05VIC)

In a sense, all homelessness housing support services (HSS) may be understood in terms of these larger social and economic contexts, and the ways that housing crises are experienced in local communities. In a long discussion, service user Belinda conveys much of the everyday anxiety of living without secure housing, along with the limited nature of emergency accommodation, and her struggles accessing support via diverse services spread out across the city. We cite from Belinda's interview at length for the insights it provides into the struggles people living without secure housing typically experience, as well as some of the reasons why people might not access emergency accommodation. In some instances, the bureaucratic hurdles associated with accessing brokered accommodation for only a limited stay appear to be more trouble than it's worth as Belinda notes:

The whole process - when you get to the point of 'Oh my god, I've got nowhere to live'-[is] someone says, 'Go to [Housing Service], see someone, they'll help you'. So you go into the office, they take your details down, then you wait for however long, sometimes it's a whole day for them to give you a key to a motel room. So brilliant, great, love it, you're off the street for a night, but that night you spend in that motel room, and that could be the first time you're in a room for months, you get in that room, sometimes it's not till 10 o'clock at night because it depends where they put you. So you get in there, you settle in, and then the anxiety - the first hour it's like 'Oh yeah, this is nice', but then you lay down, you start relaxing and then the anxiety sets in because you start looking at the time and you know that come 10 o'clock in the morning you've got to get up and go, and then it starts all over again. So with the time that it takes to access [housing], then the time to travel to wherever it is in Melbourne they put you, and then to have to be up and out the next morning so you can be back at the housing place by 9am [to try and secure accommodation for the next night], it just gets really exhausting. If that's what you're doing every day because you've got nowhere else to go, come Wednesday you just don't want to bother with it anymore and you end up leaving the motel room and you just go wherever the wind blows you. (SU07VIC)

The experience Belinda here narrates concerns the management of crisis accommodation support in Victoria via the Housing Establishment Fund (HEF), in which individuals receive financial assistance to cover the costs of short-term accommodation, paid directly to the accommodation provider (see DHHS 2018:105). While the program was not originally set up to provide an emergency crisis response to address instances of housing instability, more recently the program has expanded to address specific problems in access to transitional accommodation for individuals experiencing housing insecurity. At the time of writing, the HEF has become a central part of the Victorian Government's response to housing problems associated with the state's management of the Covid-19 pandemic. Like Belinda, most of the service users we interviewed described long histories of service contact, including periods of crisis accommodation and/or transitional housing, interspersed with periods of homelessness and insecure housing.

The following excerpt from the service user interviews offers further insight into the experiences of seeking care, including the impact of formal service provider criteria. It demonstrates the impact of a lack of stable and appropriate housing on informal support networks. The point we wish to emphasise is how contact with housing services can exacerbate existing vulnerabilities. 
I was evicted out of one transitional house and I had nowhere to go. I can't even really remember. It was pretty traumatic. My stuff was all out in the street. I sent my kids to my sister's to live, and she has four kids herself. So, I had to live in my car for over six months [and] my life just spiraled pretty badly out of control for a while. Then I got help from somewhere and I went to go live at [service] which is a safe housing community. They put me in there with my kids. And then, I managed to get into another transitional house, but there was a lot of trauma within that year from being evicted from one house to getting help for another one. It was really hard. (SU09VIC)

Despite these challenges, a strong consensus emerged in interviews with service providers regarding the goals of care and the elements of 'successful' service interventions. The paramount goal is to assist individuals to access secure and safe housing. In this respect, the central aim of care is to help individuals achieve their particular life goals, whether in terms of employment or training, social inclusion, health and wellbeing or family life. Secure housing is regarded as the critical foundation for achieving these health and social outcomes. Many service providers, and some service users, invoked the principle of 'housing first' to describe this philosophy, in which unconditional access to secure housing is regarded as the foundation for the realisation of all other life goals. Despite this clarity of vision, almost all service providers highlighted significant challenges securing safe and appropriate housing for individuals exiting residential services. Indeed, as Greg notes in the following excerpt, some service providers questioned whether existing homelessness services are even capable of delivering these longer-term goals:

\begin{abstract}
The thing we all need to remember is that our homelessness service system, with only a few limited exceptions, is only funded for a defined period of support. Really, it's mainly only shortterm support, intended to resolve a temporary crisis in someone's life. So this idea that we can overcome in some cases really, decades of disadvantage, accumulated disadvantage that starts in early childhood, goes all the way through school, and then any experience at work people might have had. The idea that you can somehow manage or make up for those sorts of things through a six-week intervention, or a period of crisis accommodation is just farcical. (SPVIC06)
\end{abstract}

It is important that we explore something of these broader housing contexts before we turn to the more specific challenges and opportunities identified within the mental health and substance use treatment sectors in New South Wales and Victoria. Individuals with the most complex health and social care needs reported extensive histories of unstable and insecure housing, including periods of rough sleeping, incarceration, voluntary and involuntary hospitalisation for mental ill health, and time in residential drug and alcohol services. Our data reveals a pattern of growing vulnerability, increasing housing challenges, and uncertain and inconsistent service responses. With growing competition for social housing access, the provision of crisis and transitional accommodation often falls short of local demands. In these respects, our findings illustrate the scale of the challenge confronting policy makers and service providers in both metropolitan and regional settings in Australia's two most populous states. Before considering how mental health and substance use treatment services are addressing issues of housing insecurity and vulnerability, we wanted to draw attention to the broader housing contexts in Melbourne and Sydney where the bulk of our interviews were completed. For individuals with complex health and social needs, housing affordability and security of tenure are longstanding challenges, which effectively undercut the effectiveness of mental health and substance use services in each state.

\title{
3.2 Mental health and housing support needs
}

A key theme in interviews with service providers and service users was the absolute centrality of safe, stable and secure housing for mental health and wellbeing. For individuals with an experience of mental illness or distress, safe and secure housing was seen as an indispensable condition for recovery. The importance of secure housing in the experience of care and recovery has been emphasised for decades in the relevant housing and mental health literature (see Evans, Wells et al. 2003; and/or Singh, Daniel et al. 2019), and this point was echoed by participants who spoke of the link between housing and recovery. At best, effective service referrals from mental health services and/or psychiatric inpatient treatment into appropriate, safe and secure housing can make a profound difference to the health and wellbeing of vulnerable individuals. Again, numerous participants spoke 
of the enduring importance of 'housing first' policies and the idea that safe and secure housing is an absolutely essential condition for care and recovery from mental health problems. Service providers were mostly of the view that when housing referrals 'work'-when they can be made in a timely fashion, to appropriate and secure accommodation, with effective follow-up and support-they can profoundly improve people's health and wellbeing and set vulnerable individuals on a new path to recovery and security.

Describing these links, service user Kim highlighted the importance of appropriate housing, and the challenges she had experienced accessing housing that she thought might help rather than hinder her recovery. Kim also alluded to how some forms of crisis accommodation might actually undermine people's experience of recovery, as she related in the following excerpt:

It's [recovery] a range of things to me, but the main concerns that I have are obviously my housing and wellbeing - just my stability really. And another big thought of mine is the way my mental health goes hand-in-hand with my housing. If I don't have safe housing or stable housing, then I can't be mentally well and I'm going to more than likely relapse again, and I don't want that. And that's also my main reason for not wanting to go back into a privately rented room or something like that is because of the drug use. Every time that l've lived in a shared house, they're got people on drugs [and] I just can't be around that for my recovery. That's why, honestly, I want my own place, so I can just shut the door on all the drugs and no one's in my house that's using. (SU12NSW)

Most service users indicated though that it typically takes quite some time to secure what they regard to be their preferred housing, with both service providers and service users describing more uncertain pathways through diverse housing supports before some individuals (often described by service providers as 'the lucky ones') manage to secure their preferred housing arrangements. Bill, an experienced housing worker in Melbourne, described this trajectory:

The best housing response takes a long time because the immediate option is usually a motel and then a rooming house, which is usually terrible, and if you can hold people for long enough then they can move onto the next thing and the next thing, it gets progressively better. Still it's never certain that you're ever going to get to that final outcome, all sorts of things can go wrong. (SPO8VIC)

\subsubsection{The coordination of housing supports in psychiatric inpatient settings}

Perhaps unsurprisingly, psychiatric inpatient units in large metropolitan hospitals emerged as one of the key sites at which vulnerable individual's housing needs come to attention. With such sites often providing crisis and emergency mental health triage for individuals experiencing acute mental health distress (see Barratt, RojasGarcia et al. 2016; Morphet, Innes et al. 2012), clinical case conferencing discussions in these settings were widely noted to be key opportunities to identify and address issues of housing insecurity or vulnerability. Even though the majority of individuals admitted to psychiatric inpatient care are typically discharged into the care of family, or they simply return to their existing accommodation, as we noted in Chapter 2, among vulnerable individuals with complex health and social needs, admission to a psychiatric unit often provides an opportunity to address their outstanding housing needs. Despite the importance of these interception sites, most service providers and many service users reported significant problems in psychiatric inpatient care, with a host of 'missed opportunities' to address more systemic housing vulnerabilities.

In highlighting this point, we do not mean to single out psychiatric settings unfairly, rather we wish to emphasise how critical psychiatric inpatient care is to the provision of mental health care and support for vulnerable individuals. We would also stress that these settings are key sites for referral to housing support services for these individuals, and for improved integration of health and external specialist housing services. Indeed, we will later make a series of recommendations regarding improvements to the integration of primary and mental health services, social care and support, and housing assistance for vulnerable individuals admitted to psychiatric inpatient wards. First, however, we must note the scale of the problem in psychiatric inpatient settings, with service providers and service users emphasising key challenges in the provision of housing care, supports and referrals in these settings. 
Of particular note is the way that housing needs are often deferred or delayed in preference to the delivery of acute primary health care. While we could scarcely criticise the importance of this care, service providers often noted how patient's housing needs were often neglected as 'someone else's problem'. With individual patients often receiving treatment and support from diverse teams of clinicians and health care professionals, alongside allied health care teams and social workers, a patient's housing needs were oftentimes said to be overlooked, or treated as a 'secondary challenge' to be addressed once a patient's psychiatric needs had been attended to. Often, housing service providers complained that they had limited contact with hospital staff in which to properly contribute to discharge planning. Other times, service providers reported knowing that an individual about to be discharged was one of their clients, but that hospital staff routinely failed to contact them to discuss 'aftercare' arrangements regarding that client. All too often, housing needs were put in the 'too hard basket' as one service provider (Sonia) put it, to be picked up again 'by someone in the community [sector]' once the patient was discharged. Sonia went on to make the point that:

Housing is a long-term thing, it typically takes a while to sort out, to get applications ready and to complete the paperwork, manage the waiting lists, that kind of thing, whereas the hospital [is] really concerned about having people out the door, and as long as there's something [accommodation] reasonable [to discharge people to], the hospital [is] happy with it. If it works on paper then that's all the hospital needs to know, is my feeling, so people do get lost at that point. (SP1OVIC)

Within psychiatric inpatient care in both New South Wales and Victoria, a patient's housing arrangements are typically considered as part of discharge planning and the development of a patient's Advance Statement, which is supposed to set out a patient's treatment preferences, care arrangements, recovery and support needs. However, we discovered significant discrepancies in discharge planning, including instances in which a patient's housing needs were not adequately considered or were disregarded altogether despite their manifest need. Ideally, discharge planning provides an opportunity for clinical and allied health professionals to liaise with community health and housing service providers to address a patient's housing needs.

Karen, who works for a community-based mental health service in Sydney, provided the following account of more integrated planning processes, grounded in the principle of 'person centred care':

In terms of pre-discharge planning, [we start with] a phone call with the person, then we usually liaise with their support person, which quite often is their social worker at the hospital. So we get information about their engagement with the program, their wellbeing, what we can do to support them. We try and provide them [client] with a sense of their housing options, to find what's going to be conducive to recovery for them. Then, we will have conversations around aftercare, medications, that sort of stuff, so we can make sure we support them in their recovery journey. (SP05NSW)

As we have noted however, this planning process can often break down, given that it is normally guided by informal processes and relationships between specific staff inside and outside of hospitals, and thus remains dependent oftentimes on the strength of these personal contacts.

In this respect, discharge planning was said to be highly variable in practice across different institutional settings, depending on staff capacity, patients' circumstances, and the range and availability of community-based health, housing and social supports. As one service provider said:

Our [hospital] system isn't really very kind, it varies enormously. You can go to one hospital and the nurses are all on the floor and they're all talking to the consumers, and there's much more happening, and you'll go to another place and the nurses are all behind in the office, you know, writing up their notes and doing their paperwork, and consumers are just wandering aimlessly around the wards. And it seems like very simple questions haven't been asked. So as a result discharge planning and supports and referrals, all those things, can be really hit and miss. (SP01NSW) 
Interestingly, many service providers put these problems down to the lack of formal administrative and governance arrangements to guide and formalise discharge planning processes and procedures in hospitals, which were said to be far more ad hoc as a result. For example, with no formal requirement to include staff from local housing and/or community services in discharge planning processes, appropriate referrals to these services were said to depend on informal local networks, and the extent to which hospital staff had existing contacts and relationships with staff at local housing services. Given that hospitals themselves have no capacity to address a patient's longer term housing needs, appropriate referral pathways from hospital into appropriate housing care and support was seen as crucial, but this was reportedly far from uniform in practice.

Some service providers attributed this situation to a lack of understanding among hospital staff, particularly clinicians, about the nature of available housing supports and a lack of awareness of referral pathways and processes between the hospital and community sector, as Brian noted:

One of the big problems I think is that there's certain attitudes in certain places [within hospitals] as to what the community-managed sector does, and their skills and a whole raft of different things. Some hospitals are really well connected to community mental health and other services and others say 'Well, we really do this stuff [clinical care], and we do all the coordination and those guys out there [in the community sector] they don't have our skills'. So there's a hell of a difference in different places as to what is available and how well coordinated things are. (SPO4NSW)

Allied to the problem of poor discharge planning is the propensity for particularly vulnerable individuals with complex health, social and housing needs to be simply 'lost to care' as a result of difficulties with follow up care post-discharge from hospital, or lack of effective referrals to community-based services. It was also noted that many of the most vulnerable individuals are highly mobile within and between service regions. In theory, mental health care should continue after discharge from hospital in a community setting, though there are a range of reasons why this does not always happen in practice. Service provider Will offered key insights into discharge planning processes, and the ways services try to manage gaps and the rationing of support:

The threshold is very high, for someone to be case managed in the community mental health teams. I would hazard a guess that it's down to funding, and the fact that there's not enough money, basically, to provide case management support for all the people that potentially need it. So a decision has to be made at some point [about who receives case management] and it tends to be 'at risk to self' or 'at risk to others'. Like, a chronic kind of schizophrenia, bipolar disorder, would be what gets you over the line, in terms of getting community mental health case management. But then it's almost like it matters who you get on the day, it's a luck of the draw. (SP07NSW)

A number of the problems with discharge planning result from inadequate resource allocations, a lack of clarity regarding key roles and responsibilities, over-worked staff and/or limited or inadequate local referral opportunities. Indeed, most service providers working in the mental health sector emphasised the burden of long working hours, increasing caseloads and resource constraints, and the burgeoning challenges of policy and administrative compliance requirements.

Many participants noted how expectations of seamlessly coordinated care did not match the realities of disjointed services and demoralised and overworked staff, as Bill noted plainly:

Inpatient social work is shit. The pressure is immense and the lack of acknowledgement of your voice is huge, and yeah that constant pressure around discharge is felt by the whole team. It's horrible. So yeah, after a while it felt like the homelessness system is just a dumping ground for everyone on the inpatient unit that they can't work out what to do with or it's just too hard. (SP08VIC) 
Echoing these concerns, another service provider Sara spoke of the specific skills required to manage housing work, and how staff often struggle with these demands:

It's just so hard navigating the system to get the right outcome for people. I mean the system is changing all the time, services come and go. It takes fortitude, knowledge of the system, language skills, the time to investigate, working with people, constantly communicating to make sure the care plan is followed. If someone drops the ball or misses a meeting, the whole thing can fall over.(SP03VIC)

We will return to consider the ways in which discharge planning might be enhanced in psychiatric inpatient settings to improve housing supports for vulnerable individuals later in the chapter, but first we will explore housing coordination and support needs in substance use treatment settings.

\subsection{Substance use and housing support needs}

Our discussions with substance use service providers - and with individuals with lived experience of different treatment settings - revealed many of the same themes reported above in Section 3.2.1. The substance use treatment sector in both New South Wales and Victoria is complex, like the mental health care sector, with a mix of public and private service providers and a great diversity of treatment and service system philosophies and approaches. Other strong similarities between the mental health service system in each state and the substance use treatment sector included similarly chronic challenges of unmet service demands, resource allocation constraints, staff training and professional development shortfalls, the enduring impact of recurrent service redesigns and adaptations, and a strong sense of geographical disparities between metropolitan, regional and remote areas regarding both the availability and quality of treatment services.

Service providers also discussed the enduring impacts of service system silos, and the subsequent lack of coordination between services (such as between mental health and AOD treatment, or between primary health care networks and specialised AOD treatment). Again, for individuals with the most complex needs, effective coordination between different service sectors was thought to be critical to their recovery experiences, though most service providers indicated that instances of effective service integration and coordination were highly variable at best.

Compounding these challenges, recent policy reforms in Victoria in particular, in which service delivery is increasingly organised via local 'catchment' areas and centralised intake and referral systems, was also said to be confusing for some client groups. This is particularly true of highly mobile clients who have historically been able to access services in various locations regardless of their 'home' catchment. Describing these reforms, service provider Louise noted:

In 2014 there was a sector-wide restructure of the drug and alcohol sector ostensibly to try and make treatment access flow and throughput better, target the right people and make it easier to navigate the system, but I wouldn't say that it's become easier to access. They created centralised intake and assessment hubs and then you have providers providing treatment. And there was a competitive tendering process and so you actually saw the number of discreet service providers in your region mushroom ... so the actual structure of the system became a bit more bewildering for clients I think because we changed all the existing intake and referral processes. We used to get a lot of drop-ins here, for instance, coming in saying, 'I want to come in and see Brad for counselling or Jo for case management'” or whatever it might be. And now we have to say, 'Oh, we need you to get in touch with [centralised intake] first, before you can go in and see them'. So we lost a lot of people to the system that way because we were saying we can't ... we're literally not allowed to see you to provide service unless you go through this [referral system] first. (SPO7VIC)

While, of course, for many individuals, centralised intake and referral processes have helped to create clearer local pathways into specialised substance use treatment services, almost all service providers (and many service users) we spoke with also emphasised how complex and 'confusing' the treatment system has become in recent years, with a burgeoning mix of public and private service providers, complicated even further by the recent 
introduction of novel care systems associated with the rollout of the National Disability Insurance Scheme (NDIS). We will have more to say about the NDIS in later chapters, but for the moment, and like our earlier discussion of the mental health service sector, we wish to emphasise here those aspects of the substance use treatment system in New South Wales and Victoria of greatest relevance to the provision of housing services and supports for vulnerable clients. We are particularly interested in identifying where improved housing coordination and support is most urgently needed, according to our participants, and how we think this enhanced coordination could be achieved.

\subsubsection{Care planning in substance use treatment}

To these ends, within residential treatment, the care plan (and associated transitional planning process) is the most relevant practice and policy instrument for addressing housing support needs and where we think improvements could be achieved to enhance the integration of housing and substance use treatment supports. Service provider Sarah described the key features of care planning processes as they are employed in most residential treatment settings:

When they [residents] come in, they have to put together a care plan [regarding] what you want to do and what your expectations are on how long you want to hang around [in treatment]. We go through that planning process every 30 days, but there's a discharge plan as well and that's when we get to find out who we can contact, who we can't contact if you decide to leave. Some people are only coming here for 30 days. They get to 30 days, 'Oh, I might stay another 30 days. I might do the whole program' and then you've got the others who come in and go, 'There's too many people here. I want to leave.' So we start working with them-engagement is the priority. (SPO3NSW)

It is important to stress how pervasive the emphasis on client 'engagement' was throughout our discussion with treatment service providers, and while we can hardly criticise this focus, it is notable that issues of housing insecurity were rarely identified in interviews with service providers, despite being a common theme in our discussions with service users. Strong practices of client engagement are undoubtedly central to the development of effective care plans for clients enrolled in residential treatment programs, although perhaps unsurprisingly service providers tended to emphasise matters of health and wellbeing, rather than housing per se, when describing the substantive contents of these care plans. Sometimes, it seems like housing issues are treated as second-order problems, with most focus directed to an individual client's unique substance use goals and their particular recovery aspirations. Again, we are not criticising this focus, only noting the scope for increased attention to housing issues in the development of care plans and the review of discharge planning arrangements in residential substance use treatment services.

With many residents experiencing housing challenges, such that some apparently regard rehabilitation as a temporary housing solution, there is ample scope to formalise relationships with relevant housing service providers to ensure that housing challenges are addressed much more explicitly and effectively in individual care planning and transition processes.

The issue of appropriate housing support for individuals leaving residential treatment was a strong focus in interviews with service users for two central reasons. First, many service users noted how their interest in attending residential drug or alcohol treatment was motivated precisely by the desire to find some 'respite' from housing situations that they regarded as either unsafe or overly 'enabling' of their continuing substance use. On this point, participants described living previously with other heavy drug users, in contexts of pervasive drug dealing and consumption, where substance use was all but normalised. For these participants, their existing (or previous) housing contexts were regarded as problematic sources of 'temptation' or 'triggers' that might inhibit their recovery and make 'relapse' more likely. Hence, escaping what were regarded as unsafe housing arrangements was a strong motivation for entering residential rehabilitation in the first place. Unsurprisingly, these participants were wary of returning to these same housing arrangements post-care, with most indicating that they felt the need to change their housing arrangements, along with most of their domestic and social routines, in order to maintain their 'recovery'. Changing their housing situation was thus identified as key to their recovery plan. 
A number of service users spoke explicitly of the challenges they had faced after leaving a residential treatment setting to return to housing situations that they regarded to be at odds with the practices, habits and outlooks they were looking to follow as part of their recovery. For some, the lack of housing support was seen as undermining their recovery. The following two excerpts from the service user interviews elaborate these dilemmas:

It's really hard, and where there seems to be a break down is you have got residents coming in here [treatment] and doing the hard yards, and this program is one of the toughest programs ever, and yet there seems to be no stepping stone out of here into somewhere safe. Somewhere that can be your home that you can then put into practice what you have learnt here and be safe. There is either no help at all, or there is, 'You are going back to where you came from'. (SU09VIC)

I've seen people just, yeah, really go downhill because they've either had to stay in emergency accommodation or they've had nowhere to go or they've had to go back to the street [after leaving treatment]. I have a friend who got housing in a good area, you know a nice [affluent] suburb, but the environment of the building is still really negative. There's dealers there. There's users there. And her addiction and her mental health's declined dramatically because of that place. So your environment plays a huge part, especially after rehab because as you've just gotten clean, you've just gotten some of the tools that you need to stay clean and then that one thing, your environment, can be your undoing. It's happened to me before and I see it all the time. (SU22NSW)

At issue here is the very character of what people understand as suitable or appropriate housing, given that while some people's housing might be secure (insofar as they have security of tenure), this does not necessarily make their housing 'safe' or appropriate in terms of their health or recovery. Service users often indicated how these nuances were overlooked in care planning and transition discussions, where their existing housing was treated as 'good enough' despite misgivings about aspects of this housing (such as who they lived with, or who might live nearby).

Many service providers discussed these challenges in pragmatic terms, noting how they often needed to prioritise housing supports for individuals at risk of being exited into homelessness (given that they had no stable housing to return to), rather than focus on the housing preferences of individuals who had what they regarded to be adequate housing already. Nonetheless, discussions about the role of housing in health and recovery post-treatment were a strong feature of our discussions with service users. Aiden summed up the key issues here as follows:

It would have been really dangerous for me to have done the program and have gone back to that house and had people turning up, you know bringing drugs. That would be really hard. I know a lot of residents here who do have commission houses [i.e. social housing] that they have still got sitting there waiting for them, but they are so scared because they know going back to that area, back to that house, is putting them back in that position where they were before they came in. I know a lot of them have called [the Department of] Housing. They have asked to get a transfer to be able to move, but no one seems to be able to offer anything for anyone at the moment. (SUO9VIC)

For other service users, without secure housing to return to, the challenges they confront planning effective transitions out of treatment are even more acute, given how limited housing options are for people leaving treatment, especially for those on low incomes. Service users in these circumstances spoke of accessing crisis, emergency and/or transitional housing, particularly immediately after leaving a residential treatment setting, and the significant challenges these transitions presented:

Trying to get out of rehab going into emergency housing, it's dangerous to say the least. I mean, in my experience, I relapsed straight away. [Last time] there was a drug dealer on site. I had no choice where I wanted to go. I begged to be put into a motel so I wouldn't be surrounded by drugs basically. But there was nothing else on offer so I just had to take it, and within days I was using. (SU2ONSW) 
Many of the service users we spoke to had a strong preference for private rental accommodation. Some of them noted specific challenges gaining access to this form of housing, given how their experience of treatment had typically interrupted their housing careers and employment histories. Others noted how challenging completing rental applications can be for people with limited experience of such things. A key issue was the need for greater support accessing private rental accommodation, particularly in tight housing markets. One service user expressed a strong wish for support in finding private rental accommodation but said that none had been available:

If only there was some help [with finding and securing rental accommodation], someone that could refer us, but there's just nothing like that available at all. It's like you're thrown in the deep end. It's hard. Being out of work for two years and you've been in a therapeutic community, a lot of people are finding themselves misleading real estate agents because there's just no other way about it. Your application, up against someone who's got a job and has a bit of rental history, is always going to be in more their favour than yours. So yeah, if there was a service there where they could recommend you with the agents where they could say, 'Look, these people don't have the best application, but they do fit certain criteria' but there's just nothing like that at all. (SU17VIC)

In Victoria, the Private Rental Assistance Program (PRAP) is supposed to address circumstances like the one referenced here, in which individuals deemed capable of sustaining private rental after a period of treatment receive financial aid and case management support to secure this accommodation. The model is reportedly not well known outside specialist housing programs in Victoria, suggesting grounds for enhancing the coordination of housing support in substance use treatment sites across the state.

Consistent with this oversight, other participants spoke of their frustrations with the ways that housing issues were addressed in treatment, with most noting how housing was incorporated into care planning, though typically without opportunities for detailed discussions about people's housing preferences. Some noted how housing matters were raised briefly at admission as part of care planning, but then left until the very last stages of exit planning, sometimes only a couple of weeks before exit. Frustrated with this approach, knowing how long waiting lists can be, and how difficult housing services can be to navigate, participants spoke of their desire to 'get on top of their housing earlier' as service user Sam put it:

I remember them saying to me when I was in the first part of the program they actually encouraged me not to apply for housing. They told me to wait until I was in transition to apply. And that really scared me because that first part of the program is three months in transition and another six months in exit, up to a year. That's not very long to be waiting for housing. People can wait years. So that scared me. I wanted to get the ball rolling right from the start but I was encouraged not to. (SU23NSW)

Other service users spoke of the challenge of getting housing applications organised while still in treatment, and their frustrations with complex bureaucratic processes and a perceived lack of support. A number of service users emphasised the notion, as we have briefly noted, that housing seemed to be regarded as a second order concern, with a lack of focus from staff-as James said:

I had to accumulate all the paperwork on my own. And I found it quite difficult because at the program I was at you had to put in an application to be able to go and see the relevant people to get the paperwork. So it was a really slow, painful process, but I did it... I guess they [staff] had other priorities, like we were encouraged to do relapse prevention plans and encouraged to get phone numbers, but as far as the support for housing and stuff I wouldn't say it was the best. (SU24NSW)

A number of other participants spoke of how disruptive experiences in residential rehabilitation can be, no matter how successful these experiences may be in helping people to manage their substance use, with almost inevitable impacts on people's social and family networks, their sense of place and belonging, and their engagement in work or training. With so many things to manage, participants spoke of the need for a stronger focus on housing, and more help navigating housing bureaucracies, applying for support, and making the transition into more suitable housing. 


\subsection{Housing coordination futures}

Meeting the housing needs of vulnerable individuals with complex histories of physical and mental ill-health, substance misuse, social isolation, and/or disrupted training and career pathways presents the health and social care system with a host of complex challenges. Our analysis suggests that there is still much work to be done to improve the integration and coordination of housing, mental health, and/or substance use services for individuals with the most complex needs. Despite strong commitments in recent policy statements to improving service coordination in the design and delivery of social care supports in the community (see Brackertz, Davidson et al. 2019; DHHS 2018), our analysis suggests that effective coordination between housing, mental health and substance use services is still nowhere near as effective as it could be across New South Wales and Victoria. Oftentimes coordination seems to depend on the efforts of individual case workers, without broader, more systemic and formalised arrangements in place to facilitate the more effective coordination of care planning for vulnerable individuals.

This then is the first and most important policy implication of the analysis presented in this chapter. It concerns the need for urgent policy attention to the more effective integration of housing supports within the delivery of mental health care, particularly in inpatient psychiatric settings, and within the delivery of community-based substance use treatment, particularly residential services. Similar arguments and recommendations have recently been made by Nicola Brackertz and colleagues (2019), following similar analysis of the role of housing in supporting individuals in the community with complex mental health challenges. Like Brackertz and colleagues (see 2019:6-12), we have observed great complexity in the delivery of community-based mental health services, and considerable strain upon psychiatric services in hospital settings, particularly in Melbourne and Sydney's largest hospitals. We have also reported significant discrepancies in the integration of housing support into mental health care, despite the obvious need for such coordination, particularly among the cohorts of "heavy service users' identified in Chapter 2.

A similar picture emerges in our analysis of substance use treatment services, with similarly patchwork mixes of public and private care providers, and great diversity of treatment models and pathways. Here too, the formal integration of housing supports into the delivery of substance use treatment services is inconsistent at best. This is despite the high demand for housing supports in treatment, and the obvious benefits that would likely follow from improvements in this support in terms of reduced substance use and relapse rates, reduced hospitalisations, and improvements in workforce participation, as numerous studies have indicated (see Duff, Jacobs et al. 2013; Hall, Walters et al. 2020; Tsemberis, Gulcur et al. 2004). There is the added challenge in the case of substance use treatment in that many individuals become dissatisfied with their existing housing as a result of the life lessons they encounter in treatment, and so come to have a strong preference for alternative housing to better support their recovery as they leave care.

As we have reported, many individuals in treatment come to associate their former housing arrangements with 'cues' for substance use behaviours and hence have a desire to move to new accommodation once they complete their program. While we acknowledge the challenge of providing housing support for individuals in contexts of chronic unmet demand, there is scope to enhance the formal integration of housing supports into substance use treatment services.

On the basis of analysis presented in this chapter, we identify the following key policy issues:

- Housing/homelessness, mental health and substance use treatment remain separate policy systems across Victoria and New South Wales, with only partial integration or coordination.

- Within these systems, there is significant unmet demand for support, as well as resource gaps and constraints on coordination between health and social care systems.

- Discharge planning arrangements in both mental health and substance use treatment offer significant unrealised opportunities to enhance the integration of housing supports. 
- Housing transition supports ought to be integrated more effectively into discharge planning in psychiatric inpatient care for individuals at risk of (or experiencing) housing insecurity.

- There is scope to enhance the role of allied health staff and external 'community' housing providers in care conferencing and coordination in psychiatric inpatient care to improve the integration of housing support for individuals at risk of (or experiencing) housing insecurity.

- There is need for enhanced financial support for those individuals who enter psychiatric care from private rental accommodation to ensure they are able to retain this accommodation for the duration of their admission. This may, for example, involve access to Commonwealth rental subsidies administered via Centrelink income support, and/or access to discretionary brokerage funding at the ward level to subsidise rental payments.

- Housing affordability, social housing shortages and lack of supported housing remain key challenges for individuals experiencing mental health and/or substance use challenges.

- Individuals exiting both mental health and substance use treatment services express strong preferences for greater choice and control over their housing transitions. 


\section{Coordinating complex service systems}

- This chapter examines participant reports of the coordination of housing and social care supports in the mental health and substance use treatment sectors.

- We explore the key barriers and enablers restricting or promoting the more effective integration of housing, health and social supports, highlighting instances of effective coordination, along with outstanding challenges.

- We reflect once more on key similarities and differences between the mental health and substance use service sectors, in terms of specific issues of care, coordination and integration, and close with key service recommendations.

\subsection{Integrating housing, health and social care}

In the last decade, reforms to the delivery of housing and social support services around the country have typically emphasised the need for more carefully targeted services with strict eligibility criteria, often in carefully designated 'catchment areas' (see Chamberlain, Johnson et al. 2014; Clarke, Parsell et al. 2020), as opposed to the population health measures that dominated in earlier times (see Pawson, Milligan et al. 2020). As a result, increased service specialisation and diversification, combined with growing geographical fragmentation have become hallmarks of housing, health and social care service responses across the country. Of particular relevance to the analysis presented in this chapter, housing support services in Victoria and New South Wales have become increasingly complex in recent decades, with greater service specialisation involving more targeted policy supports, typically calibrated to address the needs of increasingly diverse groups (Brackertz, Davidson et al. 2019; Parkinson and Parsell 2018). As housing, health and social care systems have been reformed and restructured in each jurisdiction, they have become more complex, more specialised and almost inevitably more difficult to navigate for vulnerable individuals (see Clarke, Watts et al. 2020; Sylvestre, Nelson et al. 2017).

This chapter addresses everyday practices of coordinating complex care systems described by participants. In keeping with key developments canvassed in the research and policy literatures (see Section 1.2), discussions with each participant group explored the extent to which these systems are integrated, and the ways that housing support is coordinated in particular, with a focus on the integration of mental heath, substance use treatment and housing services. We also explored service users' experiences of service coordination and their reports of gaps and problems, strengths and opportunities in this coordination. In a context of growing service complexity, we were interested in identifying the barriers and enablers to the more effective coordination of service delivery across complex housing and social care systems in Australia. 
Effective models of service delivery for vulnerable groups with complex housing and social care needs-such as 'housing first' (see Tsemberis 2011; Baxter, Tweed et al. 2019) and 'recovery' models (see Oades, Deane et al. 2005; Corrigan, Larson et al. 2019) - emphasise the need for careful coordination between different health and human welfare services. Hence, our interviews probed participants' understanding of these matters with a focus on both positive experiences of effective coordination, and instances where this coordination might have failed. Consistent with the literature, we discovered a complex care network with significant challenges integrating and coordinating care across service systems. Yet, when service integration works, service responses can significantly enhance the health and housing outcomes of vulnerable individuals.

\subsection{Coordinating care, managing silos: opportunities and problems}

Housing support work is unquestionably difficult. Clients have complex needs, referral pathways are difficult to negotiate, community services are typically stretched with long waitlists, demands on staff are immense, and problems seem often to be getting worse. Consistent with this view, service providers painted a challenging portrait of working lives characterised by long hours, complex cases, and growing demands on their time, alongside stories of great satisfaction and signal achievements. This section opens with an analysis of practices and policies of coordinating care, which all service providers regarded as key responsibilities of their role. Effective coordination of care was regarded as central to improving the health and wellbeing of service users, and a key part of managing the housing insecurity of vulnerable 'clients' in particular. Yet it was also regarded as difficult work, given the challenges of negotiating complex service bureaucracies, often across several local administrative regions and governance arrangements, in contexts of rising demand and considerable unmet need. We will start by describing participant reports of the design of services systems and the referral pathways that characterise these systems as a way of indicating the importance of service coordination across and between services. We will then describe instances where this coordination fails, or is poorly managed.

In the main, we found enduring discrepancies between how services are designed, or the ways that they are supposed to work, and the ways that systems often function in practice. We discuss these discrepancies in the following sections before closing with a review of program innovations in which service coordination has been more effectively integrated in each study context.

\subsubsection{Managing bureaucracies, managing coordination}

Both service providers and service users emphasised the specific skills and professional relationships necessary for the effective coordination of care and for the appropriate integration of services across diverse care systems. It was widely noted how difficult the work of coordination can be, and how much effective service integration depends on formal and informal professional networks, communication, and strong relationships. Even so, all participants emphasised the critical importance of the informal work of coordination between services in order to drive better outcomes for clients. While some service providers noted the importance of formal partnerships between services across different systems, including through formal memoranda of understanding (MoU) arrangements, most noted the critical importance of rich and deep professional networks among local service providers across the different care systems relevant to client needs. This was often described in almost nostalgic terms as 'old school' or 'old fashioned' care work in which service providers spoke of the value of having a long list of local service providers that they could call on to assist with the delivery of care to a particular client.

Often service providers used the language of 'person-centred-care' (see Golembiewski 2015) to describe this approach to coordination and referral and how they sought to tailor care responses:

Well, at the end of the day it's all about the client. Anyone that's around the table at a case conference we're all there for that client and we all want the best outcomes, so it's really about how we're going to work together. Because there are things that we can do, there are things we can't do, there are things they [clients] can do; they might have resources in place. So, I mean I'm not saying it happens like this every time. We do the best we can case conferencing to make sure that there's 
some really good planning that happens. A lot of it doesn't happen though. It's kind of like 'Oh, yeah, they [clients] were here [in hospital] and now they're gone'. And so we're all like 'OK, well, how do we stop this from happening again?'. It really depends on the person, how much planning we can do, and whether we can provide what people need at the right time. (FG01VIC)

This discussion provides a rich instance of the point we closed the last section with regarding the discrepancy often observed by participants between how the system is designed, or how it is supposed to work in principle, and how it actually works, most of the time, in practice. Case conferencing is supposed to result in a formal, coordinated care plan that all relevant parties adhere to, but often these plans are not adhered to, or they are not properly followed up on over time. These formal aspects of coordination, such as case conferencing in hospitals or in the community housing sector, were often said to be augmented (and in some instances entirely displaced) by informal networks, relationships and routines in which service providers relied on 'local know how' (as one provider put it) to achieve the best housing outcomes for clients:

\begin{abstract}
The most important work gets done through relationships. You can have an MoU, but as soon as the key person, or you, leaves, all that knowledge goes. So building relationships between service providers is crucial, like when you can ring up [a service partner] and go, 'hey Bill, how you doing', and you might talk about your kids, or what you did on the weekend, before you go, 'right, l've got so-and-so', right, so the trust is there. We've got people who refer to us, and they will say, 'yeah, the kid's ready for rehab' and we'll believe them, and we've got others that will say, 'oh, the kid's ready', and we won't believe them, because they're looking for an exit point, rather than what's right for the kid. So, the more you build up those relationships, the better it is [for the client]. (SP06NSW)
\end{abstract}

Most service providers endorsed the value of building local service relationships, and the importance of these networks in delivering coordinated care. This work seemed, in the main, to be one of developing and maintaining effective working relationships with a wide network of allied professionals, both inside and outside of one's immediate sector, with NGO service providers, and/or public health agencies. These networks are essential for effective coordination of care.

When managed well, care coordination was said to involve an ongoing commitment to complex problem solving according to client need, using whatever resources might be at hand:

We try really hard to work out what the client wants. It has to be client-directed and client-driven. Once you've established that relationship, down the track you can say. 'Now, you mentioned that you've been getting a few toothaches. Is that something we could look at? Could we book you into a dentist?' [Or if] their Centrelink payments have been cut off, for example, because they hadn't attended their appointments, well, that would be the thing that we would deal with that day. (SP05VIC)

Given the wide diversity of client presentations, beyond the basic delivery of housing and social supports, most service providers emphasised the value of informal care coordination, with some even questioning the extent to which these arrangements can be formalised through contracted services and MoUs. Formal MoUs are no guarantee of effective service integration between different agencies, because ultimately, care coordination depends on strong local relationships of trust and reciprocity. To highlight the value of these relationships, many services providers drew an explicit distinction between 'warm' and 'cold' referrals, and the significant differences in service outcomes that each tended to be associated with. Warm referrals were said to foster strong, local service coordination, grounded in established relationships, where the client's needs were central to all service planning. However, in instances of 'cold' referrals with little knowledge of a service or a personal contact, the inertia of bureaucratic process can often take over:

A warm referral is always going to be better than a cold referral, so sometimes it's up to us [staff] to really push. Sometimes they'll [clients] call the service and [the service will] say, 'Oh, we don't have capacity'. So then I will call and stress the urgency of the referral, and there's a little bit more weight to it. Clients know that too. They've been around the system, so they know that a referral coming from the social worker-especially from a legal centre-has a lot more weight attached. (SPO4VIC) 
These kinds of scenarios reveal the 'tips and tricks of the trade' as one service provider put it to describe advice given to him by one of his mentors. In keeping with this idea, and the critical roles of informal relationships, service system knowledge and creative problem solving already noted, participants often emphasised how effective service coordination typically requires informal 'work-arounds', creative solutions, negotiation and compromise. Finding ways to 'work the system', to make what have become highly rigid and bureaucratised service systems work for clients, have become critical 'on the job' skills for the coordination of effective and enduring health, housing and social outcomes for disadvantage clients. As one respondent said:

When I worked in [suburb] I knew of a really good one [rooming house], and I had a really good relationship with the proprietor, so it was really easy for me to ring her and say 'Oh, have you got any vacancies?' She'd often say 'Yeah, for you I have'. You know, because she knew that I would be coming and supporting that client while they were living there. And then she'd say to me, 'Oh, while you're here can you go and see that man down there? I'm not sure what's wrong with him'. So, it worked well, we would help each other out to make sure we got people they needed. (SP05VIC)

For other service providers, finding 'work-arounds', ways to coordinate care for vulnerable clients in the face of barriers thrown up by the service system itself, was central to the everyday work of coordinating care. Here again in the following excerpt we find instances of the informal work of coordinating care, and how the system sometimes stymies this work:

I met a young woman in with the adults [in inpatient care]. And there were quite a few unwell looking males on the unit that day. And she looked really frightened. I met with her, and she wasn't eligible for our service, but she told me her story. She was being discharged the following day with no follow up or community referrals. So, I called my manager, and said, this is outside of our scope, but if I don't do something, I don't think anyone else will. So, I had a conversation with the nurse manager and they - with her consent-just said, you know, she's had 30 admissions in 18 months, what are you going to do different this time? Because she's going back to homelessness in a caravan park, violent boyfriend, what are you going to do differently? So, we came up with a plan around how they would support her discharge a bit better. But that was all out of scope. It was work I wasn't even meant to be doing, but sometimes you just have to do it. (SPO2VIC)

Service users often shared stories of case workers like this one, with expert knowledge of local care networks and a real passion for supporting clients. This kind of support was highly valued, with service users often speaking of how such workers had changed their lives:

Her [case worker] ability to advocate on our behalf, I'm 100 per cent certain she probably had to make 10 phone calls every time to make things work, because I didn't have a Health Care Card. So to be eligible for near on everything in the state government service system you have to have a Health Care Card and for a lot of things you have to do co-contributions so you have to have an income, and I didn't have one. So as you can imagine, I was knocked back heaps of times, but from the time we were engaged with her [case worker], I never got a knockback. She'd take me [to appointments] where they already knew I was coming, they already knew my story, we walked in with a purpose, did whatever we went there for, all positive. She deflected any of that rejection on my behalf and only took me somewhere where she knew I was going to get a positive outcome. (SU06VIC)

In other instances, service users credited the combination of housing support and the assistance of a key staff member for their current stability and recovery progress:

My current living arrangement, being in a transitional house, is really helping keep me grounded and keeping me focussed on what I want out of recovery. I've got a case worker who's here basically every day, Monday to Friday, and she's there to help whenever I need it and it's very supportive. It's keeping me accountable, in check. If I was out on my own in my own house without this help, I don't know what l'd be doing. I don't feel like l'm really ready to be completely on my own. But soon you 
know, hopefully l'll be ready to transition into my own house. So l'm more like doing all the things that I need to do to keep my recovery on track. I have a gambling counsellor, drug and alcohol counsellor. I have a psychologist. I have loads of support to get-and loads of things that I need to work through to get me completely ready to go into my own accommodation. (SU12NSW)

Much of the everyday work of coordinating care involves helping clients navigate complex care systems, to help manage what are often bewildering if not daunting bureaucratic processes. Describing her transition out of residential treatment for her alcohol and other drug problems, and her desire to get back into private rental accommodation, Lisa highlighted her case worker's help:

The really good workers - like, the worker that I had at [names service] — he was unreal, he had a really good knowledge base of what was available. Actually it was his knowledge of things like the funding and all of that, that got us into the private rental system. We couldn't have paid bond, we didn't have a fridge, we didn't have a washing machine, none of those things, and we had no idea how to get them. And he had a really good amount of knowledge that he helped us with. Without that I wouldn't have been able to get to where I am now, you know in my own rental.(SU15VIC)

Other service users spoke of how long it took them to find a helpful case worker like this:

Because I didn't have anyone there to say, 'Hey, this is what you need to do. Don't give up now. Push on with this, push on with that,', I could've been here [secure housing] a long time ago. But I just didn't have the skills, I didn't have the knowledge, I didn't know how to manage it all, until someone put it in front of me and said to me, 'Here it is'... I think in all these 25 years that l've been in and out involved with services and whatnot, and don't get me wrong, I've had people over the years that have made a big difference in my life, but one person came into my life almost 12 months ago now, and she has done so much. She saw in me something that-she saw my potential. She saw the person that I could be if I were given the opportunity. So she put those opportunities in front of me. No one's ever done that before. That's the first time l've ever had a case manager that has actually managed my case, if that makes sense. If someone had've done that 10 years ago, my god, my life would be so different. My life could be so different. (SU07VIC)

\subsubsection{The challenge of coordinating care: policy gaps, problems and pitfalls}

While we canvassed numerous reports of effective care coordination in our discussions with both service users and service providers (for more on this see Section 4.4.), we also heard numerous reports of ineffective, piecemeal and spasmodic coordination, with key challenges and problems integrating care across services and agencies. We have already noted some of the challenges associated with coordinating care between diverse services and supports, but it is also important to stress some of the personal costs that service providers reported in terms of long working hours, increasing caseloads and resource constraints, and the burgeoning challenges of policy and administrative compliance requirements. Many service providers we spoke to noted how expectations of seamlessly coordinated care do not match the realities of disjointed services and overworked staff. Equally prevalent were reports of inconsistent and ineffective coordination between community mental health care, substance use services, and specialist housing services.

Reflecting these challenges, many service providers described what we took to be a deeply pragmatic sense of what treatment for mental health and/or substance use problems might realistically be able to achieve. This pragmatism may be observed in the gap noted by many participants between, on the one hand, the 'ideal' goals of service delivery and care coordination, and what, on the other hand, is actually possible in practice, as the following provider said:

Sometimes, people get really good care and really good experiences, and that's what the policy is, and that's how it should be, but quite often, that's not what's happening. We need more holistic approaches. I think there's a lot of 'this is our lane, we get to stay in it, and not work with other people, because that's not our job'. But you can't just treat one part of this issue for someone, you need to work with other services, be on the same page, working towards the same things. (SPO2NSW) 
Other service providers spoke in more cynical terms about this gap between policy rhetoric and actual service practice; between what governments and other providers say they are committed to doing or providing for vulnerable individuals and what actually happens in practice. In the following interview excerpt, one of the service providers we spoke to took particular aim at the growing prevalence of 'care-coordinator' positions in mental health and substance use services, often at the expense of established case management roles:

A lot of funding positions seem to be shifting away from case management, through linkage work to now care and recovery coordinator [who] ostensibly will work with the person to link them into services. Now this all sounds like a great equation on paper. If we refer you to a housing service, you'll get your housing stabilised. If we refer you to a mental health service, you'll get your mental health stabilised you know, but doesn't seem to be how it's all working in practice at the moment. (SPO7VIC)

Difficulties coordinating care were identified in metropolitan and regional and remote settings, although distinctive challenges were noted in more regional settings where basic services might be lacking in the local area, or located at some distance from clients. Describing some of these challenges in regional areas, service provider Brian also noted problems of accountability:

One of the difficulties that we find as managers [in rural and regional areas] is we try and deal with that stuff [housing problems] as early as possible, and put referrals into the right places. But one of the biggest frustrating factors for us, is [clients] not being allocated a person in time, or not having people come out to actually do the intake assessments. Or when the intake assessments are done, they seem to just fly off into the abyss, and no one seems to be allocated to them, or know about them. That's been an ongoing battle for quite some time now [in rural areas]. (SP10NSW)

Other service providers noted problems referring to appropriate housing in their local area, which often made it more difficult to maintain good engagement and strong client relationships:

Often our only options are the SRS [supported residential services] or a boarding house. And I know mental health services struggle [to find housing options] just as much as we do [AOD treatment]. The big issue is there's no housing stock locally, so we struggle sometimes to help people and that just tends to piss them off, they blame us mostly so we do lose some that way. (SP05VIC)

Of course it must also be noted that many of the problems we identified in the coordination of care between different agencies result from the uneven performance of agencies themselves, much like the lack of responsibility and accountability noted by Brian above. The quality of coordination was observed to be highly variable, differing greatly between services and between individual case workers. Service users often referred to notions of 'luck', 'chance' or the 'lottery' when describing their experiences of case coordination and referrals. Service providers too acknowledged wide discrepancies in the quality of care and service coordination offered by case workers as the following excerpt shows:

A lot of IAP [Initial Assessment and Planning] workers don't know what's around, they only know the two or three services that the organisation they work for offers. They don't know if St Vincents down the road offers something else, or if Anglicare has got something, they have no idea. I mean I guess it isn't their fault, I'm not saying that, but it puts more strain on people [looking for help]. And whether you're going to this organisation or that organisation, you're going to get a completely different answer. So it's a bit of a lottery. Like, you might be lucky, sometimes you find someone, in the industry, that have been around for years and they might have worked across a few different organisations, so they've got that knowledge. But you don't find that very often. I know it is a high stress industry, and it does have a reasonably high turnover, but that's the thing as well, you've got staff that just don't have that much information to, individually, know how to support people. (SP15VIC) 
In acknowledging some of these problems, a number of service providers spoke of the problems of increasing caseloads and the associated restrictions on their time to actually get to know clients, to come to understand their needs and then to develop effective care plans for them:

People don't have the time to form a relationship when somebody's in care, that's going to hold through afterwards when they're discharged. I think there's that sense that, especially people that have been in the system for a while, that you're not going to get this level of support anyway, so you don't look for it, from the service. You've got to look for it yourself, and if you don't have the ability to do that, or supports to help you with that, then you're fucked. I think that's the reality of the system, is that people who have support, externally, like from family or friends, if they've got their own money right, they do better than those that don't have that kind of support. Because there's nobody within the system that is going to be able to provide the level of care that's needed. (SP02VIC)

Another common theme concerned the enduring impacts of service system silos and the lack of coordination between different systems within and between these silos (such as between mental health and AOD service systems, or between psychiatric inpatient care and housing support services). While some larger AOD treatment services have integrated mental health care available on site, this is rare, with most service users describing their frustrations accessing care across these sectors. The sense here from both service users and service providers was of a lack of transparency in the system, of uncertain lines of accountability between services, and a lack of open communication. These factors all undermined the coordination of care across agencies:

I think that there is just that real lack of sharing of knowledge. You almost have to be lucky to get a worker who knows what's going on and can put you in touch with places. That's the difference is that pool of knowledge, it's not shared or its siloed. You just don't know about things. If you're lucky, you'll hear someone say, 'You should try this. I got help through x, y and z'. You think, 'All right, I'll give that a try'. It [housing support] seems to be more through informal channels than formal channels. Like you'd think that housing workers would know all this stuff, but not always. (SU02VIC)

Service providers acknowledged that vulnerable individuals with especially complex health, social and housing needs were often simply 'lost to care' as a result of these kinds of difficulties with follow up care, or for want of effective referrals to community-based services. It was also noted that many of the most vulnerable individuals are highly mobile within and between service regions, which often makes follow-up care difficult, especially in contexts of local 'catchment areas' and the geographical service exclusions they engender.

Of course, some difficulties coordinating care result from the conduct of clients themselves, which was often said to be unpredictable, if not 'chaotic'. This was particularly characteristic of highly vulnerable individuals with complex health, social and housing needs. These clients were often difficult to enrol and retain in treatment programs, and were difficult to engage in voluntary community-based care. Service providers noted how these clients often miss appointments, fail to comply with treatment program requirements, relapse into substance use or return unexpectedly to inpatient care. Describing these challenges, Teo remarked:

Well, people get lost to services. You can't tag them [laughs] so people will leave [services] on a CTO [community treatment order] that they don't agree with, and they might do everything they possibly can to avoid services, like they just disappear. Some, even though they have a home, they haven't gone back there, and the social workers, or whoever, will have tried to contact them, but you know, they've gone to Queensland or whatever. You know, you can't restrain people. (SP01NSW) 
We were also reminded by a number of service providers that individuals are often enrolled in treatment or mental health care on a voluntary basis, meaning that they are free to leave care at any time, and to refrain from participating in efforts to coordinate local care plans if they wish:

Often people are leaving [treatment] in a high emotional state-and we can't hold them because we're a voluntary facility - which means that what they want to do to manage that high emotional state by engaging in behaviours that have worked previously, which often means drugs and alcohol. Well, let's be realistic, that's what's probably going to happen. So we try and make sure that we hand them over to a service, a someone that has some ability to check on them. (SP01VIC)

In these circumstances, referrals fail and the continuity of care breaks down, leaving individuals to uncertain housing situations. We will discuss further instances of service breakdown in the next section before we turn, in Section 4.4, to discuss instances of more effective coordination.

\subsection{The effects of system failures: when coordination breaks down}

\subsubsection{Service and system failures and their effects on individuals}

Throughout the previous section, we stressed the importance of careful, systematic coordination of housing and health supports for individuals with complex care needs. For all the challenges that services face coordinating care plans for vulnerable individuals, all service providers and most service users we interviewed acknowledged the importance of effective coordination between services in the delivery of high quality care. When coordination breaks down, or where services are not well integrated, the consequences for vulnerable individuals can be significant.

Exploring these challenges, and in keeping with our research aims, discussions with service providers focussed on practices of referral into accommodation for individuals leaving either mental health or substance use treatment. These periods of transition are critical moments where effective coordination between services, particularly between care providers and external housing support agencies, can make a significant difference to individual's housing trajectories, particularly for those trying to move from temporary crisis accommodation into something more secure.

While we canvassed many of the key principles of effective care coordination in the previous section, it is important to stress that we also collected reports of service failures where care had not been coordinated adequately. In a long discussion on this theme, Lisa recounts challenges she had experienced leaving hospital, looking for referrals into more secure housing:

Even if it had of been crisis accommodation, that would've been fine, but to find me housing that was somewhere more safe and secure for someone who's just got out of hospital, that's what I really needed, but I didn't get it. There absolutely was not enough follow through or advocacy for me as a patient to [refer me to] other housing services. So I ended up at the backpackers. Due to the cost, I couldn't get a room by myself, so I got into one where it was shared, there was six bunk beds. I only remember two people coming into the room, and if I was there l'd just go under the covers because I was scared and I didn't want to see or speak to anyone. That was strange. There was massive windows with shared bathrooms, and huge-all these things would be great if you were mentally stable and on holiday, and it's fun and nice. But it was just really awful and really scary. I really felt scared and very vulnerable. I hated it, so I just left after two or three nights. (SU16VIC) 
It was also common to hear stories from service users about what they regarded to be unsafe or inappropriate housing referrals following the completion of a period of residential care. Indeed, we heard many instances of service users being returned to their existing accommodation, even though they didn't wish to return, either because service providers regarded the option as 'adequate', there were no other options, or because staff reportedly had other more challenging cases to manage. In this respect, it was reasonably common for service users to report how they felt that they had to be 'at crisis point' as one respondent put it, before they might receive care:

The first time they told me they were discharging me back to my mother, and I was really upset with that due to what was happening in the home. I was really scared. My mum was not doing well at that time, she had only come to see me when she needed to borrow money. She was really struggling, and I felt almost betrayed that they'd listened to her over me, because I knew that she [Mum] would go into the meeting and say, 'no, everything's fine, it's all good, she can come home'. So originally they [hospital] gave me two days' notice of being discharged, but I got really upset. Actually I had a bit of an episode, an upset episode, so I was put on involuntary, and they consulted the psych who said, okay, we'll give her seven days [admission]. So that's when they made referrals to refuges and that's when they started to actually do something. (SU15VIC)

It is equally important to note that, in addition to these experiences of inadequate housing referrals, we collected numerous reports from service users of patchy, inadequate and/or inconsistent experiences of referrals to other services, characterised by poor planning and coordination. Some service users also shared stories of instances where almost no discharge planning took place. Speaking critically of these gaps and problems, one service user told us:

The planning is non-existent, and there's no continuity of care. No matter how much you might try and get it, it's really just pot luck. Just from my experience of where l've asked for support around psychiatric care, 'Can you help me to find someone? I really need a new support because I am moving to a different area. Can you help me to get that?' And to have that not occur, when you ask for it [... you just think, 'Well, this is really all up to me to do this'. (SU02VIC)

These remarks touch on the need for holistic approaches to care coordination that address a wide range of social care and support needs beyond help with the administrative aspects of securing an appropriate housing referral. In this sense, access to secure housing is as much a means of promoting greater social inclusion, or wellbeing, as it is a discrete service goal in its own right.

Indeed a number of service users, including Rachel whose circumstances we note below, described the importance of resources to support people in economic and social participation:

You need the ongoing support, you can't take a homeless person and say 'right, there's a flat, see you later' and walk away. You need more, someone to help you get organised, help you set up appointments, help take you to the appointments. [...] Finding new ways of getting them out of the flat and getting them into society, help them find jobs, whatever they need. (SU05VIC)

Other service users reported more basic problems accessing support and adequate follow up:

The hardest thing is getting them to answer their phone [names agencies], they never answer their phone. You have actually got to go down there, and you have to be down there at ten to nine in the morning. They only take five appointments, so it is the first five people who get help. (SU09VIC) 
Some service users reported feeling as if they had been treated as a low priority given that they already had access to housing, even if they themselves felt that this accommodation was either unsafe or inappropriate. Other participants who had experienced inpatient psychiatric treatment said that housing supports were seemingly offered only to those individuals experiencing rough sleeping. For others living in what staff regarded to be 'adequate' housing, service supports and referrals to housing services were either not offered, or discussed only fleetingly:

It was a huge step for me to throw my hands up in the air and say, 'You know what, that's it, take me [to hospital]'. So then to get there and feel like I was put on a scale of, 'Well you're not as high risk as this one, so we'll just leave you be' kind of thing. That was really disappointing. So I just went back home, because they never really looked into that [my housing needs]. It's like they said 'yes I had support with housing, yes I was in the family home,' but the family home was obviously broken, you know you could see something's not right in the home. (SU07VIC)

lan reported that the focus of attention in hospital settings is always 'medication and symptoms' not care per se, and, as described below, he had a similar account of inadequate housing support:

The nurses and the psychiatrists [complete forms asking], 'Have they got accommodation?' and usually, it is just listing down where the person is going next and then ticking the box. They don't investigate, and I believe they should investigate. What they don't do, as well, is where the place that person is going, will it help improve their wellbeing? People just have this generalisation that as long as you have got a roof over your head, you are fine. I completely disagree with them. (SU03VIC)

As we noted in Section 3.2.1 above, many participants noted how clinical staff tend to dominate discussions in hospital settings about care planning, referrals and discharge support. As a result, housing and other social care supports are often downplayed in favour of more clinical concerns:

They're generally the people who have the quietest voice at these discussions, your allied health, social workers, peer support workers. They don't have any voice in these discussions [in hospitals about exit planning]. It's all the clinicians who hold sway. Their focus isn't on any of those things [housing and/or social supports]. Their focus is on the medication. On the consumer receiving what they consider to be the most effective treatment. I think things like housing and having that support around that isn't something that is on their radar at all. (SU02VIC)

\subsubsection{Family and social supports}

Unsurprisingly, gaps and shortcomings in service responses to housing problems create additional pressures on families and carers. In addition to experiences of 'carer burnout' there was much discussion of the extent to which familial and extended networks create specific risk factors for individuals either in terms of their mental health and/or substance use experiences, or more general vulnerabilities regarding access to secure housing. These reports are a reminder that for some individuals, their family life involves risks to their mental health and housing status.

We'll call the family member, and the family member will finally have had a break and go, 'I'm putting my foot down. No, you can't come home'. So the client may have entered with security of housing back in the family home, but all of a sudden the family are saying, 'No, this has been really nice. I no longer have to deal with your behaviours. I don't want you'. And then we have housing insecurity immediately upon that point of exit. Sometimes what happens is the family buckles and lets them back in and sometimes what happens is they go out on the street. (SP01VIC) 
In the previous section we noted the habit in treatment settings for individuals to be discharged to their family home with little apparent regard for the suitability of this accommodation, or the capacity of family or other carers to take on what remain quite difficult caring responsibilities:

We've got an absolute crisis of carer burnout at the moment in relation to people with acute mental health concerns bouncing around multiple systems. And because of the service limitations, the first thought when people are discharged from hospital is, who's the immediate next of kin? Great. We've got a place for them. We'll just send them home, regardless of how suitable that might be. (SPO3VIC)

Given experiences of carer burnout, and the significant strain caring responsibilities often engender in families, a number of participants spoke of experiences of loneliness and social isolation and the challenge of managing health and social problems in contexts of extreme housing insecurity. Sometimes family members were regarded as 'part of the problem' as we've noted, but it's also important that we stress how problems of service coordination can have an impact on families, carers and wider social networks that can further inhibit people's recovery:

I have this relationship with my ex where we can talk about stuff together. But obviously, it's very different when you're divorced and separated. But I think that that sense of isolation is something that I feel regularly. You know when you get sick friends tend to drift away. I know that l'm isolated, socially. But l've got family in [regional town] and that counts for something. I've a couple of friends here too that I rely on, but I know that I'm not the easiest person to get along with always (laughs). (SU02VIC)

Other service users spoke of the importance of informal social networks as a kind of 'replacement family', reminding us of the prevalence of family breakdown, conflict and social dislocation for people with experiences of housing insecurity and physical and mental ill-health:

The only thing they've got [homeless people] is they support one another, it's like a family. We congregate around one place like mealtimes and we get 'round and we talk about what's going on, what's happening and that's the only support we got. There's no support out there for people with mental illness. There's a lot of people on the street who's suffering from that. I was one of them, and I was left, no support, no nothing and all the people like that it pushes them into another dimension, another world. So you only have that family on the streets to support you, someone to talk to, about what's happening. But there's so much trouble on the street 'cause the pressure builds up so much and then you explode. Sometimes they say prison's better than the street. (SU05VIC)

\subsection{When it works: effective care, program successes}

Effective coordination of housing, health and social supports can make a significant difference to the lives of vulnerable individuals. While we have canvassed reports of instances where coordination is sub-optimal, it's equally important to stress that we also heard descriptions of instances in which housing, health and social supports were more effectively integrated and coordinated to support individuals source and maintain stable housing. In this respect, effective care coordination is a crucial part of supporting vulnerable individuals to access appropriate, safe and secure housing in order that they might enjoy a safe environment to continue to address their health and social care needs. No matter the particular circumstances that individuals might experience, stable and secure housing is critical. This might seem like an obvious point, but it's worth remembering that:

Housing is everything. Like most of our clients, if they had a house that they could call their own, first of all they might be able to claim some dignity back. Someone would be popping in to make sure they're eating properly and they're maintaining their medication, you know, or seeing their GP regularly. I always say that if I've got housing, then I can get someone back on track. (SP03NSW) 
Again, we have noted participant reports of chronic housing shortages and long wait lists for social housing, but service providers and service users alike also emphasised the critical importance of long-term planning, strong follow up, and the proper integration of housing, health and social supports to help individuals secure and maintain long-term housing. Developing a clear plan, ensuring that all relevant service providers are included in this planning, and then ensuring that all parties are held accountable for their responsibilities, including service users themselves where reasonable-all these elements must be in place to support positive housing outcomes.

Effective coordination starts with the development of a clear, reasonable and achievable plan, grounded in secure access to safe, affordable housing and associated health and social supports. The following discussion of care coordination pertains to circumstances in a particular residential rehabilitation and treatment facility in New South Wales, but the broad principles articulated here were common to most accounts of the 'nuts and bolts' of service coordination work and support:

When they come in [to residential treatment], they have to put together a care plan and the care plan is what you want to do and what your expectations are on how long you want to hang around. We go through that every 30 days. But there's a discharge plan as well and that's where we focus on where people are going, who we can contact, who we can't contact if people decide to leave [early]. So at all times, we try and meet the client, where their energy levels and expectations are so we can get a positive outcome-engagement is the priority. But the care plan is critical for getting everyone on the same page, so everyone knows that the deal is long-term. (SPO3NSW)

Despite widespread criticisms of existing service treatment models and programs, service providers also identified a host of reforms and service improvements that have, in recent years, led to significant improvements in the coordination of mental health, substance use treatment and housing support programs, with significant health, social and housing benefits for clients.

By way of examples, participants acknowledged increases in public funding for key projects, the introduction of new and innovative service delivery models, and improvements in communication and coordination between different elements of the housing and health service systems. In some instances, interviewees identified local, innovative 'pilot' programs or services with uncertain long-term funding, though other participants described more systemic service improvements.

Problems of poor program integration and sub-optimal service coordination have long been identified in the social care sector, and a number of innovative programs have been trialled in New South Wales and Victoria in recent years to address these problems. We will discuss a number of these programs in turn because they clearly indicate that significant improvements in service integration and coordination are possible given clear program objectives, strong community 'buy in', adequate resourcing and ongoing research and evaluation support.

It might indeed be said that we know how to solve problems of service integration and coordination-the programs described below go a long way towards confirming this argument-and so the main problem, typically, is that the lessons of these exemplary programs have not been adopted as enthusiastically, or as widely, as might be needed to address service problems 'at scale'. Many of the lessons of the programs discussed below feature strongly in our broader research findings and policy and program recommendations, so it is worth discussing each program closely here.

The first thing we'd like to emphasis is the critical importance of long-term follow up support for individuals once they have transitioned out of mental health and/or substance use treatments. Most services offer limited follow up support, but very few are able to maintain this support for more than a couple of months. Some services offer flexible casework support for greater periods of time, such as 'day programs' in select AOD treatment services, or where clients transition to peer support groups like Alcoholics Anonymous (AA) or Narcotics Anonymous (NA). Where services are able to maintain this follow up support for months, even years in the case of more vulnerable individuals, there is strong evidence that housing insecurity can be effectively eliminated, and people can be maintained in stable accommodation over the long term. 
The following discussion pertains to residential treatment but the broader principles are relevant to our specific interest in the role of coordinated care:

When they [clients] leave the centre [residential AOD treatment], we follow up [in person] if they're in close range. The first month, we do a lot of catchup with them [to] connect them with services, take them to services. Some of them don't have transport available, so we will take them to those services, link them up and just get them to actually start using the services out there that they need. Then, we gradually step back a bit and let them take more responsibility. But we contact about two to three times a week, initially, face-to-face if they're in the area. If they're not in the area, it will be three times a week, at least a phone call or a text message, then taper down. After six months, we'll follow up and see how they're doing, if they're connecting with services, and just checking up and supporting them through this. Sometimes this goes much longer if needed. (SP04NSW)

Typically, effective follow up requires a 'case-conferencing' approach where the services of multiple agencies are coordinated in an integrated care plan. The following discussion helps to indicate how demanding this work can be, but also how valuable:

I would say what works is [maintaining] really strong partnerships, with a whole heap of different stakeholders. You start with the specialist-like, if they [client] need a drug and alcohol specialist, or a mental health specialist - but you need a team of people that can support [the client] in multiple domains, with swift referrals into appropriate accommodation. For young people with vulnerabilities and mental health or drug and alcohol [issues], having a sense of stability is hugely impactful for their recovery, and a strong supportive team is vital for this. And we've seen some pretty incredible outcomes [for people] when you have this. We've had people return to family, where that's appropriate. We've had plenty of people kind of stabilise in the domains where they may have had challenges going in [to the service]. A lot of people have gotten access to the private rental subsidy, and have since moved into private rental, So, that's hugely beneficial for a lot of young people to kind of find their feet, but they need that wrap-around support to get there. (SP05NSW)

Reiterating many of these same points, we also received numerous reports of established programs in both Victoria and New South Wales that maintain high standards of care and support, that routinely manage complex clients with significant health, social and housing challenges, and that have developed a strong reputation for integrating and coordinating diverse services to support vulnerable individuals. For all the challenges and problems with service provision that we have identified in earlier sections in this report, it is important to note that we also identified a number of exemplary programs and services that routinely achieve great outcomes for clients:

[Service Name] provides quite a fair bit, they've got nurses, they've got peer support workers, housing support workers, obviously, housing support workers are the main ones [for me]. But they also have a lot of drug and alcohol support, and mental health support, which is obviously a huge part of it. So it's all right there for you, right, everything in the one place so it was all such a big help. We were struggling financially. So, they have a food van that goes there every night, so we started to eat more often, it was cheap enough that we could pay the rent there and still have money to do all the other things which allowed us to also pay for pharmacotherapy in the rehab and things like that. So, it was a complete package and we didn't have to go anywhere to get it. Even the ones that weren't offered [there] weren't too far away, so that made a big difference. (SU15VIC)

Larger well resourced services, with a broad staffing mix, are notable for their capacity to respond to the diverse needs of vulnerable individuals 'in house', or out of a single service site, combining mental health support, substance use treatment and/or primary health support along with housing assistance, life skills training and a host of social programs besides. 


\subsection{1 'Golden Ticket' housing programs}

While the broad principles of well coordinated, well integrated housing, health and social supports are clear enough, participants also acknowledged how costly these programs can be, given their significant human resource demands and the direct and indirect program costs required to deliver high quality care to individuals with complex needs. Over recent decades, successive governments in New South Wales and Victoria have supported pilot programs offering different modes of integrated service delivery in either restricted geographical regions, or with strict program eligibility, in an effort to identify the broad mix of program services and supports needed to move the most vulnerable individuals into long-term, stable housing. One service provider memorably referred to these projects as 'golden ticket' programs that offered intensive wrap-around support and long-term follow up for the 'lucky few' who were either eligible for these programs or who happened to live in the right catchment areas. A number of these programs have been widely discussed in the literature (see Miscenko, Vallesi et al. 2017; Vallesi, Flatau et al. 2019), so we concentrate our analysis on key program design and service delivery principles.

For example, the Victorian program J2SI [Journeys to Social Inclusion] confirms the enduring value of "housing first' principles, including the importance of strong health and social supports:

What we're finding with J2SI [Journeys to Social Inclusion], generally the people coming into the program have long histories of homelessness, sleeping rough and so on, and a lot of the times they'll have untreated mental health or substance use issues because they move around a lot. And so people on the J Group, the people that got the intervention, what they talk about, what made a big difference to them was the rapid access to housing. But also it's a three-year intervention, and the caseloads are relatively low; it's one to six, and we work to get people into housing as quickly as possible, community housing or public housing or even private rentals. And then once they're housed we work with them for three years to help them build their skills to manage their tenancy independently, linking them to health services and so on. It's all about social inclusion and trying to make sure people are connected to the community they're living in. (SP01VIC)

Consistent with many of the key principles underpinning the J2SI program_including rapid access to social and/ or supported housing and active case management across multidisciplinary teams of housing support workers, mental health clinicians and peer support staff-the Green Light program (delivered in a service partnership between Sacred Heart Mission, VincentCare and the Salvation Army), offers further insights into effective service partnerships and program coordination to tackle endemic housing problems. The key focus of the Green Light program is getting people into housing and then offering the key health and social supports needed to maintain this housing. This includes a strong focus on social inclusion and social connection to help individuals develop a strong sense of community participation and belonging. A number of participants spoke very highly of this initiative, as the following two interview excerpts indicate:

Through Green Light I've got [name], who is my case manager, then I've got a peer support worker, she's awesome, and I've also got a mental health support worker. So if I start feeling I need to reach out and I need to speak to someone about it they'll get in touch with [name] and she'll come in, and that's all part of Green Light. It's like they say it takes a village to raise a child; it's almost like that mentality really because I know I can ring that office any time and someone will get back to me no matter what it's for. It's on a discussion basis; I'll ring up, they'll ring up, we'll talk about things that I need to get done, talk about how my week's been whatever, how l've been feeling, how's my mental health, how's my home life, go through all the particulars, all the official stuff, if there's any appointments l've got or anything like that. Like with my dental, I'm in the process of getting that done. They've taken me to all of my appointments, they get me there. They're also helping me get my license, help me organise lessons, and if I need to go over to Vic Roads or whatever they'll come and they'll take me. So it's just like having an extra leg I guess. (SU07VIC) 
Well, once we got this place, when I was housed that's when I qualified for the Green Light Support Program. I cannot speak highly enough of them. What they do is they come in to-it's a program that's specifically for people that have been homeless, that have had reoccurring homelessness. What they do is they come in once you're housed and they're your support for two years to help keep you housed. So anything I need to do I'll give my case manager a call and just say, 'I've got to do this, I've got to do this', if I'm confused, if I'm not sure how to go about it she'll show me. I suffer with agoraphobia so l've been having a bit of trouble with that. So they come and take me out-if I need to go somewhere and I'm having too much trouble, they'll come and take me, they're just brilliant. Anything I need to ask - I didn't know how to budget, I didn't know how to get my bills paid, as silly as that sounds, I didn't know the best way to go about it. So having them, it's just been awesome. Look, I have achieved so much in the last, well it's going on 12 months now. (SU67VIC)

Similarly in New South Wales, programs like the Housing and Accommodation Support Initiative (HASI), and Rent Choices were praised by both service users and service providers for their commitment to service integration and coordination across multiple housing, health and social service supports. Key to these programs, as with J2SI and Green Light, is intensive case management and individualised support, tailored to individual's specific needs. In the case of HASI, case management involves up to 20 hours per week of tailored support including life skills, financial literacy and training support, participation in sport, leisure and community activities, and help in accessing appropriate specialist medical, addictions and/or mental health care. While housing support is not guaranteed, priority access to social housing is a strong program focus:

There's a lot of evidence that the HASI [Housing and Accommodation Support Initiative] program [in New South Wales] is very effective and it's not intrusive. And you know, we usually hear people say, '“Yes, well I like seeing my HASI worker'. You know, it's a different kind of relationship once it's been established that this person is actually not there to enforce the medication regime, and that they've got different interests in a way, they trying to fix the housing problem for you. They're trying to help you with work, get back in touch with family, get back into your community. (SU01NSW)

In earlier sections we noted how, for many service users, a return to private rental accommodation is a key housing goal, with most also referring to this achievement as a key marker of their progress or 'recovery' from particular health and social problems. However, we've also noted the struggles that many people face securing private rental accommodation, including difficulties in managing rental applications and relationships with landlords and agents, and cost-of-living pressures setting up a new household such as rent and utility payments. Some programs offer case worker support to assist individuals leaving either mental health care and/or substance use treatment to manage these challenges, such Rent Choice and Rent Choice Youth, offered in New South Wales. These programs involve direct support to access rental properties and then case management support to assist tenants maintain the property and any associated challenges:

[Rent Choice] is a fantastic program, provided people are ready. They [clients] have to kick a lot of goals to get there. And for us it's risky, because if you put someone in, who isn't ready, you burn a lot of bridges, but provided they're ready, we can support them. We work with a lot of the local [real estate] agents to educate them about the scheme, and we've developed good relationships with some because we can case manage [the clients]. So they can ring if there's a problem, oh, so-andso hasn't paid his rent, can you see what's going on? So from that point of view, it's good. It's a good partnership provided they're [clients] ready for the responsibility. (SP07NSW) 


\subsubsection{Peer support}

Debates about the place of peer support and peer leadership roles in both mental health and substance use treatment services are well advanced internationally, with strong evidence indicating the value of these roles in terms of service engagement, 'client satisfaction' with treatment supports, and improved treatment outcomes (see Ibrahim, Thompson et al. 2020 and/or Repper and Carter 2011 for a review). Interestingly, most of the services that assisted the research team with the recruitment of service provider interviews and service user interviews have well established peer programs with various designated peer roles, and both service users and service providers offered key insights into the value of peer support and peer leadership roles in service design and delivery. We hesitate to say too much about peer roles in service workforces because this was not an explicit focus of the study, nor did we set out to 'evaluate' the efficacy or value of these kinds of emerging roles and responsibilities. Even so, our participants offered a number of worthwhile insights into the ways that peers and consumers could be more effectively integrated into the ongoing development of service coordination strategies and approaches.

Arguably, the most significant contribution lies in bringing a strong 'consumer voice' to discussions about service design and delivery, alongside new ideas for reframing and reforming service delivery in specific settings. Lived experiences of homelessness and housing insecurity, and the experience of accessing housing, health and social services, provide unique insights into the 'life-cycle' of service careers, from early intervention and intake through to discharge planning, referrals and follow up care and support. Adding these 'voices' to service design conversations offers opportunities for innovation that cannot be sourced elsewhere. As part of large, well functioning teams, peer voices can add significantly to service improvements, as follows:

I am part of a team, and my story, next to the paid workers and volunteer workers, community members, school people, medical professionals, hospitals, doesn't matter, we can all talk about homelessness. So it's not a taboo subject, we talk about it, we talk about the things that are working, what's not working. We talk about the interactions we have with people and we also work very heavily with government to look at the current service models and why they're not working and where we could put different things in. So, say if we've got access to new money, we can ask the question, 'Are we going to continue with this in the future or is there a better idea?'. We need to build something better. But you know, sometimes I just pinch myself and go, 'Really?' From where I was [living] in the car, to making these significant changes, actually now, I am so glad that I'm not a paid worker anymore, because the passion that I have to do what I do now [as a peer worker] is so much more. The meaning of it, that self-gratification, and the purpose and satisfaction of it al,l is just so much more value than actually being a paid worker. I love it. (SU06VIC)

When discussing the value of peer roles like this, most spoke of the unique understandings of the homelessness system that peers have, and how these can generate important insights for reform:

People are really respectful to hear about your experiences. Because I don't think they hear a lot of it. I'm really quite surprised sometimes by how grateful people are to hear from you, when you are sitting in a room in front of people talking about your experiences. I guess often you're talking about pretty difficult moments of your life, so there's this real sense that it's very real for people. (SU02VIC)

Finally, there was a strong view that peers have a key 'wayfinding' role to play in helping service users, particularly people who are relatively new to services, to negotiate or find their way through what have become increasingly complex housing, health and social care systems in both New South Wales and Victoria. Peers often play these kinds of roles in larger services in each state, helping less experienced service users gain access to appropriate local service supports:

Peer support workers have, generally, been through it, gone there, done that, have struggled themselves, and have a secret database of information, personally, that definitely is a huge help to people. Like l'm constantly sharing what I know with friends or people I bump into. I've spoken to people on the bus before, and somehow it's come up in conversation that they're struggling, they're having a hard time, and I've suggested, 'Why don't you go to such and such a place'. So, it is just the information that I know that can really help others out. (SU15VIC) 


\subsection{Coordinating complex care systems: key policy insights}

For many years, housing, mental health and substance use treatment policy statements in both New South Wales and Victoria have emphasised the need for 'joined-up' or 'wrap-around' service delivery for vulnerable individuals with complex needs (see Brackertz, Davidson et al. 2019; DHHS 2018). Joined-up care is supposed to entail careful integration of diverse housing, health and social services, programs and supports, thereby ensuring adequate coordination of care to support vulnerable individuals to access and maintain secure housing. Despite these strong policy commitments, and in keeping with evidence presented in Chapters 2 and 3 , the findings detailed in this chapter reveal considerable variation in progress towards the realisation of full and effective service coordination across and between housing, health and social services and supports.

Certainly there are a number of agencies in each state that have made considerable progress towards these ends, and we noted key programs like Green Light and J2SI in Victoria, and HASI in New South Wales, which are explicitly guided by principles of service integration, partnership and coordination, resulting in significant improvements to the quality of care available to clients.

At the same time, our analysis also identified significant barriers inhibiting effective integration and coordination of housing, mental health and substance use services across New South Wales and Victoria. The housing, mental health and substance use treatment sectors in each state still resemble complex service silos, with a strong legacy of policy and service demarcation between each silo, which serve to effectively 'ring-fence' key service roles and responsibilities.

A key challenge across the mental health and substance use treatment sectors is that housing problems are still regarded as the proper responsibility of specialised housing services, rather than part of normal service delivery responsibilities that internal staff might be accountable for. Despite widespread commitments to 'housing first' principles in each sector across New South Wales and Victoria, we heard service providers talk again and again of the need to improve access to housing services and support for vulnerable individuals, just as they tended to regard these matters as problems for housing services, rather than problems that ought to be included in care planning responsibilities within mental health and substance use treatment services.

The literature suggests very strongly that housing should be regarded as an integral part of both mental health and substance use treatment (see Tsemberis 2011; Baxter, Tweed et al. 2019; Oades, Deane et al. 2005; and/or Corrigan, Larson et al. 2019 for reviews), rather that treated as a second order matter that might be addressed once a client's mental health and/or substance use disorder has been attended to. At present, housing supports are often relegated to a discrete external service system rather than embedded in the delivery of mental health and substance use treatment services. As we noted at the close of Chapter 3, all too often housing problems are either ignored altogether at admission into mental health and/or substance use treatment, just as they are overlooked in the development of care plans and discharge planning. Housing must be a key plank of care planning and coordination in each service sector if real progress is to be made to reduce the risks of housing insecurity among service users in these specific service systems.

On the basis of analysis presented in this chapter, we identify the following key policy issues:

- Housing and housing/homelessness support needs to be understood as formal components of mental health and substance use treatment, rather that separate policy systems.

- Housing support needs ought to be incorporated into formal admission screening and assessment protocols across all mental health and substance use treatment in each state.

- The key principles underpinning effective service integration are clearly articulated in the literature, and are guiding service innovations in a number of key programs like J2SI, Green Light and HASI. These principles ought to become service standards across housing, mental health and substance use treatment services in New South Wales and Victoria.

- There is scope to increase peer and consumer roles in housing, mental health and substance use treatment services to assist vulnerable individuals to negotiate complex care. 


\section{Infrastructure of care: supporting liveable lives}

- This chapter turns to consider the purposes of care, and the impacts and benefits more effectively coordinated treatment systems might be expected to deliver.

- We suggest that the broad purpose of coordinated care is to help vulnerable individuals achieve more 'liveable lives', a conceptual and practical framing we borrow from debates in ethics and social policy across diverse fields.

- Individuals thrive when they are well supported within strong social, affective and material infrastructures. Coordinated care helps individuals to assemble these infrastructures, as needed, as they recover the means of a 'liveable life'.

- We close with policy recommendations for the coordination of infrastructures of care within diverse housing, mental health and substance use treatment settings.

\subsection{Vulnerability, infrastructures and the support of liveable lives}

\footnotetext{
Section 1.3 introduced the conceptual framework for this study, grounded in the notions of infrastructures, care, vulnerabilities and 'liveable lives'. In developing this approach, our purpose is to clarify how care is defined and conceptualised, how it is constituted in treatment, and what care may be expected to deliver in practice. This approach has guided our analysis of the most effective ways of coordinating care to enhance the housing security of individuals exiting mental health or substance use treatment. Critical to our approach is the contention that care should be understood in terms of specific life goals or outcomes, such that the delivery of care may be construed in terms of a liveable life, that is, subjective experiences of wellbeing, belonging and purpose that ground participation in social, economic and community life (Anderson, Brownlie et al. 2015). When delivered in a coordinated and sustained fashion, care-work in mental health and substance use treatment settings can help vulnerable individuals to recover this liveable life.
} 
Liveable life, in turn, requires various formal and informal infrastructures for its maintenance and support. It depends on nested local infrastructures of care and opportunity, of which mental health care and/or substance use treatment are among the most important for vulnerable individuals experiencing health and housing problems. More broadly, liveable life requires strong social ties, vibrant communities, civil infrastructures, dynamic local labour markets, education and training infrastructures, along with thriving arts and cultural industries and opportunities. All individuals, regardless of social and economic status, require these formal and informal infrastructures to thrive (see Berlant 2016; Taylor 2013), though more vulnerable individuals tend to experience systemic barriers and disadvantages accessing such infrastructures in their local communities.

While we appreciate that mental health systems and substance use treatment facilities are not designed to address these broader infrastructural demands, as we demonstrate across this chapter, there is still a significant role for these systems to play in crafting the more intimate social, affective and material infrastructures that sustain a liveable life for vulnerable individuals. Indeed, the notion of infrastructure provides a compelling conceptual framework for thinking about the diversity of formal and informal supports, services and networks necessary to sustain liveable lives for individuals experiencing housing insecurity. Broadly speaking, essential infrastructures include health and human services, transport systems, labour market supports including education and training programs, communication networks, police and law enforcement, and banking and finance (Wilson 2016). Yet these essential infrastructures also include a host of informal social, familial, community and peer networks that are sometimes referred to by way of 'social capital', or in terms of the informal character of everyday social life (Anderson, Brownlie et al. 2015). It is these latter aspects of infrastructural support that institutional modes of care and support can sustain. Taken together then, liveable life and the forms of social inclusion and community participation that sustain it, are supported within a matrix of interlocking formal and informal infrastructures that guarantee the essential requirements of life (Star 1999; Amin 2014).

The notion of infrastructure is analytically useful precisely because it directs attention to the social, affective and material supports needed for people who have experienced residential treatment to live life well. Life is made more liveable according to the social, affective and material infrastructures that sustain it, that is, both formal and informal systems and networks. Treatment can then be understood as an effort to repair these infrastructures in order to render life more liveable (Anderson, Brownlie et al. 2015). Recent conceptual discussions of infrastructures across the social sciences illuminate the different scales of analysis required to understand the range of infrastructures necessary to support and sustain experience of a liveable life, from the social and intimate textures of everyday life, to the broader structural forces that shape individual lifecourses, and the opportunities that characterise them. This conceptual approach allows for analysis that can accommodate the intimate infrastructural contours of personal life (Wilson 2016) through to the variety of community level factors and conditions that shape vulnerabilities and life opportunities, and on up to broader structural conditions (see Amin 2014; Power and Mee 2020).

For the purposes of this chapter, we draw from this literature to concentrate on the more local and intimate aspects of these infrastructures, because this is where the delivery of properly coordinated care can have the greatest impact on the experience of a liveable life for vulnerable individuals experiencing varying degrees of housing insecurity (Power and Mee, 2020). This is also the level that most closely reflects the kinds of care delivered across mental health and substance use treatment settings. It also captures the kinds of service innovations that more effective care coordination across these sectors may deliver (see Anderson, Brownlie et al. 2015).

Before we assess the specific infrastructures of care identified in our data, it is important that we say a bit more about the specific instances of care, treatment and support captured in these reports. Care was an ubiquitous topic of discussion throughout our interviews, even though this term was used quite differently by different participants as they sought to articulate what care means, how care is delivered in service settings, and how care might contribute to the experience of a more liveable life. We dwell on these matters because it is critical that we understand what care is, how it is delivered and how it is framed and experienced, before we consider how care might be more effectively enhanced for vulnerable individuals leaving services. 
As importantly, we need to understand what the delivery of care is ideally designed to achieve. What are the goals of care and how do we know if it is being effectively delivered or not? The previous two chapters have had a lot to say about the everyday work of delivering treatment to individuals in mental health and substance use treatment settings, now we want to focus on experiences of care and how care might be more effectively coordinated in these settings. We wish to stress the ways that effective care helps individuals to realise a more liveable life by way of the material, social and affective infrastructures necessary to sustain it.

\subsection{What are the goals of care? On the support of liveable lives}

The last few months now with the dogs I'm getting out more. I'm settling in [to the area]. I'm talking more with the locals, like the lady across the road, there's a little boy across the road that comes out and he's always looking for the dogs like when we do our afternoon walk he'll come over and say hello. I've got the lady next door that comes in once a week with a plate of chocolate chip muffins. So we're starting to find, like I said it's not just a house, it's a home, and I'm finding that I feel, not only do I feel in my own personal journey but like I'm not a strain on the system like I was, I feel like, not that I'm giving back, but I feel like I'm not in trouble with the law and stuff like that. So I'm not a strain on taxpayers if that makes sense, like l'm living in my community more. (SU07VIC)

Here we find a cogent description of what we mean by a liveable life. Walking the dogs, getting to know one's neighbours, developing local ties; these are the everyday constituents of liveable life. Yet we also find in this account references to some of the infrastructural conditions necessary to sustain this life, particularly for people with histories of social disadvantage. For individuals with these kinds of experiences - 'trouble with the law', experiences of mental illness, periods of substance misuse, instances of homelessness and housing insecurityliving life well, in a supportive, secure community, requires specific networks of formal and informal infrastructural support. This vision of a liveable life, which almost all service providers and service users we spoke to endorsed in one way or another, is typically described as the objective goal of care.

For vulnerable individuals leaving mental health or substance use treatment, settling into secure accommodation, getting a dog, becoming friendly with the neighbours, feeling as if one belongs, all serve as explicit goals of care. These are the outcomes that services users and providers alike are striving to achieve. Yet how is care coordinated in such a way as to help individuals realise these goals? The following quotation begins to answer this question by revealing some of the formal and informal infrastructures required to sustain a liveable life within a vibrant community:

My partner and I really love the area. It's full of restaurants, fruit and vegetable stores, a few supermarkets. It's a very nice area. And we do try to go out there when we can. And it has been really good for us because, aside from the access to all the things that we need, one of the things I wanted to do was get more involved in the community. The library, for example, is something I was really interested in because they had a lot of social programs. I did participate in a few and they were very nice. It makes me feel good to know there are things here for people who need it. (SU18VIC)

This quotation (and the previous one) reveal the long-term goals of care, the things that participants most want for their lives, amid the varied social, affective and material supports required to achieve these goals. Yet, if the long-term goals of care are clear enough-even if they sometimes remain vague, a point we will return to shortly -the means of achieving these goals are of course much more complicated. As we noted in the previous chapter, we discovered a significant gap in participant reports between how care coordination and service integration are supposed to function, and how these processes often work in practice. To help flesh this point out, let's carefully consider the following account of effective care:

At the time I wasn't aware that I had such a superstar support worker and it's only my long-term involvement [in services] that I understand now that I was one of the lucky ones. There's a recipe that makes it work. For me a big part of it was all the paperwork, so [my worker] determined that it was time to put away the lengthy forms that we have to fill out and just start having conversations 
with us. So, I'm sure that she had to go and fill out paperwork when she finished talking to us, but she was able to, over a period of three to four interviews I guess, gather the information she needed for our case file notes, but in that time, all she focussed on was where we were successful, all by ourselves and where we were unable to solve the problem. So then she started to make referrals to a whole range of organisations that would then help us. She had youth workers come and take [my daughter] to the supermarket, or take her and get credit for her phone, take her out and about. Whether it was looking at schools and taking her to school interviews, whether it was finding guitar lessons for her and giving her a myki card so she could travel because the guitar lessons were in [suburb], but they made it so she could independently continue on doing those activities without my involvement, physically. She was always thinking two steps ahead. (SU06VIC)

This participant is offering an account of what in her view is exceptional care. Certainly she regarded this support as unusually effective. It is an example, then, of the effective delivery of care in support of the realisation of more liveable lives, for both mother and daughter. Yet this support work, which surely only accords with what case managers are supposed to do in support of vulnerable clients, is treated as the exemplary work of a 'superstar support worker'. How did the receipt of good or effective care become the exception rather than the norm? How did effective care become the preserve of 'superstar' workers rather than the standard all staff are required to adhere to? This indeed is a further instance of the 'paradox of care' much observed in the literature (see Puig de al Bellacasa 2017; Power and Mees 2020), in which care is celebrated as an innately good thing, even though care only sometimes achieves its stated goals.

In other words, we need a clearer understanding of 'good care' and 'effective care work' in order to pinpoint more directly which particular kinds of supports actually help individuals to make effective transitions out of mental health and/or substance use treatment into stable accommodation, and the wider realisation of a more liveable life. We'll consider one further account of 'exceptional care' to develop this point about the uncertain status of care:

Anything I need help with, she's [case worker] on to it, working out the referral. So far, like I wanted to lose some weight, so she's referred me to an exercise physiologist. It's individualised, and it's made to suit me. In our case management sessions, we do goal setting and each month that gets reviewed and we see how much progress I've made on each goal and what actions I've done. (SU12NSW)

Again, the care described here accords with relevant policy statements and care directives, and the 'client-centred' model of casework, which suggest that these kinds of practices ought to be the norm for all care recipients. Yet, as we have observed, not all care work actually achieves care as a realised outcome, and so not all care achieves more liveable lives for care recipients (see Power and Mees 2020). Simply caring for someone is not the same thing as helping them, as generations of scholars have observed (see Puig de la Ballacasa 2017; Tronto 1993). We would argue that care-work in the mental health and substance use treatment sectors often fails to help individuals realise a more liveable life precisely because the goals of mental health and/or substance use care are so vague and uncertain (see also Dennis 2019; Vitellone 2017).

Indeed, much of the everyday work of care may be construed in terms of service activity -filling out paperwork, organising appointments, making referrals, interviewing service users-rather than in explicit reference to an explicit outcome or goal. This kind of service work is important, it's just that bureaucratic process often takes the place of detailed care planning and follow up.

It is important to stress that service providers themselves commented on the challenges of increasingly complex bureaucratic reporting processes, how time consuming these processes can be, and the sense that recurrent policy changes and adaptations have only increased these workload pressures. Service activity here becomes a kind of 'through-put'. As new service users come into the system, they are offered assistance before they are moved on to the next part of the service system. A referral is made, case notes are recorded, the next appointment begins. 
Again, we don't wish to denigrate the difficult work of care coordination; rather we are trying to make sense of our qualitative data that paints a mixed picture of the efficacy of care coordination in mental health and substance use treatment sectors. What seems to be the expected standard of care-effective support and the realisation of significant improvements in the subjective wellbeing of clients in care-often seems to be the exception not the rule. Why is this the case?

The reason for this may be traced back to the fragmented and disconnected state of mental health, housing and substance use care systems across New South Wales and Victoria. In a sense, support workers don't always see 'the big picture'-the long-term goals of care and how these goals might systematically be achieved-and so staff remain concerned with their particular responsibilities at a given point in time, with their small piece of work before the client might be referred on to another service or another staff member for help. Once again we must stress how service providers themselves often acknowledged this problem, though they typically attributed it to ongoing policy and service design reforms, which have only made service systems more fragmented over time. The effects of these changes have sometimes served to organise care-work as 'through-put', as clients are referred to a support worker, who tries their best to make a difference, before the client is lost to care, moves away, or is referred on to another agency.

Care in this context becomes divorced from the longer term goals of treatment, and the realisation of a more liveable life. What is often missing from care-work is a clear understanding of how each 'episode of care' contributes to this bigger picture, how each service interaction might help to lead care recipients closer to their longer term goals. As a result, the risk is that these longer term goals are forgotten in favour of more immediate concerns, like a referral into transitional accommodation, or to a psychologist or a GP for someone exiting mental health care, or substance use treatment.

What is needed is a clearer conceptual and programmatic framework for understanding how each particular 'episode of care', or how each care relationship, case referral, or case coordination task, contributes to the broader realisation of a client's particular care goals. Rather than treat these individual events in transactional ways, as 'throughput' in a system of care-a model is needed to synthesise and integrate instances of care, along with their outcomes and benefits.

This is where we find such utility in the model of care infrastructures outlined in Section 1.3, and briefly referred to above. In our view, effective care, and hence effective instances of care work, contribute to the repair, restoration or recovery of particular formal and informal infrastructures of care. These infrastructures have three key elements-material, social and affective - that we will explore in each of the following three sections in turn. We will close with some brief reflections on the key policy and practice implications of framing care work and coordination in these terms.

\subsection{Housing as material infrastructure}

We have argued that a 'liveable life'-which might serve as the objective goal of care and its delivery and coordination across mental health and substance use treatment-requires distinctive formal and informal infrastructural supports. This is to regard care as the work of restoring or repairing infrastructures in order to ensure that vulnerable individuals have the supports they need to enjoy a more liveable life. We would argue further that there are three key infrastructural forms that are essential to this care and support: material, social and affective infrastructures. Understanding these infrastructures and how they support a liveable life has two central advantages in our view. First, it helps to clarify the goals of care, and care coordination, and it helps to clarify what effective care looks like, and how it helps individuals. Second, thinking about care in terms of infrastructures helps to draw together all the formal and informal care relations that are needed for vulnerable individuals in treatment to recover a form of liveable life. 
Even though service providers invest significant amounts of time in managing and supporting the more informal aspects of care, these informal care relations (see Section 1.4) are often overlooked in formal case management protocols and guidelines. In focussing on infrastructures of care our goal is to highlight the importance of informal care relations, and how critical they are to the experience of a more liveable life. We also hope to highlight how central informal care relations are to the work of case management, and thus to ensure that such relations are appropriately acknowledged and valued in the work of delivering and coordinating care. All too often, informal care supports were described by both service users and service providers as things that lay beyond the scope of formal position descriptions, key roles and tasks, as something that service providers did of their own volition, mainly outside of the formal requirements of their role. In emphasising the importance of infrastructural support we hope to elevate the importance of both formal and informal relations of care and support across social, affective and material domains of practice and support. Of course the material infrastructure of home is central to any enduring experience of a liveable life and so we will start with the materialities of housing:

When you're homeless, like you sleep in refuges, you stay on the streets and you find squats and that, or you're going through housing and they're putting you in a motel room for one night here or two nights there, you get into the pattern of waking up at a certain time and you're up, you're out, boom, you're gone. So when we finally moved in here and signed the lease, I think it was just that automatic thought that I have to go. So I found it really hard to settle in, to go into the rooms and pack our clothes away and stuff like that. When we first moved in, we slept in the lounge room, our clothes were in a box in the corner and the TV was on milk crates. Honestly, it looked like a squat. I think what slowly started helping it was we started accumulating furniture and it started looking like a house, like I started using all the rooms. Like l'd come in from shopping or something like that, and l'd go into my bedroom and put my jacket away, rather than just throwing it on the back of the couch or something. So I started consciously making an effort to settle in and I even said to [flatmate] one night, 'We need to start using the house because it's not healthy, like l'm not sleeping on the couch tonight, I'm actually going to go to bed'. What you have to remember is that people like us that have had reoccurring homelessness and that have been in and out of jail and that have been on drugs, there's no real understanding that we need guidance through some of the more mundane things in life, the everyday things that normal people do without even thinking about because it's just a regular thing, whereas we have to sit there and we've got to think what do we do now? We have to learn all these things, and that's where Green Light's been awesome for us, like we're finally getting the support we need to fit in with a more normal life. (SU09VIC)

This lengthy discussion provides a powerful illustration of how central material infrastructures are to the realisation of a more liveable life but equally, how central both formal and informal modes of care and support are to the maintenance of these infrastructures. Much of the material infrastructure of home is referenced here-a formal lease agreement, furniture, couches, clothes and personal effects-but these formal elements are clearly not enough on their own for individuals with extensive histories of insecure housing to secure a more liveable life. Informal infrastructures are critical too; learning how to live in a home, how to settle in, how to care for a home, how to make oneself at home. All these things must be learned, and these informal elements, these informal practices of care are precisely what has made a program like Green Light (see Section 4.4.1 above) so successful, and so effective for this particular individual.

We recognise that informal supports have been a central part of program design and delivery for many years across many different modes of social care and support. What are often called 'life skills' and the training designed to help vulnerable individuals acquire these skills are good examples, although they are often devalued in our view in favour of some of the more substantive, formal aspects of housing support, care and treatment in both the mental health and substance use treatment sectors (see Botvin and Griffin 2004; Gray, Shaffer et al. 2016). Despite this neglect, the realisation of a more liveable life requires both the formal material infrastructure of secure housing, alongside the informal material infrastructures realised in the myriad everyday objects, artefacts, practices and relations by which a house is lived in as a home. 
The material infrastructure of the house becomes a home as the jacket migrates from the back of the couch and onto a coat hanger in a closet in another room; it happens as the TV moves onto a side table and off the milkcrates; it happens as the sleeping body moves from the couch to the bedroom. The elements of a more liveable life may be discerned in these movements. In these respects, a liveable life requires both the formal provision of housing as a distinctive material infrastructure, along with the myriad material objects that furnish a house and its functional liveability. Yet, for many individuals, the realisation of this goal also requires modes of informal infrastructural support as they slowly acquire the capacity to make a home. The role of these formal and informal material supports can be further discerned in the following participant account:

So we finally got a place, but we had nothing in it, it was just a shell, right. The gas was on and the electricity was on, and we had running water, but as far as furniture and stuff, there was nothing. My mum doesn't live far so she gave us a few things, and my auntie lives local as well so she gave a few things too. Then three or four weeks after we moved in there was hard rubbish, and my housemate's a bit of a junkman so we ended up with two couches. Still though not enough right? So then my case manager at Green Light, she got some funding through Salvation Army and we went to the furniture store in Richmond, we picked what we could and they paid for it. (SU07VIC)

Here again we see indications of the processes, practices and supports by which the material infrastructure of home is made, and the ways these infrastructures support a liveable life. The house commences as a shell, the bare limit of material support, and so it must be made into a means of supporting a liveable life as it is crafted into a home, as objects are gathered from friends and family, even found in the street, or through program support to acquire furnishings. Of course, the informal infrastructural supports necessary to maintain a home also extend to include the everyday life skills necessary to manage a home, to manage living with other people, as the following excerpt indicates. It also further highlights the critical importance of like skills at home:

Obviously, there is a need for more public housing, but I did find that, when I was leaving rehab, I was using that flatmates.com, there are so many rooms available all across the place, in private homes and things like that, that never come into my discussions at rehab. Looking on my own, the sheer amount of rooms that were available were almost overwhelming. It was tricky because you're navigating different people and what they actually want and what not. But if people are encouraged and equipped with the ability to engage with different people and go and meet a few people, a lot of the time they can come to an arrangement with somebody they get along with, not just these crisis put together share houses. But a lot of people don't have the skills to be able to go and discuss it with private landlords and people who are looking to sublet. I think that's where the peer support can come in. If you've got a peer support worker who's got a bit more confidence, who's happy to just help out, you'd get more people into individual housing. (SU15VIC)

For some people, the material infrastructure of housing is not enough to support forms of liveable life. What is also needed is a kind of social infrastructure by which vulnerable individuals may learn how to manage relationships, to cultivate and sustain social networks, and to manage social ties within a web of relations of trust and reciprocity. A liveable life requires the material infrastructure of home just as it requires a social infrastructure of community, our next topic. 


\title{
5.4 Community as social infrastructure
}

Much of the work of care in mental health and substance use treatment settings involves restoring or repairing an individual's broad familial, peer and social networks (see Rose, 2019 for a review). Caring for individuals living with mental health and/or substance use problems involves this work of assisting individuals to manage their social and family relationships in more effective ways; for example, in ways that help to avoid conflict or to help individuals reconcile with family members after a period of estrangement. This is another example of what we mean when we argue that, ideally, the work of care in therapeutic settings helps individuals to live a more liveable life by helping them to restore aspects of the material, social or affective infrastructures necessary to sustain this 'good life'. In this section, we will emphasise the work of restoring social infrastructures, and how this work supports vulnerable individuals to realise a more liveable life. The following quotation provides a powerful illustration of the therapeutic value of these social infrastructures and how the work of care may help individuals to repair them:

\begin{abstract}
NA [Narcotics Anonymous] without a doubt has saved my life along with WHOS [We Help Ourselves], along with that stable place of residence and the fellowship of men and women in that program have saved my life. They've shown me how to live, they've loved me back to life. They've given me a place of belonging because when I go to meetings, I hear people share and they share their experience, strength and hope honestly with me, and everybody else in the room, and I identify with that. I relate to that stuff and I go 'wow, that's how I think or that's what I used to do or that's what I do or say And I just feel part of a community now, like my whole life I've never felt that. I've always felt different from everyone and l've always felt so unsafe and never known where to go or who to turn to. And I found that in NA now I have finally found my place and that belonging in this wonderful fellowship of men and women, like my friends now, who help me every day. (SU24NSW)
\end{abstract}

This discussion also highlights how the work of treatment, in this case shared between the fellowship model of Narcotics Anonymous and the WHOS (We Help Ourselves Fellowship) therapeutic community model, treats individual's social networks as a potential source of therapeutic value. Much discussion of treatment strategies in the substance use sector emphasises the potentially conflicting role of social networks in treatment, which may either support an individual's treatment goals or hinder them, particularly in instances where substance use is common within the peer group (see Goehl, Nunes et al. 1993; Linton, Haley et al. 2017).

Social networks, in other words, may support an individual's treatment goals just as they may hinder them, and because of this dynamic much substance use treatment addresses social, family and peer relationships as a central part of care. Commonly, treatment involves helping individuals to identify relationships, or aspects of relationships, that may help them to realise their treatment goals, and how to nurture and extend these relationships, while also helping individuals to identify relationships that may have a more detrimental impact on their treatment goals. In either case, it is reasonable to talk about the care delivered in substance use treatment programs in terms of the work of restoring or repairing social infrastructures in support of a more liveable life.

The following quotation provides an especially rich account of the work of restoring social infrastructures in support of a more liveable life, and how the care-work of treatment aids this goal:

The way the program at [service] is designed, everything they do, everything they teach you, all the support and everything, it all pushes you to achieve what you want to achieve, like really good friendships. Like, really trusting friendships, loving friendships at the end of it. That for me is the goal of treatment. And also, that self-confidence and all that. They're the best things. I have a friend there now that, I tell him I love them, almost on a daily basis. That's pretty special because you've got that. I've got friends who will tell me when I'm being a dickhead. If you've got that it's pretty special. I haven't had something like that my whole life. And they teach you how to do that, how to have friends like that. I think that's the best thing l've got out of it, treatment l'd say. (SU1OVIC) 
Here then is an instance of the work of care in support of the restoration of social infrastructures essential to the realisation of a liveable life. As this participant notes, he has never experienced this kind of social infrastructure (friendship and peer support) before, and so the work of treatment involved for him, at least, learning how to cultivate and sustain friendships like this, 'loving friendships'. What's more, he regards these achievements as the 'goal of treatment', and the 'best thing' he has experienced as a result of his time in treatment. It is equally important to stress how this participant attributed his improved confidence in his capacity to develop and maintain closer social relationships to the things he learned in treatment as part of the particular program he undertook. This is the work of care oriented towards the repair of social infrastructures in the service of a liveable life. The following quotation provides further indications of the benefits that individuals derive from the work of repairing social infrastructures, and the value of maintaining friendships, in this case at work. This passage indicates how care facilitates a more liveable life:

\begin{abstract}
This guy that I used to work with before I went into the house, he actually knew that I was a heroin addict while I was working for him. And I said, 'I'm really struggling and I'm going into rehab'. And he said, 'give me a call when you're ready' and so I did. And the day after [I left treatment] I called him and he said, 'can you start next week?'. That's made a huge difference to me. Like, now I have to leave work early sometimes, so I can just say to him, look this is going down, they need me in the house. And like I learned in treatment so much about honesty, about talking to your friends, about not closing down you know, just talking about your situation, so that's really helped, like I feel I can talk to him [boss] now you know, without so much bullshit. So now, he's really aware and really supportive, so that makes a huge difference to someone in my situation. So, we've been working really hard at that [maintaining a dialogue at work] and it's really helping me. (SU1OVIC)
\end{abstract}

Learning how to be honest, opening up to others; this is the work of treatment, the work of care, translated into the restoration of a social infrastructure by which this respondent has been able to secure and maintain paid work. He explicitly attributes his success at maintaining this job to the relational skills he developed in treatment that have allowed him to maintain an honest dialogue with his employer about his needs at work, such that he can maintain his obligations at work while also maintaining contact with his therapeutic community in 'the house'. Ultimately though, the capacity to forge and maintain these kinds of relationships, and the wider social infrastructures they support, depends on a deeper set of personal skills and attributes by which individuals may come to understand themselves and their habits and dispositions more explicitly. Among individuals with experiences of mental health care or substance use treatment, this affective work of understanding oneself was often highlighted in discussions of the most significant aspects of care. This is the work of developing an affective infrastructure to sustain a more liveable life.

\title{
5.5 Home as affective infrastructure
}

We will call these affective infrastructures mainly because they concern one's affective states, moods, feelings, dispositions and emotional temperaments, and the life skills that one requires to manage these affective states. Treatment for either mental health and/or substance use problems was reported by both service providers and service users alike to involve explicit work on one's affective states, feelings and temperament in the service, for example, of deeper self-awareness.

This is to be reminded of the fact that liveable life typically requires an explicit understanding of oneself, one's identity, habits, inclinations and idiosyncrasies, in order that one may come to manage the challenges of maintaining a liveable life in the face of problems like mental illness or substance misuse. Indeed, much of the work of care may be said to involve a kind of 'care of the self' in which individuals in treatment slowly acquire new capacities to look after themselves, to understand themselves and their habits and inclinations, in order that they may be more equipped once they have left care to manage life differently. 
Perhaps the strongest example of this affective work-of the work individuals undertake as they come to care for themselves differently - is what was routinely referred to in terms of 'emotion regulation'. This was referred to by individuals with experience of mental health care, and among participants with experience of residential substance use treatment, with each group talking about the value of understanding their own emotional qualities, habits, propensities and 'triggers'.

Learning how to manage one's emotions was subsequently regarded as an essential life skill, part of a specific affective infrastructure necessary for the enjoyment of a liveable life, as the following quotation begins to illustrate:

I mean, come on, we're girls in our early 20s, we were fighting constantly. Especially with the factors like being unemployed and broke and all that kind of stuff, there was a lot of tension. So that's [managing interpersonal conflict] where I got the most help. Like from my social worker, the last one I spoke to was definitely the most helpful because my problem was I just didn't have the ability to regulate my emotions. And I would just fly off the handle constantly. So she helped sort of get me to calm down and obviously not be so highly strung. She got me to recognise how l'm reacting and how I'm responding to things and how that can cause a lot of problems. So she made me self-aware basically. She gave me a sense of self-awareness I didn't otherwise have. (SU19NSW)

Interpersonal conflict is here, at least, partially attributable to one's (former) inability to identify and manage one's feelings and emotional reactions. Being 'highly strung', with a tendency to 'fly off the handle' are thus positioned as both potential causes of one's interpersonal difficulties, but also as particular habits or dispositions that can be altered or corrected with the right kinds of care and support. Learning how to manage one's emotions differently and so acquire a deeper 'self-awareness' to help develop closer personal relationships with less tension or conflict can thus be regarded as key examples of the affective infrastructures central to a more liveable life.

Self-awareness and a capacity to identify and manage one's emotions thus stand out in our data as key instances of the affective infrastructures that care-work in either mental health or substance use treatment can help individuals to cultivate. Perhaps a liveable life starts with a more positive relationship to one's self, with a deeper understanding of one's self, and one's habits, thoughts and emotional inclinations. This again is why we regard affective infrastructures to be so central to the goals of care-work as the following attests:

What did it for me was all the work on regulating your emotions, and that's something I wasn't aware of, but it gave me a lot of answers about myself. Once I understood what regulating your emotions was all about, I was able to start implementing that in my everyday interactions. This was really important for me, I mean after all this training, I now have a pretty good understanding of myself, and also a broader understanding of why I turned to substance abuse in the first place. So the support has been great, just the growth, basically, from week to week it's just amazing. (SU17VIC)

Coming to understand oneself, and one's particular emotional habits and tendencies, introduces the possibility of modifying some of these patterns in the service of cultivating stronger personal relationships, a more contented sense of self, and a better understanding, as this participant notes, of some of the reasons, situations or events that might have led to substance misuse in the past. Many participants spoke of the value of this kind of 'training' and how they were attempting to apply lessons derived from this training to other parts of their lives, as follows:

The main thing is it [therapy] teaches you to be honest and real within your friendships. And being able to challenge your friends too. Like the whole thing is about being honest and honour your feelings, which is very difficult for a lot of people that come in here [rehab centre]. So, they really teach us to do that and just to talk about and to be able to feel safe in talking about what you're feeling and what you've gone through. And so, over time we develop this trust within your peer group and it's quite a high level of trust. And the only way that will work is if you're really honest and how much work you want to put into it. I guess the more honest you are with your friends, the more they can trust you. And hopefully by then you can celebrate those really close relationships. (SU1OVIC) 
Another interesting aspect of care, noted by many, was the kind of 'identity work' involved in overcoming a history of mental illness and/or substance misuse. Many participants acknowledged the stigma that affects individuals who are identified with particular 'health problems', with much of the work of care entailing often painful attempts to overcome this stigma, to confront one's past, and to cultivate a new personal identity. Working on oneself, coming to understand one's history in new ways, constitutes a novel affective infrastructure for a novel, more liveable life:

I think the best thing [about treatment] was just like making me feel like I wasn't a freak, or that certain behaviours were normal if you're struggling as a teenager or as a young person, or as an adult. It's so easy after a while to think that some things you do or some traits about you are your mental illness; they are part of your trauma. So in therapy, talking to others, opening up and putting themselves at risk, but I think normalising our experiences right? To normalise yourself in the eyes of society was really helpful. It makes you feel like you're not so alone, and there are other people out there that have felt the way you felt before. You realise you can change right? (SU16VIC)

Of course, much of the work of care involves the work one must do to recover some semblance of hope for the future, to overcome trauma, homelessness, abuse and neglect, in order to recover the drive to work on one's health and wellbeing now and into the future. Another essential aspect, then, of the development of the affective infrastructures upon which a liveable life partially depends involves the cultivation of hope, passion, creativity and inspiration. Care work, effective care, helps individuals to re-establish hope for the future, and the means of working on this future:

I think [with services] there is just so much focus on the negatives. I mean you're constantly just telling all the negative parts of your life, especially if you're asking for help. You have to spill all this stuff out, and there isn't a moment where it's like, okay, what about a time in your life when you have been happy? You know, when you felt comfortable, content or interested in something, or passionate about something. That gets put aside. So I think that really helped, having [staff] just be more interested in my wellbeing, because sometimes you lose all passion, I find, a lot of the time in homelessness. It's just really hard to feel passionate or creative about things after so long. It's a long process, discovering what you enjoy, trying to feel more hopeful about the future. (SU21VIC)

As this participant attests, without a means of feeling hopeful about the future, without a clear understanding of the things that help individuals feel contented, comfortable, happy, it's almost impossible to live any kind of meaningful life. In these respects, affective infrastructures are essential for the enjoyment of a more liveable life. Care work, then, often entails specific activities, practices and techniques by which individuals might come to cultivate the personal affective infrastructures necessary to enjoy a more liveable life. Whether this is the work of 'emotion regulation', honesty and integrity, 'self-awareness', being “real with your friendships", all of these affective infrastructures are critical to the maintenance of secure housing, because security in any meaningful sense is fundamentally impossible without these life skills.

In other words, resolving an individual's experience of housing insecurity requires more than the formal provision of housing support (as indispensable as access to stable housing is), because the informal life skills necessary to maintain a living situation are just as critical. Learning how to make a home, how to get along with others, how to manage interpersonal conflict, how to establish good working relationships with landlords/real estate agents, bosses and colleagues, all of the skills so essential for the maintenance of secure housing are founded in the affective infrastructures by which individuals come to know themselves, their feelings and their hopes.

\subsection{Coordinating the infrastructures of liveable life}

We would argue that the work of helping individuals living with mental health and/or substance use problems overcome experiences of housing insecurity, including histories of homelessness, is best understood in terms of the work of repairing the infrastructures essential to a liveable life. 
If the goal of mental health care and/or substance use treatment is the restoration of a liveable life, then this goal may only be achieved by helping individuals rebuild the material, social and affective infrastructures necessary for the realisation of such a life. The goals of treatment, in both the mental health and substance use treatment sectors, are often couched loosely in terms of 'recovery', health or wellbeing (see Duff 2016; Best and Lubman 2012). While 'recovery paradigms' have greatly transformed treatment protocols in each sector, they rarely say much about how individual episodes of care-particular care relations-may actually contribute to the health and wellbeing of individual care recipients. If housing, mental health and substance use treatment programs are to be more effectively coordinated, such that the housing challenges that some individuals experience in these sectors may be more effectively addressed, then we need a novel conceptual framework for understanding how care relations, practices and approaches in and between these disparate sectors may be integrated. We would argue that the notion of 'infrastructure' provides the means of this conceptual and programmatic synthesis.

Service coordination sounds like a fine idea in principle until it is appreciated just how complex care systems have become in both the mental health and substance use treatment sectors. In this environment, service integration and coordination is mainly a problem of ensuring that these disparate systems might discover common points of articulation. The notion of infrastructures helps to provide this common language by emphasising what it is that the mental health and substance use treatment sectors have in common. In providing care to vulnerable individuals, each sector furnishes formal and informal resources by which the social, material and affective infrastructures necessary for the enjoyment of a more liveable life are realised. An emphasis on the role of informal modes of care and support is especially critical, given how central these social, affective and material relations are to experiences of housing security.

In making this point, we are not trying to undermine the importance of secure housing, far from it. Naturally, access to stable, secure housing is fundamental for people living with mental health and/or substance use problems, with a history of housing insecurity. Yet, as our data consistently indicates, formal housing support must be aligned with a range of informal supports by which vulnerable individuals can better manage their housing, including improved relationships with family and flatmates, landlords and estate agents. In this respect, self-awareness and a capacity to maintain stable interpersonal relationships are the critical complements to 'housing first' strategies, in that these life-skills are just as important as access to safe housing in ensuring that individuals are able to maintain a secure home over long periods of time.

We think these aspects of care ought to be emphasised in thinking about the most effective ways of integrating housing care and support across the mental health and substance use treatment sectors. We would offer the following policy and practice recommendations on the basis of the finding presented in this chapter:

- Improved coordination of care across and between the mental health, housing and substance use treatment sectors depends on a more explicit understanding of the goals of care, and more sophisticated conceptual frameworks for understanding the coordination of care.

- Care-work needs to be reconceptualised in terms of the realisation of a 'liveable life' for vulnerable individuals coping with mental health and/or substance use problems.

- In the absence of a clear, coordinated recovery plan, there is a risk that care-work becomes understood as 'through-put' whereby bureaucratic processes are adhered to with limited evidence of improvement in the health, social and material circumstances of care recipients.

- The goals of care are often vague or unclear, in which case care planning is spasmodic; after-care arrangements are unclear and follow up care is substandard as a result. 


\section{Towards more effective models of care coordination}

This chapter brings together the broad research findings to discuss policy development options and service reform recommendations. Our goal is to describe options for improving the integration and coordination of social care service delivery to enhance housing, health and social outcomes for individuals exiting mental health inpatient settings and/or residential substance use treatment.

Our findings highlight the need for new formalised service integration strategies aimed at improving referral pathways and related care coordination and case conferencing arrangements, while ensuring that barriers inhibiting service coordination continue to be addressed and overcome. Of course, any meaningful strategy for improving care coordination between services must endorse an increase in the provision of safe, affordable and secure housing.

As we have demonstrated throughout this report, safe, affordable and secure housing is a fundamental condition of health, wellbeing, social inclusion and community participation-what we have called 'liveable life' across this report-for individuals exiting institutional settings such as mental health inpatient care and/or substance use treatment (Batterham 2019a; Chamberlain, Johnson et al. 2014). National and international housing research and policy debates routinely note how individuals exiting institutional spaces experience elevated risks of housing insecurity in the weeks, months and years following discharge (see Brackertz, Borrowman et al. 2020; Willis 2016). Likewise, we found that transitions within and between services are key risk periods, where problems with transition planning can leave individuals in precarious, uncertain housing arrangements with cascading impacts on their broader health and wellbeing over time.

The recommendations offered on the following pages emphasise how these challenges-and the associated risk of housing insecurity for vulnerable individuals - may be mitigated. First, our research demonstrates that dedicated, formal housing support must be regarded as a critical component of effective treatment for mental health and/or substance use disorders. While not all people accessing such services need this help, the lack of formal integration of housing supports within these settings means that vulnerable individuals all too often 'fall between the cracks' of care with devastating consequences for their long-term health and wellbeing. Developing a systematic capacity within and across the mental health and substance use treatment sectors to address and respond to client's housing struggles, as relevant, must be addressed as a priority.

There is an equally urgent need to develop more effective screening and assessment tools for use in institutional settings to assess clients' individual housing needs, and to ensure that the necessary package of post-exit supports can be tailored to these needs. Improved screening, assessment and discharge planning will help to address the support needs of people exiting institutional spaces, and reduce the risk of individuals being discharged without adequate support. 
More broadly, our research highlights the complex interplay of material, social and affective infrastructures needed to support 'post-exit' transitions, and to help individuals sustain some measure of a liveable life. In our view, one of the key outstanding policy and practice challenges is to determine how to effectively mobilise these infrastructures to support an individual's long-term health and social care needs. While we recognise that many aspects of these infrastructures fall outside the responsibilities of staff in mental health and/or substance use treatment settings, as the evidence presented in Chapter 5 has amply demonstrated, care-work across these sectors can nonetheless have a significant impact on the repair and restoration of the local, informal, intimate and relational infrastructures crucial to individual experiences of care and recovery.

With these more general conclusions in mind, we will now outline our key policy and practice recommendations before closing with directions for further research.

\subsection{Responding to our major research questions}

\subsubsection{What models of best practice may enhance transition planning and service integration for individuals leaving residential treatment?}

Our review of the international housing and social care literature, along with our interviews with service providers and service users, identified numerous models of best practice to guide the coordination of housing, health and social care supports for individuals transitioning out of residential treatment settings for mental health and/or substance use problems. Before we consider how these models may continue to inform service design innovations in the Australian context, it is important that we emphasise the broader importance of 'housing first' models across mental health and substance use treatment settings. In line with recent critiques of conditional 'housing readiness' approaches (Clarke, Parsell et al. 2020), in which supported housing arrangements are allocated according to assessments of an individual's capacity (or 'readiness') to maintain stable housing, we are wary of any approach that undermines the provision of 'housing first' for individuals living with complex mental health and/or substance use problems.

As programs like J2SI and Greenlight in Victoria, and HASI in New South Wales clearly indicate, the unconditional provision of secure housing is typically associated with significant improvements in clients' social and community participation, and their more general health and wellbeing. In keeping with these insights, we would argue that specialist housing services need to be more formally integrated into discharge and transition planning arrangements across mental health care and substance use treatment settings. What our interview participants reported instead, was a far more uncertain and inconsistent set of transition arrangements in which housing is sometimes relegated to an external housing agency after a person has left care. We understand that effective care coordination necessarily involves referrals to specialist housing supports, but our point is that these referral pathways should be formally integrated into all discharge and transition planning arrangements from the earliest possible point in an individual's enrolment in care.

In other words, housing must be regarded as a central concern for mental health and/or substance use treatment providers, rather than a matter for external agencies alone. This insistence on 'housing first' suggests the following key service recommendations:

- Housing/homelessness support achieves the best outcomes for individuals when it is co-delivered with mental health and AOD services rather than as a discrete system.

- Complex assessment at the point of admission of an individual's living situation and how this situation might support or undermine their recovery should be the basis for more careful discharge planning and complex care coordination across distinct service systems.

- Secure, safe and affordable housing, alongside broader health and social supports, enhances recovery and protects against relapse, re-hospitalisation and homelessness. 
Our research also has important implications for ongoing discussions about the organisation and delivery of social care - for debates about work design matters, leadership and governance arrangements, key role descriptions and task allocations-across and between specialist housing services, mental health and substance use treatment services. Successive periods of policy change, disruption and innovation (coupled with the ongoing evolution of funding arrangements and organisational structures within and across the broad community health and social care sector) have had enormous impacts on the everyday work of delivering care in specialist housing services, and mental health and substance use treatment services in Victoria and New South Wales. Unquestionably, the service system landscape is becoming more complex, more fragmented, more competitive and more focussed on delivering short-term outcomes for vulnerable individuals.

While this broader policy landscape was not an explicit focus of the current study, it is important to note how these broader policy changes are affecting the everyday delivery of care by, for example, complicating referral pathways, disrupting service relationships between agencies, and transforming role descriptions and task allocations within and between specialist housing services, mental health and substance use treatment services. While these changes are, in some instances, leading to distinctive improvements in service delivery and associated health and social care outcomes for vulnerable individuals, they are also leading to further service fragmentation and complexity.

More complex policy and funding arrangements, coupled with growing care specialisation and increased fragmentation in service delivery across geographical regions, is undoubtedly making the work of coordinating care between health and housing services more difficult across Victoria and New South Wales. The ongoing rollout of the NDIS is further complicating matters as significant numbers of new service providers have emerged to cater to new social care markets in new service delivery catchment areas.

As a result of these organisational changes, service pathways are becoming more complex with significant impacts on individual care 'trajectories' across specialist housing services, mental health and substance use treatment services. In response we would note the following:

- Formal and informal relationships between services, organisations and individuals are central to successful care coordination and smooth transitions between services.

- Trust and rapport established over time between service providers and service users, and strengthened through formal relationships between agencies maintaining active referrals, produce the best housing and recovery outcomes for vulnerable individuals.

- 'Wrap around' tailored support is dependent on strong relationships between health and mental health services/staff and allied health and community services/staff.

As noted, we would also emphasise the need for new in-take, screening and assessment protocols, along with more effective discharge/transition planning processes, to enhance the integration and coordination of specialist housing services, mental health and substance use treatment services. Enhanced formal screening and assessment tools that more thoroughly assess an individual's living situation and care needs at the point of intake or admission in mental health or substance use treatment settings should drive more effective discharge planning. These instruments will need to be implemented in consistent ways across public and private settings and between health and social care sectors. Peer workers and lived experience advisory groups working within housing, mental health and/or AOD treatment spaces are a significant source of expertise that could be drawn on in the development of these tools and instruments.

Furthermore, there is a strong case for increased funding to support wider provision of case management roles and services in and between housing, mental health and substance use treatment settings across Victoria and New South Wales. Our findings suggest that assertive case management, while resource intensive, is an effective means of supporting vulnerable individuals with complex care needs to access and maintain stable housing over time. 
The following service design, policy and funding recommendations follow from these more general observations:

- Housing support must be regarded as an integral part of treatment and care planning in the provision of specialist mental health and substance use treatment.

- More comprehensive housing screening assessments are needed at intake into specialist mental health and substance use treatment to inform all aspects of discharge planning, including the establishment of allied health and community-based supports post-discharge.

- New systems and structures are needed to support complex care coordination and more effective transitions between housing, mental health and substance use treatment services. These systems and structures must be formalised with each sector being accountable for an individual's housing and recovery outcomes.

\subsubsection{How does residential treatment affect individual housing careers overtime?}

The impact of residential treatment on individual housing careers is complex. Our research demonstrates that innovative care and treatment services delivered by highly skilled, dedicated professionals working in well organised teams (for example, linking mental health, housing and substance use treatment and support) can have a profoundly positive impact on the health and wellbeing of vulnerable individuals with complex needs. At the same time, we also identified significant gaps, service failures and fragmentation within and between housing, mental health and substance use treatment service systems. Failures to adequately plan for and support stable transitions into safe and secure housing can have catastrophic implications for an individual's health and wellbeing over time. In exploring discharge planning and transition arrangements, we identified significant opportunities to improve care coordination and enhance housing security.

Of critical importance is the issue of improving the choice and control that individuals exiting institutional spaces have over their housing arrangements, while improving the coordination of service supports during these transitions. There is strong evidence that individuals who have a greater degree of choice over their housing futures post-treatment experience improved health, social and economic outcomes in the period following this transition (see Brackertz, Borrowman et al. 2020; Brunero, Fairbrother et al. 2007; Tran, Lambeth et al. 2020). Of course, the chronic lack of affordable housing is a key issue for individual's experiencing mental health issues and/or substance use problems. Without safe and secure housing, long-term and sustainable recovery from mental health and/or substance use issues is not possible. Insecure housing inevitably disrupts community, economic and social relations reducing, in turn, the liveability of life and the longer term health and social care of individuals exiting these settings.

Our linked data analysis indicates a strong correlation between the volume and frequency of service contacts and the risk of housing insecurity. This finding is consistent with national and international reports that have consistently found that frequency and volume of service useage, particularly for mental health, housing and/or substance use services, predicts housing insecurity across the lifecourse (see Aubry, Goering et al. 2016; Clarke, Watts et al. 2020; Dunt, Benoy et al. 2017: Hanratty, Miller et al. 2020). Our data confirm that service transitions can have a significant impact on housing trajectories, particularly for vulnerable individuals with complex needs. This relationship is bi-directional in that frequency of service contact is obviously an indication of service demand and the complexity of an individual's health and social needs. Yet it is also the case that service contacts, particularly service experiences that involve periods of residential treatment (for example in mental health and/ or substance use treatment settings) can themselves disrupt individuals' housing arrangements. As we noted in Chapters 2 and 3, periods of residential care may themselves disrupt what were formerly relatively stable housing arrangements, for example, when individuals enter residential treatment from private rental accommodation. On the other hand, individuals may decide, partially as a result of their treatment, that they wish to alter their housing arrangements post-treatment, in favor of other accommodation in a different location. 
In terms then of our second key research question regarding the ways that residential treatment impacts housing trajectories, we would note the following recommendations:

- There is a need for high quality, consistent data to allow for the identification and tracking of particular cohorts that might be at risk of housing insecurity to permit more effective planning and service system design.

- Improving data linkage between government services would be helpful. At a state level this would include data from education and adult justice, and at federal level, Medicare, Centrelink and potentially even tax records. Linking these data would provide further information on socio-economic status without intrusive questionnaires on service admission. This would also permit analysis of what happens to people who don't use services, thus facilitating more fine-grained differentiation of positive and negative impacts of housing care and support.

\subsubsection{How can post-exit support packages be tailored and delivered to individuals leaving residential treatment who are most at risk of homelessness?}

Housing insecurity is an existential condition characterised by experiences of fear, insecurity and vulnerability. Homelessness cannot be reduced to the lack of a roof but involves a complex breakdown of the affective, material and social infrastructures necessary for the enjoyment of a liveable life. Our research findings suggest that housing insecurity and mental health and/or substance use issues are inseparable and must be considered concurrently to improve individual outcomes. As such, housing supports need to be more effectively integrated into the delivery of mental health and substance use treatment programs for all individuals who need such support.

Our research has revealed highly inconsistent and sometime ineffective discharge planning arrangements between different mental health and/or substance use treatment providers across Victoria and New South Wales. As we reported in Chapters 4 and 5, 'after-care' and transition planning often occur at the point of discharge, where it is not as effective as it otherwise might be. Typically, such arrangements are further constrained by structural and systemic limitations that, at best, leave individuals vulnerable to being placed in poor quality transitional accommodation without community-based supports or, at worst, being effectively discharged into homelessness.

In terms of the key structural limitations that inhibit more effective transition planning and care coordination, we observed how bureaucratic and administrative processes can limit effective transition planning and curtail care and support provision. For example, the existing structure and design of mental health, housing and substance use treatment service systems means that care and support provision is often fragmented and dislocated across sectors, leaving individuals to navigate complex care systems often without direct support. This means that the onus is often on individuals themselves to manage their own care and service support needs in the period immediately following their exit from mental health and/or substance use treatment. While we certainly observed examples of highly effective follow up support during this transition phase, sadly, such coordinated support is not uniformly extended to all individuals who need it.

Individual transition packages must be designed and delivered on the basis of what they enable an individual to do in their everyday life following their exit from an institutional space. Transitional packages of support ought to address needs in relation to material infrastructures such as housing and finances, social infrastructures including community integration, employment, and so on, and, affective infrastructures such as the home, personal relationships, and self-identity. Furnishing the infrastructures central to a more liveable life ought to be the key focus of transition planning for individuals exiting mental health or substance use treatment settings, taking in both formal and informal housing, health and social care and support needs (Power and Mee 2020). Such a focus shifts the goals of transition planning beyond the immediate objectives of a particular service or system to emphasise an individual client's explicit care goals and support needs. 
To sustain improvements in the design and delivery of transitional care and support packages for individuals exiting institutional spaces, the following recommendations should be implemented:

- The key objective of the delivery of effective care and support must be the restoration of affective, material and social infrastructures necessary to sustain a liveable life.

- In line with the principles of person-centred care (Brackertz, Borrowman et al. 2020) and consumer definitions of recovery (Duff, Jacobs et al. 2013), an individual's explicit care and support goals must be considered as the principal objective of post-exit support packages.

- Expanded roles for carers and peer support workers in the design and delivery of coordinated care arrangements should be considered to ensure that the needs of individuals exiting institutional settings are more systematically integrated into exit plans.

- Individual support packages must be flexible and adaptive. Supports need to be in place at the point of discharge and must evolve in a responsive way as new needs are identified.

- Further detailed qualitative research is needed to understand how effective discharge planning and complex care coordination occurs in practice. Ethnographic research examining screening and assessment tools, formal and informal assessment and discharge planning and processes, follow up care delivery, and an individual's post-exit housing experience, including within supported and/or independent living, is required to understand trajectories through housing, mental health and AOD treatment systems.

\subsubsection{Effectiveness of existing service integration and opportunities for improvements}

We observed wide discrepancies in the character and effectiveness of service integration and coordination planning and service delivery models between mental health and/or substance use treatment providers and specialised housing services in New South Wales and Victoria. While we found a host of instances of effective care coordination and service integration (see Section 4.4), we also identified significant opportunities for enhancing the integration and coordination of specialised housing and health and social care supports for vulnerable individuals. In this respect, it bears repeating that a lack of referral pathways, gaps between services and programs, and key policy and service limitations profoundly hinder an individual's ability to recover from mental health issues and/or substance use problems. These systemic and structural failings can be severely traumatising, increasing a person's vulnerability to homelessness, relapse and/or hospitalisation, while leaving some vulnerable individuals at risk of becoming 'lost to care'.

We found that systemic, formal and enduring integration of housing supports for individuals in residential treatment for mental health and/or substance use problems is the exception rather than the norm. Again, we observed instances of effective service integration, but far more common were informal ad hoc arrangements that depend on personal relationships between service providers across service sectors to sustain complex care coordination arrangements and referral pathways. All too often we heard reports of these informal arrangements breaking down as staff moved to a different part of an organisation or departed for other employment. The lack of formal integration of housing, mental health, and substance use service provision means that integration occurs on an informal basis with uncertain governance provisions that rarely specify, for example, penalties for noncompliance or service improvement targets.

This informality generates significant risks for individuals accessing services across distinct and functionally separate systems. The lack of formal administrative requirements, governance arrangements, and contractual relationships between services undermines more effective models of discharge planning and care coordination. In the absence of formal models and guidelines mandating specific care coordination arrangements, discharge and transition care arrangements across the provision of residential mental health and substance use treatment remain ad hoc and informal, stymied by structural limitations. Indeed, we collected reports of instances in which housing issues are all but ignored in discharge and transition planning with disastrous effect. 
Considered in more structural terms, it is clear that housing, mental health and substance use treatment sectors in both New South Wales and Victoria remain largely separate policy and service systems with little formal integration and coordination. There is significant scope therefore, to enhance the integration of housing, mental health and/or substance use treatment services, along with other health and social care supports as needed, through much more systemic and formal organisational and governance arrangements. Given what is already known about the significant risk of housing insecurity faced by individuals receiving care and treatment in residential mental health and/or substance use treatment settings, there is an urgent need to more formally integrate housing support into these treatment settings.

Poor integration and a lack of coordination results in significant unmet demand across the mental health care and substance use treatment sectors resulting in higher rates of inpatient care, increased need for substance use treatment services, and greater pressure on specialist housing support services following an individual's discharge from residential care. On the basis of these findings, we make the following policy recommendations:

- The emphasis on bureaucratic and administrative processes over and above an individual's care needs must be reversed. All care and discharge planning must begin from the point of view of the individual in care in more 'person-centred' approaches to care coordination.

- Mental health, substance use treatment, and specialised housing support services ought to be more formally integrated through policy and service system design innovations.

- Housing assessments ought to be formally integrated into all admissions and care-planning protocols in psychiatric inpatient settings and residential substance use treatment:

- such assessments may then inform the preparation of advance statements and formal discharge planning arrangements in psychiatric inpatient settings

- housing assessments may inform the tailored delivery of 'after care' and transition support for individuals leaving AOD residential treatment.

- The formal integration of housing assessments into screening protocols in each service sector will enable formal assessment of individuals' existing housing status including their housing preferences upon discharge, along with their risk of housing insecurity.

- Representatives of specialised housing services ought to be formally integrated into discharge planning processes in psychiatric in-patient settings for all individuals who need housing assistance. Housing representatives could work with the allied health teams including social workers to enhance discharge and transition planning processes.

- Within residential substance use treatment settings, housing supports ought to be more formally integrated into transition planning arrangements right from the point of intake.

\subsection{Concluding remarks}

There is ample scope to enhance the coordination of housing, health and social care supports for individuals leaving psychiatric inpatient settings or residential substance use treatment in New South Wales and Victoria. Our research makes a compelling case for the more formal integration of specialist housing services into both residential psychiatric and substance use treatment settings, given the significant risks of housing insecurity that many individuals experience in these settings, including all too common experiences of homelessness. There are several instances of good practice to guide these efforts, including examples derived from innovative housing and social justice programs like 'Journeys to Social Inclusion' and 'Green Light' in Victoria, and the Housing and Accommodation Support Initiative (HASI) in New South Wales. 
These programs clearly indicate the benefits of more formal integration of housing, health and social supports, demonstrating that long-term stable housing can be sustained for individuals regardless of the complexity of their health, housing and social support needs. In this respect, we already have clear models of effective care coordination and successful service integration to guide the provision of stable housing for all Australians. The task now is to scale up these endeavours to ensure that all Australians who need such support receive it, regardless of their circumstances. Equally critical is the need to increase funding support for the provision of new social housing to guarantee access to safe and secure housing for all Australians who need it.

Access to safe and secure housing must remain the foundation of efforts across the country to enhance the coordination of health and social supports for vulnerable individuals, and to improve the integration of these services across diverse health and social care sectors. After all, enhanced care coordination and improved service integration are not, on their own, solutions to the housing crises that many Australians experience. The only longterm solution is stable and secure housing. 


\section{References}

Alam, A. and Houston, D. (2020) 'Rethinking care as alternate infrastructure', Cities, 100, 102662, https://doi.org/10.1016/j. cities.2020.102662.

Amin, A. (2014) 'Lively infrastructure', Theory, Culture \& Society, vol. 31(7-8), 137-161, https://doi.org/10.1177/0263276414548490.

Anderson, S., Brownlie, J. and Milne, E. J. (2015) The liveable lives study: understanding everyday help and support, The Joseph Rowntree Foundation, London, accessed 30 August 2020, https://www.jrf.org.uk/report/liveable-livesstudy-understanding-everyday-help-and-support.

Aubry, T., Goering, P., Veldhuizen, S., Adair, C. E., Bourque, J., Distasio, J., ... and Tsemberis, S. (2016) 'A randomized controlled trial in five Canadian cities of the effectiveness of Housing First with assertive community treatment for persons with serious mental illness and a history of homelessness', Psychiatric Services, vol. 67, no. 3: 275-281, https://doi.org/10.1176/appi.ps.201400587.

Australian Bureau of Statistics (ABS) (2017). The 2016 Census of Population and Housing. ABS, Canberra, accessed 31 August, 2020, https://www.abs.gov.au/ausstats/abs@.nsf/Lookup/by\%20Subject/1001.0 2016-17 Main\%20 Features The\%202016\%20Census\%20 of\%20Population\%20and\%20Housing 10009.

Australian Institute of Health and Welfare (AlHW) (2019a) Mental health services-in brief 2019, cat. no. HSE 228, AlHW, Canberra, accessed 30 August 2020, https://www.aihw.gov.au/reports/mental-health-services/mental-healthservices-in-australia-in-brief-2019/contents/table-of-contents.

Australian Institute of Health and Welfare (AIHW) (2019b) Specialist Homelessness Services annual report 2018-19, cat. no. HOU 318, AlHW, Canberra, accessed 29 August 2020, https://www.aihw.gov.au/reports/homelessnessservices/shs-annual-report-18-19.

Australian Institute of Health and Welfare (AlHW) (2019c) Housing assistance in Australia 2019, AlHW, Canberra, accessed 29 August 2020, https://www.aihw.gov.au/reports/housing-assistance/housing-assistance-in-australia-2019/data.

Backer, T. E., Howard, E. A. and Moran, G. E. (2007), 'The role of effective discharge planning in preventing homelessness', The Journal of Primary Prevention, vol. 28, no. 3: 229-243, https://doi.org/10.1007/s10935-007-0095-7.

Barratt, H., Rojas-García, A., Clarke, K., Moore, A., Whittington, C., Stockton, S., Thomas, J., Pilling, S. and Raine, R. (2016) 'Epidemiology of mental health attendances at emergency departments: systematic review and meta-analysis', PLoS One, vol. 11, no. 4(e0154449), https://doi.org/10.1371/journal.pone.0154449.

Batterham, D. (2019a) 'Defining 'At-risk of Homelessness': re-connecting causes, mechanisms and risk', Housing, Theory \& Society, vol. 36, no. 1:1-24, https://doi.org/10.1080/14036096.2017.1408678.

Batterham, D. (2019b) 'Homelessness as capability deprivation: a conceptual model', Housing Theory \& Society, vol. 36, no. 3: 274-297, https://doi.org/10.1080/14036096.2018.1481142.

Baxter, A. J., Tweed, E. J., Katikireddi, S. V. and Thomson, H. (2019), 'Effects of Housing First approaches on health and well-being of adults who are homeless or at risk of homelessness: systematic review and meta-analysis of randomised controlled trials', Journal of Epidemiology and Community Health, vol. 73, no. 5: 379-387, https://doi.org/10.1136/jech-2018-210981.

Beer, A., Faulkner, D. and Gabriel, M (2006), 21st Century housing careers and Australia's housing future: literature review, Australian Housing and Urban Research Institute, Melbourne. 
Benjaminsen, L. and Andrade, S. B. 2015 'Testing a typology of homelessness across welfare regimes: shelter use in Denmark and the USA', Housing Studies, vol. 30:858-876, https://doi.org/10.1080/02673037.2014.982517.

Berlant, L. (2011) Cruel Optimism, Duke University Press, Durham. https://doi.org/10.1515/9780822394716.

Berlant, L. (2016) 'The commons: infrastructures for troubling times', Environment and Planning D: Society and Space, vol. 34, no. 3: 393-419, https://doi.org/10.1177/0263775816645989.

Best, D. W. and Lubman, D. I. (2012) 'The recovery paradigm: a model of hope and change for alcohol and drug addiction', Australian family physician, vol. 41, no. 8: 593.

Blunden, H. and Drake, G. (2015) 'Homelessness, the 'Housing First' approach and the creation of 'home' in R. DuftyJones and D. Rogers (eds), Housing in 21st Century Australia: People, Practices and Policies, Routledge, London.

Botvin, G. J. and Griffin, K. W. (2004) 'Life skills training: empirical findings and future directions', Journal of primary prevention, vol. 25, no. 2: 211-232, https://doi.org/10.1023/B:JOPP.0000042391.58573.5b.

Brackertz, N., Davidson, J. and Wilkinson, A. (2019) Trajectories: the interplay between mental health and housing pathways, a short summary of the evidence, Report prepared by AHURI Professional Services for Mind Australia, Australian Housing and Urban Research Institute, Melbourne.

Brackertz, N., Borrowman, L., Roggenbuck, C., Pollock, S. and Davis, E. (2020) Trajectories: the interplay between mental health and housing pathways, AHURI Research Paper, Mind Australia, Australian Housing and Urban Research Institute Limited, Melbourne, https://www.ahuri.edu.au/research/research-papers/trajectories-report.

Brown, K. (2011) “Vulnerabilty': handle with care', Ethics and Social Welfare, vol. 5, no. 3: 313-321, https://doi.org/10.1080/1 7496535.2011.597165.

Brunero, S., Fairbrother, G., Lee, S. and Davis, M. (2007) 'Clinical characteristics of people with mental health problems who frequently attend an Australian emergency department', Australian Health Review, vol. 31, no. 3: 462-470, https://doi.org/10.1071/AH070462.

Brunette, M. F., Mueser, K. T. and Drake, R. E. (2004) 'A review of research on residential programs for people with severe mental illness and co-occurring substance use disorders', Drug and alcohol review, vol. 23, no. 4: 471-481, https://doi.org/10.1080/09595230412331324590.

Butler, J. (2016) Frames of War: When is Life Grievable? Verso, London: 224.

Caldwell, T., Jorm, A. and Dear, K. (2004). 'Suicide and mental health in rural, remote and metropolitan areas in Australia', The Medical Journal of Australia, vol. 181, no. 7:10-14, https://doi.org/10.5694/j.1326-5377.2004.tb06348.x.

Caton, C. (2017) The Open Door: Homelessness and Severe Mental IIIness in the Era of Community Treatment, Oxford University Press. Oxford, https://doi.org/10.1093/acprof:oso/9780190463380.001.0001.

Centre for Data Linkage (2018) Review of CVDL data linkage methodologies V2.0, report to Department of Premier and Cabinet, Victorian Government, Centre for Data Linkage, Curtin University, Western Australia.

Chamberlain, C. and Johnson, G. (2013) 'Pathways into adult homelessness', Journal of Sociology, vol. 49, no. 1: 60-77, https://doi.org/10.1177/1440783311422458.

Chamberlain, C., Johnson, G. and Robinson, C. (eds) (2014) Homelessness in Australia: an Introduction, University of New South Wales Press, Sydney.

Chamberlain, C. and MacKenzie, D. (2008) Counting the Homeless, Australia, 2006, Australian Census Analytic Program, Australian Bureau of Statistics, Canberra.

Clarke, A., Parsell, C. and Vorsina, M. (2020) 'The role of housing policy in perpetuating conditional forms of homelessness support in the era of Housing First: evidence from Australia', Housing Studies, vol. 35, no. 5: 954-975. https://doi.org /10.1080/02673037.2019.1642452.

Clarke, A., Watts, B. and Parsell, C. (2020) 'Conditionality in the context of housing-led homelessness policy: comparing Australia's Housing First agenda to Scotland's 'rights-based' approach, Australian Journal of Social Issues, vol. 55, no. 1: 88-100, https://doi.org/10.1002/ajs4.97.

Corrigan, P. W., Larson, J. E., Smelson, D. and Andra, M. (2019) 'Recovery, peer support and confrontation in services for people with mental illness and/or substance use disorder', The British Journal of Psychiatry, vol. 214, no. 3: 130-132, https://doi.org/10.1192/bjp.2018.242. 
Craig, T. and Hodson, S. (1998) 'Homeless youth in London: childhood antecedents and psychiatric disorder', Psychological Medicine, vol. 28: 1379-88, https://doi.org/10.1017/S0033291798007351.

Culhane, D. (2016) 'The potential of linked administrative data for advancing homelessness research and policy', European Journal of Homelessness, vol. 10, no. 3:109-126.

Culhane, D., Metraux, S. and Hadley, T. (2002) 'The impact of supportive housing for homeless people with severe mental illness on the utilization of the public health, corrections, and emergency shelter systems: The New York-New York Initiative', Housing Policy Debate, vol. 13, no. 1: 107-163, https://doi.org/10.1080/10511482.2002.9521437.

Deegan, P. (1997) 'Recovery and empowerment for people with psychiatric disabilities', Social Work in Health Care, vol. 25, no. 3: 11-24, https://doi.org/10.1300/J010v25n03_02.

Dej, E., Gaetz, S. and Schwan, K. (2020) ‘Turning off the tap: a typology of homelessness prevention', The Journal of Primary Prevention, vol. 41: 397-412, https://doi.org/10.1007/s10935-020-00607-y.

Dennis, F. (2019) Injecting Bodies in More-Than-Human Worlds, Taylor and Francis, London, https://doi.org/10.4324/ 9780429466137.

Dodd, S. (2007) 'Depending on care: recognition of vulnerability and the social contribution of care provision', Biosocieties, vol. 21, no. 9: 500-510, https://doi.org/10.1111/j.1467-8519.2007.00595.x.

Duff, C., Jacobs, K., Loo, S. and Murray, S. (2013) The role of informal community resources in supporting stable housing for young people recovering from mental illness, AHURI Final Report No. 199, Australian Housing and Urban Research Institute Limited, Melbourne.

Duff, C. 2016. 'Atmospheres of recovery: assemblages of health', Environment and Planning A, vol. 48, no. 1: 58-74, https://doi.org/10.1177/0308518X15603222.

Dufty-Jones, R. and Rogers, D. (eds) (2016) Housing in 21st-Century Australia: People, Practices and Policies, Routledge, London, https://doi.org/10.4324/9781315587110.

Dunt, D., Benoy, A., Phillipou, A., Collister, L., Crowther, E., Freidin, J. and Castle, D. (2017) 'Evaluation of an integrated housing and recovery model for people with severe and persistent mental illnesses: the Doorway Program', Australian Health Review', vol. 41:573-581. https://doi.org/10.1071/AH16055.

Easterlow, D. and Smith, S. J. (2004) 'Housing for health: can the market care?, Environment and Planning A, vol. 36, no. 6: 999-1017, https://doi.org/10.1068/a36178.

Enticott, J., Meadows, G., Shawyer, F., Inder., B. and Patten, S. (2016) 'Mental disorders and distress: associations with demographics, remoteness and socioeconomic deprivation of area of residence across Australia', Australia and New Zealand Journal of Psychiatry, vol. 50:1169-79, https://doi.org/10.1177/0004867415615948.

Evangelista, G. (2010) ‘Poverty, homelessness and freedom: an approach from capabilities theory', European Journal of Homelessness, vol. 4: 189-202.

Evans, G. W., Wells, N. M. and Moch, A. (2003) 'Housing and mental health: a review of the evidence and a methodological and conceptual critique', Journal of social issues, vol. 59, no. 3: 475-500, https://doi.org/10.1111/1540-4560.00074.

Fawcett, B. (2009) 'Vulnerability: questioning the certainties in social work and health', International Social Work, vol. 52, no. 4: 473-484, https://doi.org/10.1177/0020872809104251.

Fineman, M. (2008) 'The vulnerable subject: anchoring equality in the human condition', in M. Fineman (ed.), Transcending the Boundaries of Law: Generations of Feminism and Legal Theory, Taylor and Francis, London: 1-24.

Fitzpatrick, S. (2005) ‘Explaining homelessness: a critical realist perspective', Housing, Theory and Society, vol. 22, no. 1: 1-17, https://doi.org/10.1080/14036090510034563.

Flatau, P., Conroy, E., Clear, A. and Burns, L. (2010), The integration of homelessness, mental health and drug and alcohol services in Australia, AHURI Positioning Paper, No. 132, AHURI, Melbourne.

Fomiatti, R. (2020) 'It's good being part of the community and doing the right thing': (re)problematising 'community' in new recovery oriented policy and consumer accounts', International Journal of Drug Policy, vol. 80: 1-9, https://doi. org/10.1016/j.drugpo.2019.04.007.

Frank, D. (2018) 'I was not sick and I didn't need to recover': methadone maintenance treatment (MMT) as a refuge from criminalisation', Substance Use \& Misuse', vol. 53, no. 2: 311-322, https://doi.org/10.1080/10826084.2017.1310247. 
Goehl, L., Nunes, E., Quitkin, F. and Hilton, I. (1993) 'Social networks and methadone treatment outcome: the costs and benefits of social ties', The American Journal of Drug and Alcohol Abuse, vol. 19, no. 3: 251-262, https://doi. org/10.3109/00952999309001617.

Golembiewski, J. A. (2015) 'Mental health facility design: the case for person-centred care', Australian and New Zealand Journal of Psychiatry, vol. 49, no. 3:203-206, https://doi.org/10.1177/0004867414565477.

Gooding, P. (2013) 'Supported decision-making: a rights-based disability concept and its implications for mental health law, Psychiatry, Psychology and Law, vol. 20, no. 3: 431-451, https://doi.org/10.1080/13218719.2012.711683.

Gray, H. M., Shaffer, P. M., Nelson, S. E. and Shaffer, H. J. (2016) 'Changing social networks among homeless individuals: a prospective evaluation of a job-and life-skills training program', Community Mental Health Journal, vol. 52, no. 7: 799-808, https://doi.org/10.1007/s10597-014-9817-5.

Greer, A. L., Shinn, M., Kwon, J. and Zuiderveen, S. (2016) 'Targeting services to individuals most likely to enter shelter: evaluating the efficiency of homelessness prevention', Social Service Review, vol. 90, no. 1: 130-155, https://doi. org/10.1086/686466.

Grohmann, S. (2020) The Ethics of Space: Homelessness and Squatting in Urban England, HAU Books, Chicago.

Gulcur, L., Stefancic, A., Shinn, M., Tsemberis, S. and Fischer, S. (2003) 'Housing, hospitalization, and cost outcomes for homeless individuals with psychiatric disabilities participating in continuum of care and housing first programmes', Journal of Community and Applied Social Psychology, vol. 13, no. 2: 171-186, https://doi.org/10.1002/casp.723.

Hadley, T., McGurrin, M., Pulice, R. and Holohean, E. J. (1990) 'Using fiscal data to identify heavy service users', Psychiatric Quarterly, vol. 61: 41-48, https://doi.org/10.1007/BF01065163.

Hadley, R., Culhane, D. and McGurrin, M. (1992) 'Identifying and tracking 'heavy users' in acute psychiatric inpatient services', Administration and Policy in Mental Health, vol. 19, no. 4:2790-290, https://doi.org/10.1007/BF00708320

Haffner, M. and Elsinga, M. (2019) 'Housing deprivation unravelled: application of the capability approach', European journal of Homelessness, vol. 13, no. 1: 13-28.

Hall, G., Walters, S., Gould, H. and Lim, S. (2020) 'Housing versus treatment first for supportive housing participants with substance use disorders: A comparison of housing and public service use outcomes', Substance Abuse, vol. 41, no.1: 70-76, https://doi.org/10.1080/08897077.2018.1449049.

Hanratty, J., Miller, S., Keenan, C., Cowman, J., Hamilton, J., Mackie, P. (2020) ‘PROTOCOL: Discharge programmes for individuals experiencing, or at risk of experiencing, homelessness: a systematic review', Campbell Systematic Reviews, 2020;16:e1109, https://doi.org/10.1002/cl2.1109.

Henwood, B. F., Stefancic, A., Petering, R., Schreiber, S., Abrams, C. and Padgett, D. K. (2015) 'Social relationships of dually diagnosed homeless adults following enrollment in housing first or traditional treatment services, Journal of the Society for Social Work and Research, vol. 6, no. 3: 385-406, https://doi.org/10.1086/682583.

Holmes, A., Carlisle, T., Vale, Z., Hatvani, G., Heagney, C. and Jones, S. (2017) 'Housing First: permanent supported accommodation for people with psychosis who have experienced chronic homelessness', Australasian Psychiatry, vol. 25, no. 1: 56-59, https://doi.org/10.1177/1039856216669916.

Ibrahim, N., Thompson, D., Nixdorf, R., Kalha, J., Mpango, R., Moran, G., ... and Puschner, B. (2020) 'A systematic review of influences on implementation of peer support work for adults with mental health problems', Social Psychiatry and Psychiatric Epidemiology, vol. 55, no. 3: 285-293, https://doi.org/10.1007/s00127-019-01739-1.

Insel, T. and Fenton, W. (2005) 'Psychiatric epidemiology: It's not just about counting anymore', Archives of General Psychiatry, vol. 62: 590-592, https://doi.org/10.1001/archpsyc.62.6.590.

Issacs, A. Enticott, J., Meadows, G. and Inder, B. (2018) 'Lower income levels in Australia are strongly associated with elevated psychological distress: implications for healthcare and other policy areas', Frontline Psychiatry, vol.9: 1-9, https://doi.org/10.3389/fpsyt.2018.00536.

Jessop, N., Hassall, J., Geffen, J. and Yellowlees, P. (2000) 'Community treatment for heavy users of private mental health services: Who benefits?', Australian Psychiatry, vol. 8, no. 1:56-58, https://doi.org/10.1046/j.1440-1665.2000.00242.x.

Johnson, G. and Chamberlain, C. (2008) 'Homelessness and substance abuse: Which comes first? Australian Journal of Social Issues, vol. 46, no. 1: 342-356, https://doi.org/10.1080/03124070802428191. 
Johnson, G. and Chamberlain. C. (2011) 'Are the homeless mentally ill?', Australian Journal of Social Issues, vol. 46, no. 1: 29-48, https://doi.org/10.1002/j.1839-4655.2011.tb00204.x.

Johnson, G., Parkinson, S. and Parsell, C. (2012) Policy shift or program drift? Implementing Housing First in Australia, AHURI Final Report No. 184, Australian Housing and Urban Research Institute, Melbourne.

Johnson, G., Natalier, K., Mendes, P., Liddiard, M., Thoresen, S., Hollows, A., Bailey, N. (2010) Pathways from out-of-home care, AHURI Final Report No. 147, Australian Housing and Urban Research Institute Limited, Melbourne.

Johnson, G., Scutella, R., Tseng, Y. P. and Wood, G. (2019) 'How do housing and labour markets affect individual homelessness?', Housing Studies, vol. 34, no. 7: 1089-1116, https://doi.org/10.1080/02673037.2018.1520819.

Kamieniecki, G. (2001) 'Prevalence of psychological distress and psychiatric disorders among homeless youth in Australia: A comparative review', Australian and New Zealand Journal of Psychiatry, vol. 35, no. 3:352-358, https://doi.org/10.1046/ j.1440-1614.2001.00910.x.

Kavanagh, A., Aitken, Z., Baker, E., Lamontagne, A., Milner, A. and Bentley, R. (2016) 'Housing tenure and affordability and mental health following disability acquisition in adulthood', Social Science \& Medicine, vol.151: 225-232, https://doi. org/10.1016/j.socscimed.2016.01.010.

Kelly, P. J., Leung, J., Deane, F. P. and Lyons, G. C. (2016) 'Predicting client attendance at further treatment following drug and alcohol detoxification: Theory of Planned Behaviour and Implementation Intentions', Drug and alcohol review, vol. 35, no. 6: 678-685, https://doi.org/10.1111/dar.12332.

Kertesz, S. G. and Johnson, G. (2017) Housing First: Lessons from the United States and challenges for Australia', Australian Economic Review, vol. 50, no. 2: 220-228, https://doi.org/10.1111/1467-8462.12217.

Kessler, R., Berglund, P., Demler, O., Jin, R., Merikangas, K. and Walters, E. (2005) 'Lifetime prevalence and age-of-onset distributions of DSM-IV disorders in the National Comorbidity Survey Replication', Archive of General Psychiatry, vol. 62, no. 6: 593-602, https://doi.org/10.1001/archpsyc.62.6.593.

Kidd, S. A. (2013) 'Mental health and youth homelessness: A critical review' in S. Gaetz, B. O'Grady, K. Buccieri, J. Karabanow and A. Marsolais (eds), Youth Homelessness in Canada: Implications for Policy and Practice, Canadian Observatory on Homelessness Press, Toronto, 217-227.

Kuhn, R. and Culhane, D. (1998) 'Applying cluster analysis to test a typology of homelessness by pattern of shelter utilization: Results from the analysis of administrative data', American Journal of Community Psychology, vol. 26: 207-232, https://doi.org/10.1023/A:1022176402357.

Linton, S. L., Haley, D. F., Hunter-Jones, J., Ross, Z. and Cooper, H. L. (2017) ‘Social causation and neighborhood selection underlie associations of neighborhood factors with illicit drug-using social networks and illicit drug use among adults relocated from public housing', Social Science \& Medicine, vol. 185: 81-90, https://doi.org/10.1016/j. socscimed.2017.04.055.

Larimer, M., Malone, D., Garner, M., Atkins, D., Burlingham, B., Lonczak, H., Tanzer, K., Ginzler, J., Clifasefi, S. and Hobson, W. (2009) 'Health care and public service use and costs before and after provision of housing for chronically homeless persons with severe alcohol problems', JAMA, vol. 301, no. 13: 1349-1357, https://doi.org/10.1001/ jama.2009.414.

Lubman, D. I., Garfield, J. B., Manning, V., Berends, L., Best, D., Mugavin, J. M., ... and Room, R. (2016) 'Characteristics of individuals presenting to treatment for primary alcohol problems versus other drug problems in the Australian patient pathways study', BMC psychiatry, vol. 16, no. 1: 250-56, https://doi.org/10.1186/s12888-016-0956-9.

Lucas, B., Harrison-Read, P., Tyrer, P., Ray, J., Shiplety, K., Hickman, M., Patel, A., Knappp, M. and Lowin, A. (2001) 'Costs and characteristics of heavy inpatient service users in outer London', International Journal of Social Psychiatry, vol. 47, no. 1:63-74, https://doi.org/10.1177/002076400104700106.

Mackie, P. K., Thomas, I. and Bibbings, J. (2017) 'Homelessness prevention: Reflecting on a year of pioneering Welsh legislation in practice', European Journal of Homelessness, vol. 11, no. 1: 81-107.

Malone, R. (1995) 'Heavy users of emergency services: social construction of a policy problem', Social Science and Medicine, vol. 40, no. 4:469-477, https://doi.org/10.1016/0277-9536(94)E0116-A.

Manning, V., Garfield, J. B., Best, D., Berends, L., Room, R., Mugavin, J., ... and Lubman, D. I. (2017) ‘Substance use outcomes following treatment: Findings from the Australian Patient Pathways Study', Australian \& New Zealand Journal of Psychiatry, vol. 51, no. 2: 177-189, https://doi.org/10.1177/0004867415625815. 
Marel, C., Mills, K., Kingston, R., Gournay, K., Deady, M., Kay-Lambkin, F., Baker, A. and Teesson, M. (2016) Guidelines on the Management of Co-occurring Alcohol and other Drug and Mental Health Conditions in Alcohol and Other Drug Treatment Settings, 2nd edn, Centre of Research Excellence in Mental Health and Substance Use, National Drug and Alcohol Research Centre, University of New South Wales, Sydney, Australia.

Martijn, C. and Sharpe, L. (2006) 'Pathways to youth homelessness', Social Science and Medicine, vol. 62: 1-12, https:// doi.org/10.1016/j.socscimed.2005.05.007.

McSherry, B. and Waddington, L. (2020) 'The convention on the rights of persons with disabilities and the challenge to treatment without consent of individuals with psychosocial disabilities', in P. Hagenaars, M. Plavšić, N. Sveaass, U. Wagner and T. Wainwright (eds) Human Rights Education for Psychologists, Routledge, London: 165-178, https:// doi.org/10.4324/9780429274312-15.

Mendes, P. and Snow, P. (2016) Young People Transitioning from Out-of-Home Care: International Research, Policy and Practice, Palgrave Macmillan, https://doi.org/10.1057/978-1-137-55639-4.

Miscenko, D., Vallesi, S., Wood, L., Thielking, M., Taylor, K., Mackelprang, J. anf Flatau, P. (2017) Chronic homelessness in Melbourne: The experiences of Journey to Social Inclusion, Mark Il study participants, Sacred Heart Mission, Melbourne.

Morphet, J., Innes, K., Munro, I., O’Brien, A., Gaskin, C. J., Reed, F. and Kudinoff, T. (2012) 'Managing people with mental health presentations in emergency departments-A service exploration of the issues surrounding responsiveness from a mental health care consumer and carer perspective', Australasian Emergency Nursing Journal, vol. 15, no. 3: 148-155, https://doi.org/10.1016/j.aenj.2012.05.003.

Nathan, S., Bethmont, A., Rawstorne, P. R., Ferry, M. and Hayen, A. (2016) 'Trends in drug use among adolescents admitted to residential treatment in Australia', The Medical Journal of Australia, vol. 204, no. 4: 149-150, https://doi. org/10.5694/mja15.01018.

Nicholls McNaughton, C. (2010) 'Housing, homelessness and capabilities', Housing, Theory and Society, vol. 27, no. 1: 23-41, https://doi.org/10.1080/14036090902764588.

Nowell, L. S., Norris, J. M., White, D. E. and Moules, N. J. (2017) ‘Thematic analysis: Striving to meet the trustworthiness criteria', International journal of qualitative methods, vol. 16, no. 1:1-23, https://doi.org/10.1177/1609406917733847.

Nussbaum, M. ( 2011) Creating Capabilities: The Human Development Approach. Cambridge, Mass: Belknap Press of Harvard University Press.

Nurjannah, I., Mills, J., Usher, K. and Park, T. (2013) 'Discharge planning in mental health care: An integrative review of the literature', Journal of Clinical Nursing, Vol. 23: 1175-1185, https://doi.org/10.1111/jocn.12297.

Oades, L., Deane, F., Crowe, T., Gordon Lambert, W., Kavanagh, D. and Lloyd, C. (2005) 'Collaborative recovery: An integrative model for working with individuals who experience chronic and recurring mental illness', Australasian Psychiatry, vol. 13, no. 3: 279-284, https://doi.org/10.1080/j.1440-1665.2005.02202.x.

O'Hagan, M. (2004) 'Guest editorial', Australian e-Journal for the Advancement of Mental Health, vol. 3, no. 1: 5-7, https:// doi.org/10.5172/jamh.3.1.5.

Paquette, K. and Pannella Winn, L. (2016) 'The role of recovery housing: prioritizing choice in homeless services', Journal of dual diagnosis, vol. 12, no. 2: 153-162, https://doi.org/10.1080/15504263.2016.1175262.

Parkinson, S. and Parsell, C. (2018) 'Housing first and the reassembling of permanent supportive housing: the limits and opportunities of private rental', Housing, Theory and Society, vol. 35, no. 1: 36-56, https://doi.org/10.1080/14036096 .2017 .1281163 .

Parsell, C., Petersen, M. and Culhane, D. (2016) 'Cost offsets of supportive housing: evidence for social work', British Journal of Social Work, vol. 47, no. 5: 1534-1553, https://doi.org/10.1093/bjsw/bcw115.

Patel, V., Lund, C., Hatherill, S., Plagerson, S., Corrigall, J. and Funk, M. (2010) 'Mental disorders: equity and social determinants' in E. Blas and A. S. Kurup (eds), Equity, Social Determinants and Public Health Programmes, World Health Organization, Geneva.

Pawson, H., Milligan, V. and Yates, J. (2020) Housing Policy in Australia, Springer, Singapore, https://doi.org/10.1007/978981-15-0780-9. 
Pickett, K. and Wilkinson, R. (2010) 'Inequality: an underacknowledged source of mental illness and distress', British Journal of Psychiatry, vol. 197:426-8, https://doi.org/10.1192/bjp.bp.109.072066.

Poremski, D., Whitley, R. and Latimer, E. (2014) 'Barriers to obtaining employment for people with severe mental illness experiencing homelessness', Journal of Mental Health, vol. 23, no. 4: 181-185, https://doi.org/10.3109/09638237.201 4.910640.

Power, E. (2019) 'Assembling the capacity to care: Caring-with precarious housing', Transactions of the Institute of British Geographers, vol. 44, no. 4: 763-777, https://doi.org/10.1111/tran.12306.

Power, E. and Mee, K. (2020) 'Housing: an infrastructure of care', Housing Studies, vol. 35, no. 3:484-505, https://doi.org/ 10.1080/02673037.2019.1612038.

Puig de la Bellacasa, M. (2017) Matters of Care: Speculative Ethics in More than Human Worlds, University of Minnesota Press, Minneapolis, MN.

Reavley, N., Cvetkovski, S., Form, A. and Lubman, D. (2010) 'Help-seeking for substance use, anxiety and affective disorders among young people: results from the 2007 Australian National Survey of Mental Health and Wellbeing', Australian and New Zealand Journal of Psychiatry, vol. 35, no. 3: 352-358, https://doi.org/10.3109/00048671003705458.

Repper, J. and Carter, T. (2011) 'A review of the literature on peer support in mental health services', Journal of Mental Health, vol. 20, no. 4: 392-411, https://doi.org/10.3109/09638237.2011.583947.

Richter, D. and Hoffmann, H. (2017) 'Preference for independent housing of persons with mental disorders: systematic review and meta-analysis', Administration and Policy in Mental Health and Mental Health Services Research, vol. 44, no. 6: 817-823, https://doi.org/10.1007/s10488-017-0791-4.

Ritter, A., Berends, L., Chalmers, J., Hull, P., Lancaster, K. and Gomez, M. (2014) New Horizons: The Review of Alcohol and other Drug Treatment Services in Australia, Drug Policy Modelling Program, National Drug and Alcohol Research Centre, Sydney.

Rose, N. (2019) Our Psychiatric Future, Polity Press, London.

Royal Australian and New Zealand College of Psychiatrists (2016) The Economic Cost of Serious Mental IIIness and Comorbidities in Australia and New Zealand, RANZCP, Melbourne.

Scott, C., Foss, M. and Dennis, M. (2005) 'Pathways in the relapse-treatment-recovery cycle over 3 years', Journal of Substance Abuse Treatment, vol. 28, no. 2: S63-S72, https://doi.org/10.1016/j.jsat.2004.09.006.

Scutella, R., Johnson, G., Moschion, J., Tseng, Y. and Wooden, M. (2012) Journeys Home: Research Report No. 1, Melbourne Institute of Applied Economic and Social Research, Melbourne.

Sen, A. (1999) Development as Freedom, Oxford University Press, Oxford.

Sen, A. (2005) 'Human rights and capabilities', Journal of human development, vol. 6, no. 2: 151-166, https://doi. org/10.1080/14649880500120491.

Singh, A., Daniel, L., Baker, E. and Bentley, R. (2019) 'Housing disadvantage and poor mental health: a systematic review', American journal of preventive medicine, vol. 57, no. 2: 262-272, https://doi.org/10.1016/j.amepre.2019.03.018.

Slade, T., Johnston, A., Oakley Browne, M., Andrews, G. and Whiteford, H. (2009) '2007 national survey of mental health and wellbeing: methods and key findings', Australian New Zealand Journal of Psychiatry, vol. 43: 594-605, https://doi.org/10.1080/00048670902970882.

Smith, S. J., Alexander, A. and Easterlow, D. (1997) 'Rehousing as a health intervention: miracle or mirage?', Health \& Place, vol. 3, no. 4: 203-216, https://doi.org/10.1016/S1353-8292(97)00015-4.

Somerville, P. (2013) ‘Understanding homelessness', Housing, Theory and Society, vol. 30, no. 4: 384-415, https://doi.org/ 10.1080/14036096.2012.756096.

State of Victoria (2019) Royal Commission into Victoria's Mental Health System, Interim Report, Parliamentary Paper No. 87 (2018-19).

Star, S. (1999) 'The ethnography of infrastructure', American Behavioral Scientist, vol. 43, no. 3: 377-391, https://doi. org/10.1177/00027649921955326.

Stein, M. (2012) Young People Leaving Care: Supporting Pathways to adulthood, Jessica Kingsley Publishers, London. 
Stergiopoulos, V., Mejia-Lancheros, C., Nisenbaum, R., Wang, R., Lachaud, J., O'Campo, P. and Hwang, S. W. (2019) 'Longterm effects of rent supplements and mental health support services on housing and health outcomes of homeless adults with mental illness: extension study of the At Home/Chez Soi randomised controlled trial', The Lancet Psychiatry, vol. 6, no. 11: 915-925, https://doi.org/10.1016/S2215-0366(19)30371-2.

Sylvestre, J., Nelson, G. and Aubrey, T. (eds) (2017) Housing, Citizenship, and Communities for People with Serious Mental IIIness: Theory, Research, Practice, and Policy Perspectives, Oxford University Press, New York, https://doi.org/10.1093/acprof:0so/9780190265601.001.0001.

Taylor, A. (2013) 'Lives worth living': theorizing moral status and expressions of human life, Disability Studies Quarterly, vol. 33, no. 4, https://doi.org/10.18061/dsq.v33i4.3875.

Taylor, S. and Johnson, G. (2019) Service use patterns at a high-volume homelessness service: A longitudinal analysis of six years of administrative data, Unison Housing, Melbourne.

Thornicroft, G., Deb, T. and Henderson, C. (2016) 'Community mental health care worldwide: Current status and further developments', World Psychiatry, vol. 15: 276-286, https://doi.org/10.1002/wps.20349.

Tran, Q. N., Lambeth, L. G., Sanderson, K., de Graaff, B., Breslin, M., Huckerby, E. J., ... and Neil, A. L. (2020) ‘Trend of emergency department presentations with a mental health diagnosis in Australia by diagnostic group, 2004-05 to 2016-17', Emergency Medicine Australasia, vol. 32, no. 2: 190-201, https://doi.org/10.1111/1742-6723.13451.

Tronto, J. C. (1993) Moral Boundaries: A Political Argument for an Ethic of Care, Routledge, New York.

Tsemberis, S. (2011) 'Housing First: The pathways model to end homelessness for people with mental illness and addiction manual', European Journal of Homelessness, vol. 5, no. 2.

Tsemberis, S., Gulcur, L. and Nakae, M. (2004) 'Housing first, consumer choice, and harm reduction for homeless individuals with a dual diagnosis', American journal of public health, vol. 94, no. 4: 651-656, https://doi.org/10.2105/ AJPH.94.4.651.

Turner, B. (2006) Vulnerability and Human Rights, The Pennsylvania State University Press, Pennsylvania.

United States Department of Housing and Urban Development (USDHUD), Office of Policy Development and Research and Pearson, C. L. (2007) The applicability of Housing First models to homeless persons with serious mental illness, US Department of Housing and Urban Development, Office of Policy Development and Research.

Vallesi, S., Flatau, P., Thielking, M., Mackelprang, J. L., Taylor, K. M., La Sala, L., ... and Lester, L. (2019) 'A mixed methods randomised control trial to evaluate the effectiveness of the journey to social inclusion-phase 2 intervention for chronically homeless adults: study protocol', BMC public health, vol. 19, no. 1: 334, https://doi.org/10.1186/s12889019-6644-1.

Vitellone, N. (2017) The Social Science of the Syringe, Routledge, London, https://doi.org/10.4324/9781315622729.

Watson, D., Wagner, D. and Rovers, M. (2013) 'Understanding the critical ingredients of facilitating consumer change in Housing First programming: a case study approach', The Journal of Behavioural Health Sciences and Research, vol. 40, no. 2 : 169-179, https://doi.org/10.1007/s11414-012-9312-0.

Williams, M. (2017) 'Care-full justice in the city', Antipode, vol. 49, no. 3:821-839, https://doi.org/10.1111/anti.12279.

Willis, M. (2016) Supported housing for prisoners returning to the community: a review of the literature, Australian Institute of Criminology, Canberra.

Wilson, A. (2016) 'The infrastructure of intimacy', Signs: Journal of Women in Culture and Society, vol. 41, no. 2: 247-280, https://doi.org/10.1086/682919.

Xiao, S., Tourangeau, A., Widger, K. and Berta, W. (2019) 'Discharge planning in mental healthcare settings: a review and concept analysis', International journal of mental health nursing, vol. 28, no. 4: 816-832, https://doi.org/10.1111/ inm.12599. 


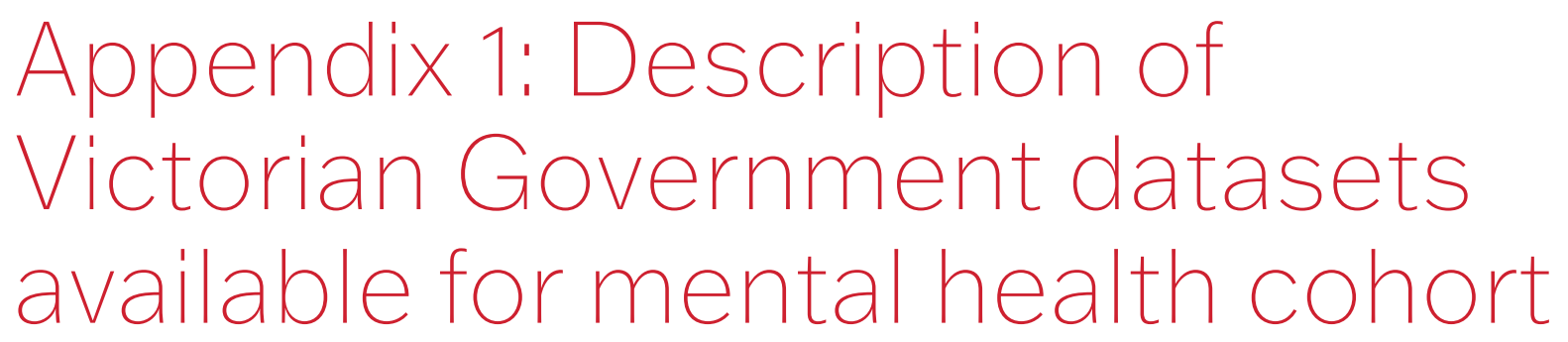

\section{Victorian Admitted Episodes Dataset}

The Victorian Admitted Episodes Dataset contains data on all public and private hospital admissions in Victoria, including rehabilitation centres, extended care facilities and day procedure centres, and report a minimum set of data for each admitted patient episode. The dataset includes detailed information on diagnosis and cause, along with information on separation type and referrals at separation.

There were a total of 62,312 admission records for those in the mental health cohort. Our study received a record for each person at each hospital admission during the study period from 2011 to 2018. Over two-thirds of admissions (68\%) occurred after the reference event admission, 22 per cent occurred prior to the reference admission and 10 per cent occurred during the reference admission.

Transfers between wards within a hospital or between hospitals results in an additional admission record created for this part of their stay. For this study, to avoid double-counting, these records were joined together to form a continuous inpatient stay.

\section{Victorian Emergency Management Dataset}

The Victorian Emergency Management Dataset (VEMD) contains information on all emergency department presentations at Victorian public hospitals with dedicated emergency departments. It contains symptom information, and diagnosis and cause information where available for each presentation, along with departure and referral information. The VEMD does not capture emergency department presentations at private hospitals. Our study received a record for each person in the mental health cohort at each emergency room presentation in the study period from 2011 to 2018 . There were a total of 73,318 presentation records for the mental health cohort.

\section{Cause of Death Unit Record File}

The Cause of Death Unit Record File contains information on all individuals who have died in Victoria registered with Births, Deaths and Marriages, including their date of death and cause of death. There were 108 individuals from the mental health cohort who died in Victoria. The cause of death for these individuals was predominantly suicide and overdose. The remainder included those where the cause of death had not been finalised, deaths from traffic accidents and deaths from medical conditions (e.g. cancer). 


\section{Alcohol and Drug Information System}

The Alcohol and Drug Information System contains data on assessment, treatment and support services provided to adults and young people who have alcohol and/or drug use problems, and to their families and carers. These services are funded by the Victorian Government but delivered primarily by independent agencies. Our dataset contains information on the type of drug use, service outcome and referral pathways, but limited information on the service received. Individuals could have more than one record of service. There were 12,279 records of service in our dataset for the mental health cohort of which 95 per cent of records where the individual in our cohort was the alcohol/drug user, while for the remaining 5 per cent the individual in our cohort was receiving services as the carer or family member of the alcohol/drug user. For those individuals in our cohort who received services for their own alcohol/drug use, 23 per cent were primarily for alcohol and 77 per cent for other substances.

\section{Child protection}

This dataset contains information on all child protection and out-of-home care clients in Victoria. Our dataset includes information on allegations, substantiations, and information on care placements for all closed cases for those in the mental health cohort. Dates of services were generally not available in this dataset, with only the financial year recorded. There were 3,913 records of service for the mental health cohort. Individuals could have more than one record of service.

\section{Mental Health Community Support Services}

This data system contains information on non-clinical support services provided in the community for those with severe mental illness. For example, they support people with psychiatric disability to manage their self-care, improve social and relationship skills and achieve broader quality of life It contains information on the individual's mental health condition and support needs. This data contains limited information on services provided and, unlike many of the other datasets listed here, does not contain dates of service delivery; only the financial year that services were provided. Individuals could have more than one record of service. There were a total of 8,750 service records for individuals in the mental health cohort.

\section{CMI/ODS (Clinical Mental Health)}

This data system contains information on clinical public mental health services (both inpatient and outpatient) provided in Victoria. It includes both summaries of the services provided for each patient within a financial year, along with information on each individual contact with the mental health system. The records for inpatients has some overlap with the hospital data (i.e. someone in a mental health ward in a hospital should be in both collections) but there are also inpatient mental health facilities that are not part of the hospital data collection. Outpatient records is not found anywhere else. Individuals found in this dataset typically have many records; there were 56,539 records in total for individuals in the mental health cohort in this dataset.

\section{Family Services (IRIS)}

The family services dataset contains information on the provision of services to vulnerable children, young people and their families. The dataset contains information on the referral source, the outcome of the case, and the reason for case closure, along with activity information undertaken by case workers. Data was available from July 2013 onwards only. This data contains limited information on the reason for the service. There were 376 records for individuals in the mental health cohort. The referral source was varied, but the most common was from DHHS Child Protection. Individuals could have more than one case. 


\section{Family Violence (IRIS)}

The family violence dataset contains information on services provided to both victims and perpetrators of family violence within the mental health cohort. The dataset contains information on the referral source, the outcome of the case, and the reason for case closure, along with activity information. Data was available from July 2013 onwards only. There were 1,234 records of use of this service by individuals in the mental health cohort. Individuals could have more than one case record. In addition to data on case records, there was also data on service activities in the dataset. The service activities information included a high-level description of the activity ('Case Work', 'Initial Assessment', 'Outreach', etc.) and the date it occurred for each case.

\section{Sexual Assault Support Services (IRIS)}

This dataset contains information on services provided to those who have been victims of sexual assault, and also services provided to perpetrators of sexual assault. The dataset contains information on the referral source, the outcome of the case, and the reason for case closure. This data contains limited information on the nature of the service provided, or the reason for the service. There were 826 records in the dataset for individuals from the mental health cohort. Individuals could have more than one record of service. Data was available from July 2013 onwards only.

\section{Housing Integrated Information Program}

This dataset contains information on Victorian public housing. This includes information on applications for housing, tenancies, funding support for tenancies, and income sources used to pay rent. This dataset contains information on 1,841 applications and 786 tenancies for individuals in the mental health cohort. Note that as we are dealing with such a young cohort, many applications and tenancies related to the family unit of which the individuals in our cohort were part of, rather than independent applications and tenancies.

\section{DHHS Homelessness Data Collection}

The homelessness dataset captures information about homelessness services provided for the full range of homelessness issues including crisis, family violence, homelessness risk, etc. The DHHS Homelessness Data Collection mirrors the Specialist Homelessness Services Collection (SHSC) conducted by the Australian Institute of Health and Welfare (AIHW). The dataset contains information on the individual's current living arrangement, the reason for requiring assistance, and the reason for the service episode ending. Almost no data was available in this dataset prior to 2015, limiting our knowledge about the housing status of our cohorts until one/two years after exit. There were 8,070 records in this dataset for those in the mental health cohort (see Appendix Table 1) For 56 per cent $(n=4,457)$, the individual was recorded as being currently homeless, while for 34 per cent $(n=2,715)$ the individual was recorded as being at risk of homelessness. The most common reason for seeking homelessness services was a housing crisis (e.g. eviction; $31 \%$ ), followed by domestic and family violence (18\%). Individuals could have more than one record of service. 
Table A 1: Service information from the homelessness dataset for each cohort

\begin{tabular}{|c|c|c|}
\hline & \multicolumn{2}{|c|}{ Mental health cohort } \\
\hline & $\mathrm{N}$ & $\%$ \\
\hline Records of service & 8,070 & $100 \%$ \\
\hline \multicolumn{3}{|l|}{ Housing situation } \\
\hline Homeless: No shelter/improvised dwelling & 1,219 & $15 \%$ \\
\hline Homeless: Short-term temporary accommodation & 1,769 & $22 \%$ \\
\hline Homeless: At house, townhouse or flat-couch surfer/no tenure & 1,093 & $14 \%$ \\
\hline Homeless: Other & 376 & $5 \%$ \\
\hline At risk-Public/community housing-renter or rent free & 1,362 & $17 \%$ \\
\hline At risk: Private or other housing-renter, rent free or owner & 660 & $8 \%$ \\
\hline At risk: Institutional settings & 302 & $4 \%$ \\
\hline At risk: Other & 391 & $5 \%$ \\
\hline Not stated & 898 & $11 \%$ \\
\hline \multicolumn{3}{|l|}{ Reason for seeking assistance } \\
\hline Financial difficulties & 685 & $8 \%$ \\
\hline Housing affordability stress & 273 & $3 \%$ \\
\hline Housing crisis (eviction) & 2,523 & $31 \%$ \\
\hline Inadequate or inappropriate dwelling conditions & 808 & $10 \%$ \\
\hline Previous accommodation ended & 389 & $5 \%$ \\
\hline Relationship/family breakdown & 262 & $3 \%$ \\
\hline Domestic/family violence & 1,489 & $18 \%$ \\
\hline Mental health issues & 455 & $6 \%$ \\
\hline Transition from custodial arrangements & 161 & $2 \%$ \\
\hline Transition from foster care and child safety residential placements & 12 & $0 \%$ \\
\hline Transition from other care arrangements & 40 & $0 \%$ \\
\hline Other & 973 & $12 \%$ \\
\hline
\end{tabular}

\section{Youth justice}

The youth justice dataset contains data on all criminal court orders in the youth justice system in Victoria. There were 2,527 youth justice records in the mental health cohort, with 43 per cent for custodial orders and 57 per cent for community based orders. Individuals could have more than one youth justice record. The dataset does not contain information on underlying offending, however it is important to note that typically each offence carries with it multiple court orders. 


\section{Appendix 2: Mental health diagnosis categories}

The categories are based on the following International Classification of Diseases (ICD) codes of each individual's primary diagnosis on entry to their reference event.

\begin{tabular}{ll}
\hline Classification used in report & Corresponding ICD codes \\
\hline Depression & F32-34, F38-39 \\
\hline Anxiety & F40-41 \\
\hline Stress/adjustment disorders & F43 \\
\hline Personality disorders & F60-62 \\
\hline Schizophrenia' & F20-F29 \\
\hline Childhood-related disorders & F90-98 \\
\hline Other mental health conditions ${ }^{2}$ & F42-F48, F50-59, F63-69, F30-31, F99 \\
\hline
\end{tabular}

\section{Notes:}

1. Includes schizotypal/delusional, other psychotic disorders.

2. Most common 'other' mental health conditions are bipolar and eating disorders. 


\section{Appendix 3: Interview and focus group schedules}

\section{Questions and prompts-Service providers (Projects A, B and C)}

Thank you for taking the time to meet with us today. The purpose of this focus group is to explore and understand your experiences as service providers in providing support and coordinated services to people exiting (out-ofhome care/prison/residential facility).

1. Please introduce yourself, your agency and your role in supporting people leaving (out-of-home care/prison/ residential facility).

2. What is your approach to supporting someone to leave (out-of-home care/prison/residential facility)?

a. Starting the conversation (timing, content, working with barriers or resistance)

b. Planning processes

c. Referral processes

d. Follow up/after-care processes

e. Service coordination.

3. What are some of the issues you face in providing support and coordinated services to people exiting (out-ofhome care/prison/residential facility)?

4. What have you found works when supporting people to leave (out-of-home care/prison/residential facility)?

5. Are there some key messages you would like policy makers to hear about your experience of supporting people to leave (out-of-home care/prison/residential facility)?

\section{Interview schedule-service users (Projects A, B and C)}

Thank you for taking the time to meet with me today. The purpose of this interview is to ask you about your experiences of leaving (out-of-home care/prison/residential facility). These questions are not intended to upset you, or bring up painful memories. If however, you find this happens let me know, and we can stop the interview and take a break, finish up and return to the interview another day, or you might decide to withdraw from the research.

1. Thinking about preparing to leave (out-of-home care/prison/residential facility), what were your most pressing needs and concerns? Prompts may include:
a. Housing
b. Health
c. Income
d. Wellbeing (emotional, social and mental)
e. Social supports and connections
f. Cultural connections
g. Sexuality, gender, identity. 
2. Can you tell me about the support you received in planning to leave (out-of-home care/prison/residential facility)?

a. Who provided this support?

b. How much support did they provide and over what period of time?

c. Can you tell me about your readiness to have these conversations? If not ready, what needed to be in place for you to feel ready?

d. Can you give me some examples of what was covered in the conversation(s) about planning to leave (out-of-home care/prison/residential facility)?

e. We have heard many people talk about the importance of flexible support, tailored to the unique needs of the person. Was this something you experienced? (Ask for examples to support answer.)

3. I would like to explore the support and help available to you when you left (out-of-home care/prison/residential facility):

a. Were you referred to other organisations (which ones)?

b. Were there organisations you planned to stay connected to (which ones)?

c. If you were referred, can you tell me about the referral process?

i. Was there discussion about the agencies (description of service, intended impact of referral, choice of agency etc.)

ii. Can you explain how the worker referred you to other services (i.e. warm referral, phone/email/written referral with no service user involvement etc.)?

d. If you are continuing to receive the services of existing organisations, was there any communication from the (out-of-home care/prison/residential facility) services to these agencies? (Prompt for details of this.)

4. After you left (out-of-home care/prison/residential facility), what was your experience of the different agencies working together?

a. Sharing information/repeating one's story to different services

b. Duplication of services

c. Gaps in and between services

d. Anything else.

5. Thinking about your experiences of leaving (out-of-home care/prison/residential facility):

a. What worked?

b. What did not work/could be improved?

c. What could the different agencies who are supposed to support people in similar circumstances do differently?

6. Are there some key messages you would like service providers to hear about your experience of leaving (out-of-home care/prison/residential facility)?

\section{DEMOGRAPHICS and CONTEXT}

7. Basic demographic data: age, gender, NESB, ATSI status, disability, income, single or partnered, children, employed or studying

8. Where did you live immediately before entering [inst]? [location, with whom, tenure type]

9. Where did you leave immediately after leaving [inst]? [location; with whom; tenure type]

a. Was this accommodation secure, appropriate and affordable? 
10. Where do you live now? [location; with whom; tenure type]

11. Is this accommodation secure, appropriate and affordable?

a. Would you like [are you planning] to live somewhere else? [location, with whom, tenure type]

b. Do any conditions of your release affect where you can live?

c. How many moves have you made since leaving [inst]?

12. Have you participated in any programs (e.g., case work, rehabilitation, counselling, employment services) since leaving [inst]?

13. Have you used drugs or alcohol since leaving [inst]? How would you describe your use: not a problem—minor problem-moderate problem-serious problem?

14. Have you been well since leaving [inst]? How would you describe your health: not a problem - minor problem -moderate problem-serious problem.

15. Have you had contact with police since leaving [inst]?

16. Has a past housing issue affected your housing since being released (e.g., listed on tenancy database, social housing debt, previous unsatisfactory social housing tenancy)? 


\section{AHURi}

Australian Housing and Urban Research Institute Level 12, 460 Bourke Street

Melbourne VIC 3000

\section{Australia}

+61396602300

information@ahuri.edu.au

ahuri.edu.au

(2) twitter.com/AHURI_Research

f facebook.com/AHURI.AUS

in Australian Housing and Urban Research Institute 